

\title{
The Heterogeneity Among Commodity-Rich Economies: Beyond the Prices of Commodities
}

\author{
Troug, Haytem \\ university of Exeter
}

14 February 2019

Online at https://mpra.ub.uni-muenchen.de/92599/

MPRA Paper No. 92599, posted 11 Mar 2019 13:24 UTC 


\title{
The Heterogeneity Among Commodity-Rich Economies: Beyond the Prices of Commodities
}

\author{
Haytem Troug*
}

March 8, 2019

\begin{abstract}
The existing literature has always assumed that commodity-rich countries are a homogeneous group, resulting in the generalisation of any findings obtained from a single commodityrich economy. This paper proposes a small open economy model for a commodity-rich country and studies the triggers of business cycles for four different commodity-rich economies to highlight the existence of heterogeneity among commodity-rich economies. The model introduces government consumption in a non-separable form to the utility function. Commodities have a central role in private consumption, production of final goods, and windfalls for the domestic government. We feed the model with a variety of shocks that were previously proposed by the previous literature. The estimations of the model show that oil-rich economies are more vulnerable to external shocks than their commodity-rich counterparts. This is mainly the result of the size of commodity windfalls in the economy, as the share of oil revenues are significantly higher than the revenues of other commodities, as a ratio of output. The results also show that there exists a policy crowding out effect of fiscal policy to monetary policy in oil-rich economies, all explaining the choice of an exchange rate peg regime in most oil-rich economies.
\end{abstract}

Keywords: New Keynesian models, Business Cycle, Open Economy Macroeconomics, Joint Analysis of Fiscal and Monetary Policy, Commodity Prices.

JEL classification: E12, E32, E63, F41.

${ }^{*}$ University of Exeter Business School, Department of Economics, Streatham Court, Rennes Drive, Exeter, EX4 4PU, UK. E-mail: ht321@exeter.ac.uk 


\section{Introduction}

There exists a long and growing literature that investigates the effect of commodities on commodityrich economies. The seminal paper by Sachs and Warner 1995 illustrated the adverse effect of the abundance of natural resources on economic growth. In addition, Ploeg and Poelhekke 2009 illustrate that the high volatility of commodity prices seems to be the quintessence of the resource curse since it generates large real exchange rate fluctuations and less investment, especially in countries where financial development is lagging (Aghion et al. 2009). Nevertheless, the above findings were challenged by numerous papers that have questioned the natural resource curse, pointing to examples of commodity-exporting countries that have done well, such as Chile, Norway and Botswana ${ }^{1}$. Moreover, Alexeev and Conrad 2009, Cotet and Tsui 2010 and Havranek et al. 2016 find very little evidence in support of the natural resource curse, while Ploeg 2011 showed empirical evidence that either outcome is possible, leading the literature to deviate from consensus on this issue. Another seminal paper by Mehlum et al. 2006 showed that institutions are a vital factor for the effect of resources on economic performance ${ }^{2}$.

One possible explanation for the above disparity is that the literature mentioned above usually assumes that this group of countries is homogeneous. For instance, many studies that have been conducted on a single commodity-rich economy assumed that their results apply on all commodityrich economies, labelling their case study as "prototypical" or "quintessential"3 . In this paper, we try to contribute to the growing literature on natural resources and economic performance by highlighting one possible source of heterogeneity among commodity-rich economies. We try to capture this heterogeneity by imposing the same commodity-price shock on a number of resourcerich economies. Doing so will allow us to show how the social capabilities of each economy and the characteristics of the commodity affect the response of key macroeconomic variables to a commodity-price shock. Two findings in the literature motivate our approach. The first is Rodrik 1999's findings that the magnitude of a country's growth deceleration since the 1970's is a function

\footnotetext{
${ }^{1}$ Larsen 2006 exhibited Norway as an example of an oil-rich country that was able to escape the Resource Curse. Englebert 2000, Sarraf and Jiwanji 2001, Acemoglu et al. 2003 and Iimi 2006 are among those noting Botswana's conspicuous escape from the Resource Curse.

2 These findings refute the findings of Sachs and Warner 1995 of an insignificant role for institutions in overcoming the resource curse, and they show that the quality of institutions has to increase as the size of resources increase in the economy.

${ }^{3}$ See, for example, Isham et al. 2005, Ploeg and Poelhekke 2009, and Dauvin and Guerreiro 2017.
} 
of both the magnitude of the shocks and a country's social capability for adapting to shocks. Also, Fernández et al. 2018 findings that there is strong comovement among the prices of commodities. Thus, this will enable us to isolate the two factors affecting the response of macroeconomic variables in each economy, and solely concentrate on the social capabilities and the characteristics of the commodity. To the extent of our knowledge, the existing literature has not yet addressed this phenomenon.

This paper proposes a small open economy model for a commodity-rich country to quantitatively study the triggers of business cycles in different commodity-rich economies. This paper extends the model used in Troug 2019 by adding some features to the model to make it more relevant for a commodity-rich economy. The model contains four key features. First, the supply of commodities is exogenous, and it is affected by political, geographical, and technical factors, i.e., non-economic factors. Second, the government is the sole owner of commodities and it collects the windfalls of selling them to the rest of the world ${ }^{4}$. Third, the small open economy is a price taker for all goods and services it produces and consumes. Also, the small open economy is affected by the second second-round effect of an increase in the commodity prices in the form of high foreign inflation and low world demand. Fourth, households and firms, both in the domestic economy and the rest of the world economy, use commodities for consumption and as a factor of production, respectively. In addition, the main behavioural parameters that the paper focuses on are the elasticity of substitution between government consumption and private consumption and the response of government consumption to fluctuations in the commodity prices. The former parameter is an indicator of the efficiency of government consumption and its effect on private consumption (crowding-in versus crowding-out), while the latter captures the behaviour and the stance of fiscal policy during booms and busts of commodity prices, along with the size of the commodity windfalls in the government's revenue.

The analysis of this paper proceeds in four steps. First, we empirically estimate our behavioural parameters. Second, we generate the impulse response of the data using a structural VAR model. Third, we illustrate the full structure of our DSGE model. The model generates extra sources of stochastic processes that were proposed by the existing literature. The calibration of the parameters

\footnotetext{
${ }^{4}$ Introducing the fiscal sector was neglected by Fernández et al. 2018, leaving out the most significant transmission channel for commodities-price shocks in commodity-rich economies, as highlighted by Cespedes and Velasco 2014 and Pieschacon 2012.
} 
for our DSGE model is made for all of our economies of interest based on the empirical findings of this paper and the long-term averages found in the data. Fourth, we use Bayesian estimation techniques to calculate the variance decomposition of our variables of interest. The empirical and theoretical findings of this paper show that consumption is excessively volatile relative to output, which is consistent with the findings of the previous literature ${ }^{5}$. However, our findings show that this might also be the case for developed countries which are rich with natural resources, as in the case of Australia. The results also show that, once we control for the commodity prices, there is heterogeneity in the forces driving the business cycle within commodity-rich economies. The fiscal sectors in these economies drive these forces, along with institutional factors and the share of commodity windfalls in the government's total revenue.

Our results show the existence of a procyclical fiscal stance in developing, commodity-rich countries. This is consistent with the findings of Kaminsky et al. 2005, Frankel 2011, and Bastourre et al. 2012. Nevertheless, we find that adopting the fiscal rule, as in the case of Chile and Australia, reverses this behaviour, consistent with the findings of Cespedes and Velasco 2014. Our findings also support the findings of Rodrik 1999 and Isham et al. 2005 of how the abundance of commodities erodes institutions, and that, in return, will affect how economies react to commodity shocks. The results of this paper, at least regarding commodity-rich economies, strongly support the findings of Gali et al. 2007 and Bouakez and Rebei 2007 who show that government consumption has a crowding in effect on private consumption.

The paper also shows significant heterogeneity in the contribution of terms of trade to business cycles among commodity-rich economies and illustrate that oil-rich economies are more vulnerable to these shocks. These results complement the work of Fernández et al. 2018, Shousha 2016, Fernández Martin et al. 2017, and Drechsel and Tenreyro 2017, who show a significant role for the proxy of terms of trade (commodity prices) in driving business cycles in developing economies ${ }^{6}$. The results of the paper show that the effect of external shocks on commodity-rich economies is sensitive to the degree of openness in these economies and the adopted fiscal regime in each economy. This is attributed to the fact that the government is the main channel for the transmission of these

\footnotetext{
5 See, for example, Neumeyer and Perri 2005, Aguiar and Gopinath 2007, Garcia-Cicco et al. 2010, Akinci 2014, and Drechsel and Tenreyro 2017.

6 The findings of Broda 2004 support these results, but they were challenged by Schmitt-Grohe and Uribe 2017 who undermine the role of commodities in driving business cycles.
} 
fluctuations in commodity-rich economies as illustrated by Arezki and Ismail 2013. Our results also show that oil-rich countries, in this case as well, are more affected by external shocks than their commodity-rich counterparts.

The organisation of the remainder of this paper is as follows. In the second chapter, we illustrate our stylized facts and empirical findings for our economies of interest. In the third chapter, we build a DSGE model for a commodity-rich small open economy. We add some structural shocks that were suggested by the previous literature and calibrate the model based on our empirical findings and the long-term parameters found in the data. In the fourth chapter, we estimate the model using Bayesian estimation techniques. Chapter five concludes.

\section{Stylized Facts}

\section{$2.1 \quad$ Data}

Figure 1: Real GDP Growth and Commodities Prices

(a) Real GDP per Capita Growth

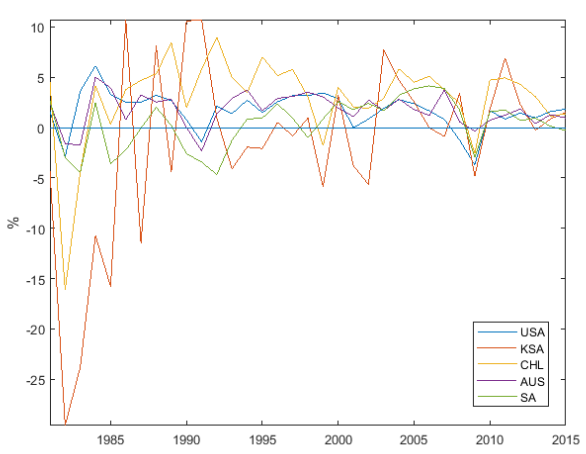

(b) Commodities Prices

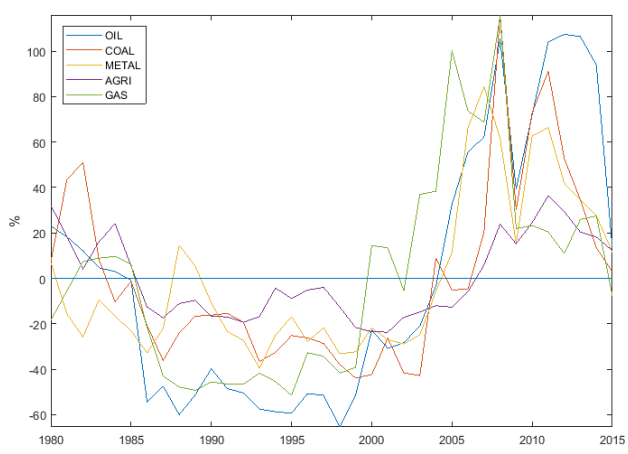

This paper uses real government consumption, real private consumption, and inflation for a selected number of commodity-rich economies ${ }^{7}$. In addition to this, we add the same variables for the U.S economy, as it will be used to calibrate the moments of the rest of the world, as shown below.

\footnotetext{
${ }^{7}$ The selected countries are Chile, a Copper-rich economy; Australia, a minerals-rich economy; Saudi Arabia, an oil-rich economy; and South Africa a coal and minerals-rich economy.

${ }^{8}$ Due to the unavailability of the required data for the Chilean CPI inflation at the WDI database, we use the series available at inflation.eu.
} 
The source of this data is World Bank's World Development Indicators (WDI) database, and all of the series are presented in annual per capita terms.

The commodity prices indices were retrieved from the World Bank commodity prices database (the pink sheet). All commodity prices were deflated using the U.S. CPI index. The deflation is done to reflect the real purchasing power of commodity windfalls. We also use mean deviation of real commodity prices rather than de-trending the series in order to capture long persistence in commodity prices (super cycles). The data for the supply of commodities was downloaded from the IEA database.

The above graph shows significant heterogeneity in the growth rate of GDP per capita among the selected commodity-rich economies. We also include the US growth rate for reference. The above figure illustrates how the growth rates of commodity-rich economies deviate from the growth rate of GDP per capita in the US by different magnitudes. One possible explanation for this behaviour is the volatility of the prices of commodities in these economies ${ }^{9}$, as shown in panel (b) of the above figure.

The above graph also shows comovement in the prices of commodities, consistent with the findings of Fernández et al. 2018. As noted, the fluctuation of commodities prices results in high volatility in commodity-rich economies. In this paper, we impose the same commodity price on all of our selected economies to capture the heterogeneity among these economies beyond the different price fluctuations of each commodity. The price index that we impose in this paper is an average of both the energy and non-energy indices. The energy price index is a weighted average of crude oil prices, natural gas prices, and coal prices. Agricultural products and metal, on the other hand, represent almost $97 \%$ of the non-energy price index.

\subsection{What Affects Commodity Prices?}

The framework of the theoretical model assumes that commodity prices are determined by commodity supply ${ }^{10}$, World output, World technology, and World government consumption. Therefore, the analysis of this section will not affect the structure nor the design of this model, as the parameters that govern the effect of our independent variables on real commodity prices are derived

\footnotetext{
${ }^{9}$ See, for example, Rodrik 1999.

10 We use energy supply as a proxy for commodity supply due to the unavailability of total commodities supply.
} 
endogenously in the model and not estimated. Nevertheless, this exercise is useful as it will give us an indication of how real commodity prices are affected by developments in the macro variables of the world economy. The regression of this section is specified in the following from:

$$
\tilde{P}_{O, t}^{*}=\beta_{0}+\beta_{1} Y_{t}^{*}+\beta_{2} G_{t}^{*}+\beta_{3} O_{t}^{* s}+\epsilon_{t}
$$

Where $\tilde{P}_{O, t}^{*}=\frac{P_{O, t}-\bar{P}_{O}}{P_{O}} * 100$ is the mean deviation of real commodity prices. $Y_{t}^{*}, G_{t}^{*}, O_{t}^{* s}$ are world output, world government consumption and the supply of commodities, respectively. The results of the regression are shown in the below table and they highlight a significant effect of the supply of commodities and world output on real commodity prices. World government consumption, however, does not significantly affect commodity prices. The signs of the effect of the supply of commodities and world output are in line with the derivations of the DSGE model of this paper, as shown below.

Table 1: Regression Results for Commodity Prices

\begin{tabular}{cc}
\hline Commodity Prices & \\
\hline World Output & $1.46^{* *}$ \\
& $(0.566)$ \\
World Government Consumption & -1.046 \\
& $(1.434)$ \\
Commodities Supply & $-7.787^{* * *}$ \\
& $(2.753)$ \\
Constant & -614.7 \\
& $(800.355)$ \\
Observations & 36 \\
R-squared & 0.38 \\
\hline Standard errors in parentheses \\
$* * * \mathrm{p}<0.01, * * \mathrm{p}<0.05, * \mathrm{p}<0.1$ \\
\hline \hline
\end{tabular}

\subsection{The Effect of Government Consumption on Private Consumption}

In this section, we empirically estimate the effect of government consumption on private consumption in the four commodity-rich economies and the U.S. economy, which represents the world economy in this model. For the U.S. economy, we estimate the effect of government consumption on private consumption, controlling for the commodity price index, U.S. output, and U.S. inflation. As for the other four economies, we control for world output, the commodity price index, domestic 
inflation, and domestic output. The regression of this section is specified in the following from:

$$
\ln \left(C_{t}\right)=\beta_{0}+\chi \ln \left(G_{t}\right)+\beta_{1} \ln \left(X_{t}\right)+\epsilon_{t}
$$

Where $C_{t}$ is private consumption, $G_{t}$ is government consumption, and $X_{t}$ is a vector of control variables including world output, domestic output, domestic inflation and the real price of commodities. All variables are expressed in log forms. The key parameter of interest in this regression is $\chi$, which denotes the effect of government consumption on private consumption. The results of the regressions show a significant positive effect of government consumption on private consumption for all five economies. As these results represent one of our behavioural parameters, we will use the below results in the baseline calibration part of our DSGE model, and they will be included as priors in the Bayesian estimation.

Table 2: Regression Results for the Effect of $G$ on $C$

\begin{tabular}{|c|c|c|c|c|c|}
\hline Domestic Consumption & USA & KSA & CHL & SA & AUS \\
\hline \multirow[t]{2}{*}{ World Output } & $1.151^{* * *}$ & $-0.701^{* * *}$ & $-0.378^{* *}$ & -0.037 & $0.781^{* * *}$ \\
\hline & $(0.016)$ & $(0.162)$ & $(0.175)$ & $(0.027)$ & $(0.177)$ \\
\hline \multirow[t]{2}{*}{ World Government Consumption } & 0.056 & & & & \\
\hline & $(0.038)$ & & & & \\
\hline \multirow[t]{2}{*}{ World Inflation } & $-0.524^{* * *}$ & & & & \\
\hline & $(0.143)$ & & & & \\
\hline \multirow[t]{2}{*}{ Domestic Output } & & -0.073 & $1.119^{* * *}$ & $1.127^{* * *}$ & $-0.624^{* * *}$ \\
\hline & & $(0.202)$ & $(0.114)$ & $(0.106)$ & $(0.176)$ \\
\hline \multirow[t]{2}{*}{ Domestic Government Consumption } & & $0.736^{* * *}$ & $0.221^{*}$ & $0.145^{* *}$ & $0.712^{* * *}$ \\
\hline & & $(0.170)$ & $(0.121)$ & $(0.062)$ & $(0.135)$ \\
\hline \multirow[t]{2}{*}{ Domestic Inflation } & & 0.642 & -0.01 & -0.074 & -0.34 \\
\hline & & $(1.63)$ & $(0.205)$ & $(0.276)$ & $(0.369)$ \\
\hline \multirow[t]{2}{*}{ Commodity Prices } & $0.035^{* * *}$ & 0.177 & -0.053 & -0.022 & $0.038^{*}$ \\
\hline & $(0.005)$ & $(12.45)$ & $(0.04)$ & $(0.027)$ & $(0.02)$ \\
\hline \multirow[t]{2}{*}{ Constant } & $-250.58^{* * *}$ & $1116.506^{* * *}$ & -138.52 & $-283.99^{* * *}$ & $172.256^{* *}$ \\
\hline & $(23.47)$ & $(358.63)$ & $(125.65)$ & (93.027) & $(68.047)$ \\
\hline Observations & 36 & 36 & 36 & 36 & 36 \\
\hline R-squared & 0.99 & 0.82 & 0.99 & 0.97 & 0.92 \\
\hline
\end{tabular}

The below results also contribute to the divided literature on the effect of government consumption on private consumption ${ }^{11}$. Our results support the literature that shows government consumption as a complement to private consumption, at least in commodity-rich countries. Nevertheless, some of causality tests for all the regressions in this section show conflicting signs of

\footnotetext{
${ }^{11}$ Coenen et al. 2013, Gali et al. 2007, and Fiorito and Kollintzas 2004 find that government consumption has a crowding in effect on private consumption. Aschauer 1985 and Ahmed 1986, on the other hand, show that government consumption has a crowding out effect on private consumption.
} 
the directions imposed by the regression assumptions. Also, we acknowledge the possibility of the presence of endogeneity in the estimations. However, using a DSGE model in the next section will allow us to overcome these problems, because it takes into account the fact that these variables are simultaneously determined. Moreover, We will also further investigate this issue in the Bayesian estimation section and, as shown below, the Bayesian estimations show that the explanatory power of the data overcomes the prior values that we extract from the regression results in this section.

\subsection{Business Cycle Moments}

Table 3: Business Cycle Moments for Selected Economies

\begin{tabular}{|c|c|c|c|c|}
\hline World & GDP growth & Gov. Growth & Cons. Growth & Inflation \\
\hline Mean & 1.68 & 0.57 & 2.01 & 2.03 \\
\hline Std. Deviation & 1.86 & 1.68 & 1.74 & 0.86 \\
\hline Persistence & 0.32 & 0.59 & 0.50 & 0.33 \\
\hline Correlation with GDP growth & 1.00 & -0.04 & 0.94 & -0.04 \\
\hline Correlation with Gov. Growth & -0.04 & 1.00 & 0.06 & -0.23 \\
\hline Correlation with Cons. Growth & 0.94 & 0.06 & 1.00 & -0.14 \\
\hline Correlation with inflation & -0.04 & -0.23 & -0.14 & 1.00 \\
\hline KSA & GDP growth & Gov. Growth & Cons. Growth & Inflation \\
\hline Mean & -1.51 & 2.40 & 1.47 & 1.35 \\
\hline Std. Deviation & 8.75 & 10.02 & 9.21 & 2.33 \\
\hline Persistence & 0.31 & 0.12 & 0.36 & 0.72 \\
\hline Correlation with GDP growth & 1.00 & -0.05 & -0.14 & 0.28 \\
\hline Correlation with Cons. Growth & -0.05 & 1.00 & 0.40 & 0.30 \\
\hline Correlation with Gov. Growth & -0.14 & 0.40 & 1.00 & 0.45 \\
\hline Correlation with inflation & 0.28 & 0.30 & 0.45 & 1.00 \\
\hline CHL & GDP growth & Gov. Growth & Cons. Growth & Inflation \\
\hline Mean & 2.99 & 1.70 & 3.37 & 9.98 \\
\hline Std. Deviation & 4.32 & 2.86 & 6.01 & 8.59 \\
\hline Persistence & 0.25 & 0.44 & -0.41 & 0.79 \\
\hline Correlation with GDP growth & 1.00 & 0.35 & 0.92 & -0.02 \\
\hline Correlation with Gov. Growth & 0.35 & 1.00 & 0.25 & -0.65 \\
\hline Correlation with Cons. Growth & 0.92 & 0.25 & 1.00 & -0.01 \\
\hline Correlation with inflation & -0.02 & -0.65 & -0.01 & 1.00 \\
\hline SA & GDP growth & Gov. Growth & Cons. Growth & Inflation \\
\hline Mean & 0.41 & 0.96 & 0.62 & 3.55 \\
\hline Std. Deviation & 2.45 & 2.56 & 3.99 & 1.94 \\
\hline Persistence & 0.43 & 0.35 & 0.03 & 0.77 \\
\hline Correlation with GDP growth & 1.00 & 0.32 & 0.86 & 0.10 \\
\hline Correlation with Gov. Growth & 0.32 & 1.00 & 0.26 & 0.14 \\
\hline Correlation with Cons. Growth & 0.86 & 0.26 & 1.00 & -0.03 \\
\hline Correlation with inflation & 0.10 & 0.14 & -0.03 & 1.00 \\
\hline AUS & GDP growth & Gov. Growth & Cons. Growth & Inflation \\
\hline Mean & 1.75 & 0.38 & 0.38 & 2.42 \\
\hline Std. Deviation & 1.66 & 1.22 & 1.85 & 1.04 \\
\hline Persistence & 0.21 & 0.58 & 0.02 & 0.42 \\
\hline Correlation with GDP growth & 1.00 & -0.03 & -0.40 & -0.37 \\
\hline Correlation with Gov. Growth & -0.03 & 1.00 & 0.19 & -0.43 \\
\hline Correlation with Cons. Growth & -0.40 & 0.19 & 1.00 & 0.15 \\
\hline Correlation with inflation & -0.37 & -0.43 & 0.15 & 1.00 \\
\hline
\end{tabular}

The above table shows that private consumption in developing countries fluctuates more than output which, as mentioned above, consistent with the existing literature on developing economies. Nevertheless, the business cycle moments for Australia, which is a developed economy, show that 
consumption fluctuates more than output, highlighting the possibility of commodities affecting the business cycle of developed economies the same way they affect developing economies. The above persistence measures were estimated by fitting an $\mathrm{AR}(1)$ model for each variable.

The above table also shows that the behaviour of the growth rates of per capita government consumption demonstrates significant differences among the above economies. This variable shows more volatility in Saudi Arabia (an oil-rich economy). The growth rates of the same variable for South Africa and Chile, although three times less volatile than that of the Saudi economy, are still higher than the volatility of government consumption in the U.S. economy. Conversely, the growth of government consumption in Australia, which is a developed economy, showed less volatility than all of the above countries, including the U.S. Furthermore, the volatility in government consumption is positively correlated with the volatility of output per capita and the persistence of the growth of government consumption is negatively correlated with its volatility across all economies. These indicators demonstrate the different degrees of volatility among commodity-rich economies which might result from different factors that we aim to study in this paper we remove the effect of commodity prices.

\subsection{The Reaction of Government Consumption to Changes in Commod- ity Prices}

In this section, we estimate the second and probably most important behavioural parameter in the model. We empirically estimate the reaction of government consumption in our selected four economies to changes in the average commodity index. The magnitude of the response of government consumption to changes in commodity prices will be an indicator of two important factors. The first is the fiscal disciplines of the domestic government while the second is the size of the resource rent in the economy. We control for domestic output and domestic CPI inflation. The regression of this section is specified in the following from:

$$
\ln \left(G_{t}\right)=\beta_{0}+\phi_{g} \tilde{p}_{O, t}^{*}+\beta_{1} \ln \left(X_{t}\right)+\epsilon_{t}
$$

Where $G_{t}$ is is government consumption, $\tilde{p}_{O, t}^{*}$ is the mean deviation of the real prices of commodities, and $X_{t}$ is a vector of control variables including domestic output and domestic inflation. All 
variables are expressed in log forms. As noted above, the key parameter of interest in this regression is $\phi_{g}$, which denotes the response of government consumption to changes in real commodity prices.

Table 4: Regression Results for the reaction of $\mathrm{G}$ to changes in Commodity prices

\begin{tabular}{lcccc}
\hline Government Consumption & KSA & CHL & SA & AUS \\
\hline Commodity Prices & $0.78^{* * *}$ & $0.25^{* * *}$ & -0.04 & -0.01 \\
& $(0.14)$ & $(0.048)$ & $(0.08)$ & $(0.017)$ \\
Domestic Output & -0.713 & $0.44^{* * *}$ & $0.87^{* * *}$ & $0.29^{* * *}$ \\
& $(2.27)$ & $(0.10)$ & $(0.26)$ & $(0.025)$ \\
Domestic Inflation & -0.212 & 0.11 & 2.24 & $-0.9 *$ \\
& $(0.375)$ & $(0.314)$ & $(0.59)$ & $(0.48)$ \\
Constant & $1161.3^{* * *}$ & $637.95^{* * *}$ & -33.16 & $475.7^{* * *}$ \\
& $(418.13)$ & $(162.69)$ & $(278.30)$ & $(26.9)$ \\
Observations & 36 & 36 & 36 & 36 \\
R-squared & 0.63 & 0.94 & 0.77 & 0.83 \\
\hline \hline Bootstrap standard errors with 10,000 replications are in parentheses. \\
$* * * \mathrm{p}<0.01, * * \mathrm{p}<0.05, * \mathrm{p}<0.1$.
\end{tabular}

The above results show that the reactions of the domestic governments display considerable differences among commodity-rich economies. While government consumption does not significantly react to changes in the prices of commodities in Australia and South Africa, it was significantly positive in Chile and Saudi Arabia with responses of differing degrees. The response of government consumption in Saudi Arabia is three times the response of government consumption in Chile. One possible explanation for this behaviour is the size of the resource rents in the economy. During our estimation period, resource rents as a percentage of GDP in Saudi Arabia, Chile, South Africa, and Australia averaged $34 \%, 10.9 \%, 6.25 \%$ and $4.8 \%$, respectively (as shown in Appendix C. 3$)^{12}$.

The above estimations of this behavioural parameter will also be used below in the baseline calibration of our model. These values will also be used as priors in the Bayesian estimation to be undertaken later.

\subsection{Structural VAR Model}

In this section, we address the effect of a commodity shock on the domestic economy by providing an empirical measure based on a Structural VAR model. Commodity shocks are easier to capture as they are observed, different from unobserved technology shocks. Thus, understanding the

\footnotetext{
${ }^{12}$ In Appendix C.3 we report the resource rents averages for 88 countries. The stark finding in the data is the relatively higher share of natural resources, as a percentage of GDP, when the commodity is crude oil compared to other commodities.
} 
channels by which the effect of commodity prices affects economic activity is crucial from a policy perspective.

The Structural VAR model for each domestic economy includes four variables, namely the real commodity price index, the growth rate of real government consumption per capita, the growth rate of real private consumption per capita, and domestic CPI inflation, using annual data over the period 1980 to 2015 and defined as follows:

$$
A_{0} Y_{t}=\alpha_{t}+A_{1} Y_{t-1}+\ldots . .+A_{p} Y_{t-p}+u_{t}
$$

$Y_{t}$ is a vector containing the four variables of interest for each economy. The underlying assumption that we make for this Structural VAR model is that real commodity prices are not contemporaneously affected by developments in the domestic economies. This is consistent with the small open economy framework that we adopt in this paper. Thus, having commodity prices first in the order of our variables in a Cholesky decomposition is a plausible assumption. The second variable in order is the growth rate of government consumption. This ordering is in line with Pieschacon 2012, Gali et al. 2007 and Fatas and Mihov 2001. It is also consistent with the analysis of this paper in showing how commodity shocks are transmitted to the economy through the fiscal sector. The results below are robust to different ordering between private consumption and inflation. In addition, the optimal lag criteria suggests that a lag of order 1 is the optimal choice for each of the four economies.

The economic principle behind the effect of a commodity price shock in our model is simple. When positive, a commodity-price shock acts as an income shock that increases government consumption. In return, The increase in government consumption will boost private consumption and put inflationary pressure on domestic prices, if government consumption has a crowding in effect on private consumption. 
Figure 2: Response to a Commodity Shock
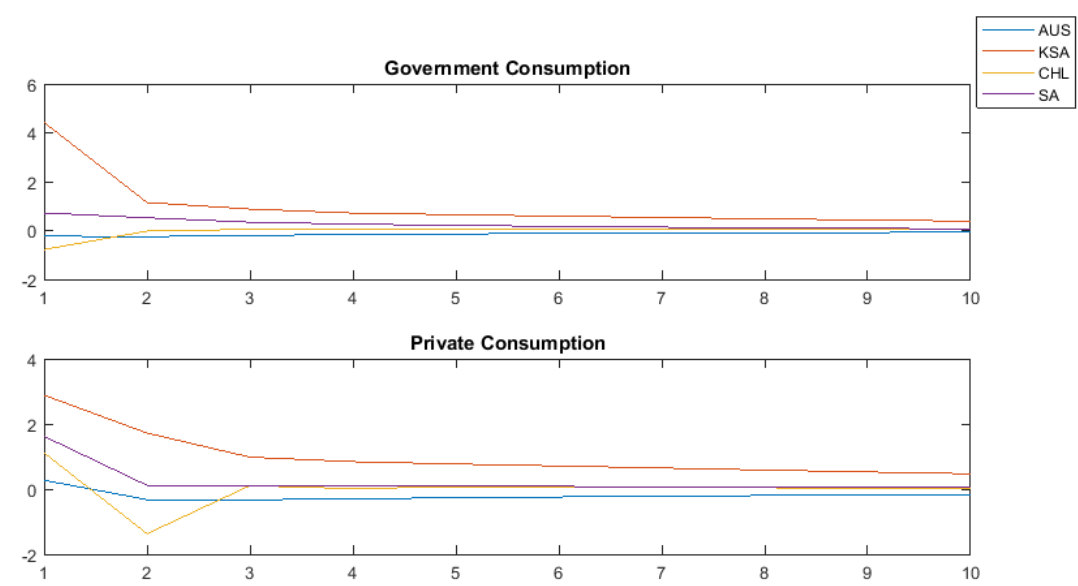

Inflation

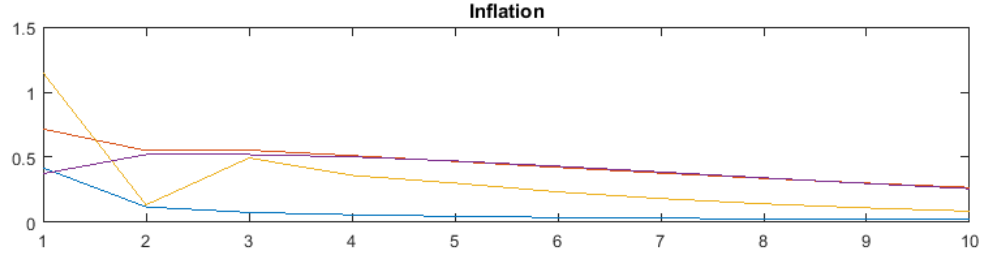

The impulse responses illustrate how government consumption growth responds in a different manner among commodity-rich economies. The response of government consumption in Saudi Arabia, an oil-rich country, is the highest among its counterparts in this study. In addition, the insignificant response of Australia and Chile reflect the adopted fiscal policy objective or rule in these two economies. The reaction of the South African government consumption shows a positive reaction to a commodity-price shock. This contradicts with the findings of the previous estimations of this paper. Nevertheless, the Bayesian estimation section should confirm one of these findings.

The reaction of private consumption and domestic CPI inflation is determined by the crowding in effect of government consumption and the implemented subsidies schemes that are adopted in different commodity-rich economies. In this regard, the size of the consumption of commodities in the aggregate consumption bundle should reflect the size of these subsidies in our DSGE model below.

The next section builds a dynamic general equilibrium model guided by these stylized facts where we formally articulate a mechanism by which exogenous changes in commodity prices turn 
into fluctuations in real economic activity, along with other exogenous shocks that have been suggested by the previous literature.

\section{The Model}

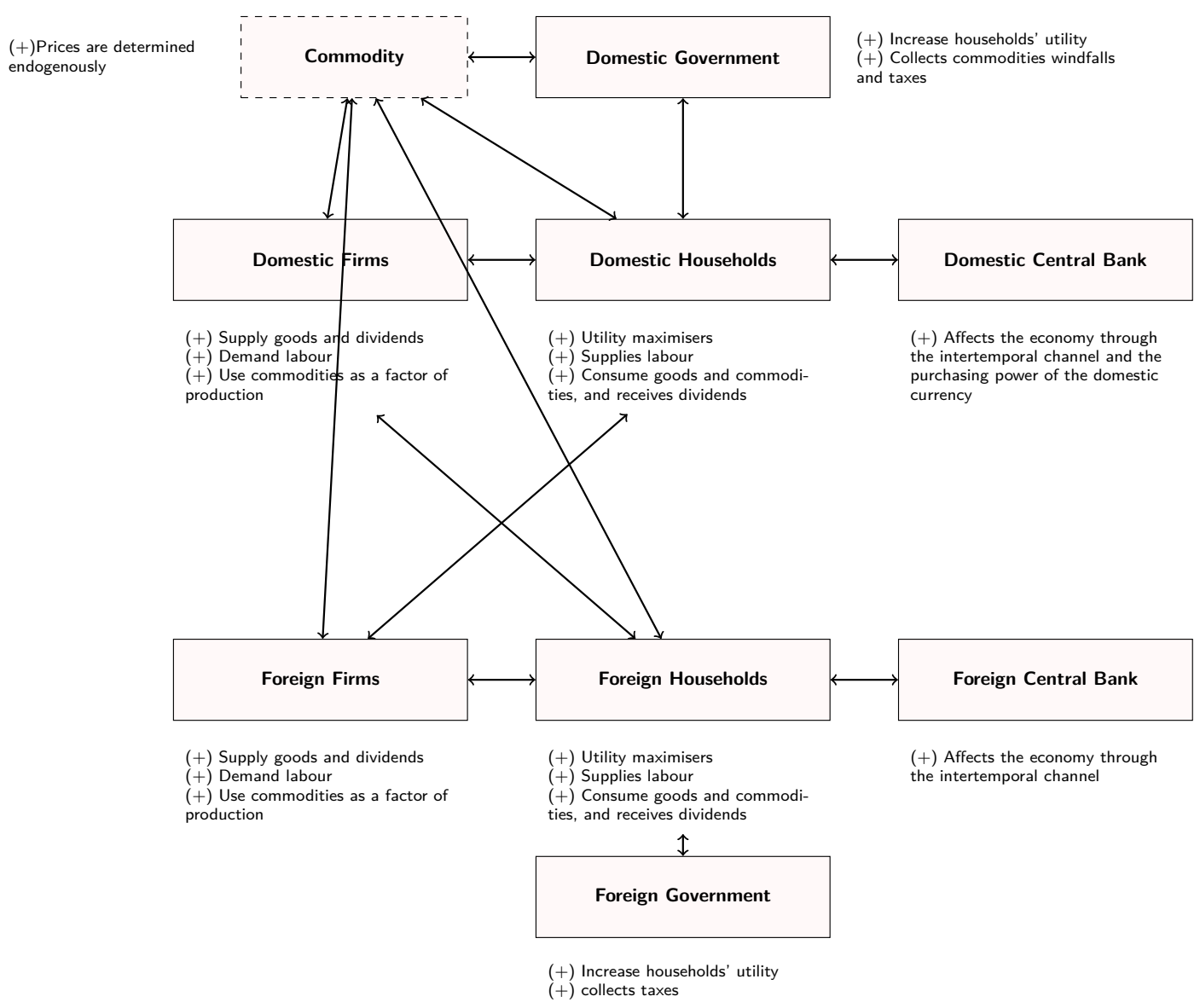

Figure 3: Structure of the Model

In this section we construct a small open economy model for a commodity-rich economy by using the framework of Galí and Monacelli 2005. Moreover, we extend the model used in Troug 2019 by adding some features that were missing in the model to make it relevant for a commodity-rich economy. Our model allows for a quadruple role for commodities. First, the domestic government collects the windfalls from selling commodities to the rest of the world. Second, commodities are consumed by households both in the domestic economy and the foreign economy. Third, firms 
both in the domestic economy and the foreign economy use commodities as an input factor in their production. Lastly, the domestic economy is affected by the second-round effect of an increase in commodity prices in the form of high foreign inflation and low world demand or vice versa.

\subsection{Domestic Economy}

\subsubsection{Household}

The representative consumer in the domestic economy seeks to maximise the following discounted lifetime utility function:

$$
E_{0} \sum_{t=0}^{\infty} \beta^{t} U\left(\bar{C}_{t}, N_{t}\right)
$$

The utility function is assumed to be continuous and twice differentiable. $N_{t}$ is the number of hours worked; $\beta$ is the discount factor; $\bar{C}_{t}$ is the aggregate consumption bundle. The aggregate consumption bundle is a constant elasticity of substitution aggregate that consists of private consumption $C_{t}$ and government consumption $G_{t}$ :

$$
\bar{C}_{t}=\left[\delta^{\chi} C_{t}^{1-\chi}+(1-\delta)^{\chi} G_{t}^{1-\chi}\right]^{\frac{1}{1-\chi}}
$$

Where $\delta$ is the equilibrium share of private consumption in the aggregate consumption bundle and $\chi$ is the inverse elasticity of substitution between private consumption and government consumption. From equations (5) and (6) we can notice that the utility function is non-decreasing in government consumption $G_{t}$. The above utility function is subject to the following budget constraint:

$$
\int_{0}^{1} P_{H, t}(j) C_{H_{t}}(j) d j+\int_{0}^{1} \int_{0}^{1} P_{i, t}(j) C_{i_{t}}(j) d j d i+E_{t} Q_{t, t+1} D_{t+1} \leq D_{t}+W_{t} N_{t}+T_{t}
$$

Where $D_{t}$ is the nominal payoff for bonds, shares in firms and deposits held at the end of period $\mathrm{t}$ and mature at period $\mathrm{t}+1 . Q_{t, t+1}$ is a stochastic discount factor of nominal payoffs and it is equal to $\frac{1}{R_{t}} ; W_{t}$ is wages; $T_{t}$ is lump-sum transfers to the households net of lump-sum taxes. All units are expressed in terms of domestic currency. In addition, the private consumption basket is 
a composite of core consumption and consumption of commodities:

$$
C_{t}=\left[(1-\varpi)^{\frac{1}{\mu}} C_{Z, t}^{\frac{\mu-1}{\mu}}+\varpi^{\frac{1}{\mu}} C_{O, t}^{\frac{\mu-1}{\mu}}\right]^{\frac{\mu}{\mu-1}}
$$

In the above equation, $C_{O, t}$ is consumption of commodities by the domestic economy's households, and $\varpi$ is the share of commodities consumption in the household's consumption bundle. $C_{Z, t}$ is the non-commodity consumption bundle (core consumption), and it has a size of $(1-\varpi)$ in the household's consumption bundle. $\mu$ is the elasticity of substitution between core consumption and consumption of commodities. The core consumption bundle $C_{Z, t}$ is a CES composite of home and foreign goods defined as follows:

$$
C_{Z, t}=\left[(1-\alpha)^{\frac{1}{\eta}} C_{H, t}^{\frac{\eta-1}{\eta}}+(\alpha)^{\frac{1}{\eta}} C_{F, t}^{\frac{\eta-1}{\eta}}\right]^{\frac{\eta}{\eta-1}}
$$

The above equation is the same household's consumption bundle used by Galí and Monacelli 2005 , which is the workhorse for small open economies. $\alpha$ here is the degree of openness in the economy which represents the share of imported goods $C_{F, t}$ in the household's consumption bundle. The home bias parameter $(1-\alpha)$ produces the possibility of a different consumption bundle in each economy. This is a consequence of having different consumption baskets in each country, despite the law of one price holding for each individual good. $\eta>0$ is the elasticity of substitution between domestically produced goods and imported goods in the household's consumption bundle.

The above utility function assumes two separabilities. The first is the separation between consumption and the amount of hours worked, and the second is time separability. The household's problem is analysed in two stages here. We first deal with the expenditure minimisation problem faced by the representative household to derive the demand functions for commodity goods, noncommodity goods, domestic goods and foreign goods. In the second stage, the households choose the level of $C_{t}$ and $N_{t}$, given the optimally chosen combination of goods. The standard optimality condition for households will be as follows:

$$
\frac{W_{t}}{P_{t}}=N_{t}^{\varphi} \bar{C}_{t}^{\sigma}\left(\frac{C_{t}}{\bar{C}_{t}}\right)^{\chi} \delta^{-\chi}
$$


The intertemporal optimality condition is:

$$
\beta\left(\frac{\bar{C}_{t+1}}{\bar{C}_{t}}\right)^{\chi-\sigma}\left(\frac{P_{t}}{P_{t+1}}\right)\left(\frac{C_{t}}{C_{t+1}}\right)^{\chi}=Q_{t, t+1}
$$

Taking the conditional expectation of equation (11) and rearranging the terms we get:

$$
\beta R_{t} E_{t}\left[\left(\frac{\bar{C}_{t+1}}{\bar{C}_{t}}\right)^{\chi-\sigma}\left(\frac{P_{t}}{P_{t+1}}\right)\left(\frac{C_{t}}{C_{t+1}}\right)^{\chi}\right]=1
$$

\section{$3.2 \quad$ Firms}

\subsubsection{Price Setting Behaviour}

The firms in this model set their prices in a staggered manner following Calvo $1983^{13}$. Under Calvo contracts, we have a random fraction $1-\theta$ of firms that are able to reset their prices at period $t$, while prices of the remaining firms of size $\theta$ are fixed at the previous period's price levels. Therefore, we can say that $\theta^{k}$ is the probability that a price set at period $t$ will still be valid at period $t+k$. Also, the probability of the firm re-optimising its prices will be independent of the time passed since it last re-optimised its prices, and the average duration for prices not to change is $\frac{1}{1-\theta}$. Given the above information, the aggregate domestic price level will have the following form:

$$
P_{H, t}=\left[\theta\left(P_{H, t-1}\right)^{1-\epsilon}+(1-\theta)\left(\bar{P}_{H, t}^{1-\epsilon}\right)\right]^{\frac{1}{1-\epsilon}}
$$

Where $\bar{P}_{H, t}$ is the new price set by the optimising firms. From the derivations shown in Appendix C.2, we get the following form for inflation:

$$
\Pi_{H, t}^{1-\epsilon}=\theta+(1-\theta)\left(\frac{\bar{P}_{H, t}}{P_{t-1}}\right)^{1-\epsilon}
$$

The above equation shows that the domestic inflation rate at any given period will be solely determined by the fraction of firms that reset their prices at that period. When a given firm in the economy sets its prices, it seeks to maximise the expected discounted value of its stream of profits,

\footnotetext{
${ }^{13}$ The Calvo model makes aggregation easier because it gets rid of the heterogeneity in the economy. The alternative pricing scheme is the quadratic cost of price adjustment by Rotemberg 1982. The two dynamics are equivalent up to a first-order approximation.
} 
conditional that the price it sets remains effective:

$$
\max _{\bar{P}_{H, t}} \sum_{k=0}^{\infty} \theta^{k} E_{t}\left\{Q_{t, t+k}\left[c_{j t+k \mid t}\left(\bar{P}_{H, t}-\Psi_{t+k}\right)\right]\right\}
$$

The above equation is subject to a sequence of demand constraints: $c_{j t+k}=\left(\frac{\bar{P}_{H, t}}{P_{H, t+k}}\right)^{-\epsilon} C_{t}$. Solving this problem (also shown in Appendix C.2) yields the following optimal decision rule:

$$
\sum_{k=0}^{\infty} \theta^{k} E_{t}\left\{Q_{t, t+k} C_{t+k}\left[\frac{\bar{P}_{H, t}}{P_{H, t-1}}-\mathcal{M} M C_{t+k \mid t} \Pi_{t-1, t+k}^{H}\right]\right\}=0
$$

Where $\mathcal{M}$ is the firm's markup at the steady state and $M C_{t}$ is real marginal cost. As we can see from equation (16), in the sticky price scheme producers, given their forward-looking behaviour, adjust their prices at a random period to maximise the expected discounted value of their profits at that period and in the future. Thus, firms in this model will set their prices equal to a markup plus the present value of the future expected stream of their marginal costs. This is done because firms know that the price they set at period $t$ will remain effective for a random period of time in the future. We also assume that all firms in the economy face the same marginal cost, given the constant return to scale assumption imposed on the model and the subsidy that the government pays to firms, as we will see in the following section. The firms also use the same discount factor $\beta$ as the one used by households, and this is attributed to the fact that the households are the shareholders of these firms. Additionally, all the firms that optimise their prices in any given period will choose the same price which is also a consequence of the firms facing the same marginal cost. Equation (16) also shows that the inflation rate is proportional to the discounted sum of the future real marginal costs additional to a mark-up resulting from the monopolistic power of the firms.

\subsubsection{Production}

Firm $(j)$ in the domestic economy produces a differentiated good following a linear production function:

$$
Y_{t}(j)=\left[A_{t} N_{t}(j)\right]^{\nu} O_{t}^{d}(j)^{1-\nu}
$$

In the above equation, $Y_{t}(j)$ is the output of final good $(\mathrm{j})$ in the home economy. $A_{t}$ is the level 
of technology in the production function. It evolves exogenously and is assumed to be common across all firms in the economy. $N_{t}(j)$ is the labour force employed by firm (j). $O_{t}^{d}$ is the commodity used in the production process and $(1-\nu)$ is the size of commodities in the production function. The $\log$ form of total factor productivity $a_{t}=\log \left(A_{t}\right)$ is assumed to follow an $\operatorname{AR}(1)$ process: $a_{t}=\rho_{a} a_{t-1}+\epsilon_{a, t}$. Where $\rho_{a}$ is the autocorrelation of the shock and the innovation to technology $\epsilon_{a, t}$ is assumed to have a zero mean and a finite variance $\sigma_{a}$. The cost minimisation function for firm (j) has the following form:

$$
(1-\tau)(1-\nu) W_{t} N_{t}(j)=\nu P_{o, t} O_{t}^{d}(j)
$$

We note that in the above equation we left $W_{t}$ without any firm specification, as we have a competitive labour market in this model. Also, $\tau$ is the subsidy that the government gives to firms in order to eliminate the markup distortion created by the firms' monopolistic power. The marginal cost equation takes the following form:

$$
M C_{t}(j)=\frac{(1-\tau) W_{t}}{\nu A_{t}^{\nu} O_{t}^{d}(j)^{1-\nu} N_{t}(j)^{\nu-1}}
$$

Using the above cost minimising equation, the above marginal cost equation is utilised to:

$$
M C_{t}(j)=\frac{(1-\tau)^{\nu} W_{t}^{\nu} P_{o, t}^{1-\nu}}{\nu^{\nu}(1-\nu)^{(1-\nu)} A_{t}^{\nu}}
$$

Lastly, given that aggregate output and aggregate employment in the domestic economy are defined by the Dixit and Stiglitz 1977 aggregator, the aggregate production function will take the following form:

$$
Y_{t}=\left[A_{t} N_{t}\right]^{\nu} O_{t}^{d(1-\nu)}
$$

\subsection{Fiscal Policy}

The government levies a lump sum tax on households and pays a subsidy to firms in order to eliminate its monopolistic power. The government also collects windfalls from sales of its natural resources, and has access to the financial markets. Therefore, the government budget constraint is 
defined as $^{14}$ :

$$
G_{t}+\left(1+R_{t-1}\right) B_{t-1}+\tau=B_{t}+T_{t}+\phi_{g} P_{t, o} Y_{t, o}
$$

Where $B_{t}$ is the quantity of a riskless one-period bond maturing in the current period, which pays one unit. $R_{t}$ denotes the gross nominal return on bonds purchased in period t. The government levies a non-distortionary lump-sum tax $T_{t}$ to finance its consumption and pay a subsidy $\tau$ to firms. In addition, $p_{t}^{o}$ is the price of commodities dominated in domestic currency and $Y_{t}^{o}$ is the output of that commodity ${ }^{15}$. Given the above, $G_{t}$ is government consumption will take the following form:

$$
\frac{G_{t}}{G}=\left\{\frac{G_{t-1}}{G}\right\}^{\rho_{g}}\left\{\frac{P_{o, t} Y_{o}}{P_{o} Y_{o}}\right\}^{\phi_{g}} \exp \left(\zeta_{G, t}\right)
$$

Where $0<\rho_{g}<1$ is the autocorrelation of government consumption, and it captures the persistence of government consumption. $\phi_{g}$ captures the response of government consumption to changes in the prices of commodities. $\zeta_{G, t}$ represents an i.i.d. government spending shock with constant variance $\sigma_{g}^{2}$.

\subsubsection{Monetary Policy}

The monetary authorities in this model use a short-term interest rate as their policy tool. In this case, we have a cashless economy where money supply is implicitly determined to achieve the interest rate target. It is also assumed that the central bank will meet all the money demanded under the policy rate it sets.

$$
\frac{R_{t}}{R}=\left\{\frac{\Pi_{Z, t}}{\Pi_{Z}}\right\}^{\phi_{\pi}}\left\{\frac{Y_{t}}{Y}\right\}^{\phi_{x}} \exp \left(\zeta_{R, t}\right)
$$

The parameters of the above equations $\left(\phi_{\pi}, \phi_{x}\right)$ describe the strength of the response of the policy rate to deviations in the variables on the right-hand side. These parameters are assumed

\footnotetext{
${ }^{14}$ The definition of government consumption includes all government recurrent spending items. We do this to establish consistency in the mapping between the model's government consumption variable and the observed government consumption variable.

${ }^{15}$ Given the fact that the production of natural resources is capital intensive, we follow the existing literature (e.g., Wills 2014, Berg et al. 2013 and Agénor 2014) by assuming that production of natural resources is exogenous. moreover, the share of employment in the natural resource sector does not exceed $3 \%$ of total employment in natural resource-rich economies, according to the ILO database, and the labour force lacks mobility between the two sectors.
} 
to be non-negative. The inflation response parameter $\phi_{\pi}$ in the above policy rule must be strictly greater than one in order for the solution of the model to be unique, as shown by Bullard and Mitra 2002. Lastly, $\zeta_{R, t}$ represents an i.i.d. monetary policy shock with constant variance $\sigma_{R}^{2}$.

\subsection{International Linkages}

We first start by the defining the terms of trade as the ratio of imported prices to domestic prices. The bilateral terms of trade index between the domestic economy and any other small economy (country i) is defined as: $S_{i, t}=\frac{P_{i, t}}{P_{H, t}}$. The aggregate terms of trade index is defined as: $S_{t}=\left(\int_{0}^{1} S_{i, t}^{1-\gamma} d i\right)^{\frac{1}{1-\gamma}}$. Defining $P_{F, t}=\left(\int_{0}^{1} P_{i, t}^{1-\gamma} d i\right)^{\frac{1}{1-\gamma}}$ allows as us to define the aggregate effective terms of trade as:

$$
S_{t}=\frac{P_{F, t}}{P_{H, t}}
$$

If we plug in the log-linearised representation of the imported prices index from the above equation $\left(p_{F, t}=s_{t}+p_{H, t}\right)$ in the log-linearised form of the CPI price index equation, we can derive the CPI index as a function of the domestic prices index and the terms of trade:

$$
p_{t}=p_{H, t}+\alpha s_{t}
$$

The above function shows that the gap between the CPI index and the domestic price index is filled by the terms of trade, representing imported inflation. This gap is parametrised by the degree of openness of the domestic economy. Before progressing on further derivations, we first define the bilateral exchange rate $\mathcal{E}_{i, t}$ as the value of country i's currency in terms of the domestic currency. Assuming that the law of one price holds, the price of any good in country (i) will be equal to:

$$
P_{i, t}(j)=\mathcal{E}_{i, t} P_{i, t}^{i}(j)
$$

Integrating the above equation yields the price index for country (i). Solving this integral for the imported prices index in the domestic economy yields:

$$
P_{F, t}=\mathcal{E}_{t} P_{t}^{*}
$$


The nominal effective exchange rate is equal to $\mathcal{E}_{t} \equiv \int_{0}^{1} \mathcal{E}_{i, t} d i$, and the world price index is defined as $P_{t}^{*} \equiv \int_{0}^{1} P_{i, t} d i$. Plugging the value of the imported prices index from the above equation in the definition of the terms of trade yields:

$$
S_{t}=\frac{\mathcal{E}_{t} P_{t}^{*}}{P_{H, t}}
$$

We now define the bilateral real exchange rate as the ratio of the price index in country (i) to the CPI index in the domestic economy: $R E E R_{i, t}=\frac{\mathcal{E}_{i, t} P_{t}^{i}}{P_{t}}$. Integrating the bilateral real exchange rate equation yields the real effective exchange rate equation for the domestic economy: $R E E R_{t}=\frac{\mathcal{E}_{t} P_{t}^{*}}{P_{t}}$. From the definitions of the terms of trade and the real effective exchange rate, we can define the equation that links the two variables in a log-linearised form as follows:

$$
q_{t}=(1-\alpha) s_{t}
$$

Under the assumption of complete international financial markets, the price of a one-period riskless bond dominated in the domestic economy's currency from country $(i)$ is equal to: $\mathcal{E}_{i, t} Q_{t}^{i}=$ $E\left[\mathcal{E}_{i, t+1} Q_{t, t+1}\right]$. If we add this equation to the domestic bond's price equation $\left(Q_{t}=E\left[Q_{t, t+1}\right]\right)$, we get the uncovered interest parity condition:

$$
\frac{Q_{t}^{i}}{Q_{t}}=E_{t}\left(\frac{\mathcal{E}_{i, t+1}}{\mathcal{E}_{i, t}}\right)
$$

The uncovered interest parity condition is crucial for the no-arbitrage condition to hold in the international bonds market. Under the uncovered interest parity we assume that foreign bonds are perfect substitutes to domestic bonds once both are expressed in the same currency. The uncovered interest parity equation also implies that higher foreign interest rates or a depreciation in the exchange rate will put upward pressure on domestic interest rates.

The last thing that we need do in this section is to derive the international risk condition. Under the assumptions of complete international markets and the identical preferences assumption, the foreign consumer's Euler equation can be presented as: 


$$
\beta\left(\frac{\bar{C}_{t+1}^{*}}{\bar{C}_{t}^{*}}\right)^{\chi-\sigma}\left(\frac{P_{t}^{*}}{P_{t+1}^{*}}\right)\left(\frac{C_{t}^{*}}{C_{t+1}^{*}}\right)^{\chi}\left(\frac{\mathcal{E}_{t}}{\mathcal{E}_{t+1}}\right)=Q_{t, t+1}
$$

We divide the domestic inter-temporal optimality condition (eq. 11) by the foreign economy's inter-temporal optimality condition (eq. 32) to get:

$$
1=E_{t}\left(\frac{\left(\frac{\bar{C}_{t+1}}{C_{t}}\right)^{\chi-\sigma}\left(\frac{P_{t}}{P_{t+1}}\right)\left(\frac{C_{t}}{C_{t+1}}\right)^{\chi}}{\left(\frac{\bar{C}_{t+1}^{*}}{\bar{C}_{t}^{*}}\right)^{\chi-\sigma}\left(\frac{P_{t}^{*}}{P_{t+1}^{*}}\right)\left(\frac{\mathcal{E}_{t}}{\mathcal{E}_{t+1}}\right)\left(\frac{C_{t}^{*}}{C_{t+1}^{*}}\right)^{\chi}}\right)
$$

Plugging the definition of the real effective exchange rate in the above equation yields:

$$
C_{t}=\mathcal{V}_{t} C_{t}^{*}\left(R E E R_{t}\right)^{\frac{1}{x}}\left(\frac{\bar{C}_{t}}{\bar{C}_{t}^{*}}\right)^{\frac{\chi-\sigma}{x}}
$$

Where $\mathcal{V}_{t}=\frac{C_{t+1} \bar{C}_{t}^{*} \frac{x-\sigma}{x}}{C_{t+1}^{*} \bar{C}_{t+1}^{\frac{x-\sigma}{x}} R E E R_{t+1}^{\frac{1}{x}}}$ is a constant and it depends on the initial relative wealth position. We assume that we have a symmetric initial condition and set $\mathcal{V}_{t}=1$; meaning that the net position of foreign assets is equal to zero. Thus, the international risk sharing condition simplifies to:

$$
C_{t}=C_{t}^{*}\left(R E E R_{t}\right)^{\frac{1}{x}}\left(\frac{\bar{C}_{t}}{\bar{C}_{t}^{*}}\right)^{\frac{\chi-\sigma}{x}}
$$

Complete security markets ensure that risk-averse consumers are able to trade away the risks and the shocks they encounter. Under this setting, consumers are able to purchase contingent claims for realisations of all idiosyncratic shocks, and this will enable them to diversify all idiosyncratic risk through the capital markets. The above international risk sharing condition also shows how a depreciation in the real effective exchange rate boosts domestic consumption relative to the foreign economy's consumption. The log-linearised form of the above international risk sharing condition is:

$$
c_{t}=c_{t}^{*}+\frac{\left(\sigma-\sigma_{\delta}\right)}{\sigma_{\delta}}\left(g_{t}^{*}-g_{t}\right)+\frac{1}{\sigma_{\delta}} q_{t} .
$$

Where $\sigma_{\delta}=\delta \sigma+(1-\delta) \chi$ is a weighted average of the intertemporal elasticity of substitution $\sigma$ and the inverse elasticity of substitution between government consumption and private consumption $\chi$. 


\subsubsection{Market clearing conditions}

We start by identifying the market clearing condition for the domestically produced products in the small open economy. Domestic output of good $(\mathrm{j})$ is absorbed both by domestic demand and foreign demand:

$$
Y_{t}(j)=C_{H, t}(j)+\int_{0}^{1} C_{H, t}^{i}(j) d i
$$

In the above equation, $C_{H, t}(j)$ is domestic demand for good (j) and $C_{H, t}^{i}$ is country (i)'s demand for good $(\mathrm{j})$ in the domestic economy. We plug the domestic demand function for good (j). As for foreign demand for domestic good $(\mathrm{j})$, we use the assumption of symmetric preferences across all the countries of the world economy to get:

$$
C_{H, t}^{i}(j)=\left(\frac{P_{H, t}(j)}{P_{H, t}}\right)^{-\epsilon}\left(\frac{P_{H, t}}{\mathcal{E}_{i, t} P_{F, t}^{i}}\right)^{-\gamma}\left(\frac{P_{F, t}^{i}}{P_{t}^{i}}\right)^{-\eta}
$$

Plugging in the respective demand bundles transforms the market clearing condition for domestic production of good (j) to:

$$
Y_{t}(j)=\left(\frac{P_{H, t}(j)}{P_{H, t}}\right)^{-\epsilon}\left((1-\alpha)\left(\frac{P_{H, t}}{P_{t}^{i}}\right)^{-\eta} C_{t}+\alpha \int_{0}^{1}\left(\frac{P_{H, t}}{\mathcal{E}_{i, t} P_{F, t}^{i}}\right)^{-\gamma}\left(\frac{P_{F, t}^{i}}{P_{t}^{i}}\right)^{-\eta} C_{t}^{i}(j) d i\right)
$$

Using the Dixit-Stiglitz aggregator of domestic output, we can write the above equation in aggregate terms:

$$
Y_{t}=\left(\frac{P_{H, t}}{P_{t}^{i}}\right)^{-\eta}\left((1-\alpha) C_{t}+\alpha \int_{0}^{1}\left(\frac{\mathcal{E}_{i, t} P_{F, t}^{i}}{P_{H, t}}\right)^{\gamma-\eta} Q_{i, t}^{\eta} C_{t}^{i} d i\right)
$$

In the above equation, we took $\left(\frac{P_{H, t}}{P_{t}^{i}}\right)^{-\eta}$ as common factor. We have also used the definition of the bilateral real exchange rate. If we divide and multiply the term $\left(\frac{\mathcal{E}_{i, t} P_{F, t}^{i}}{P_{H, t}}\right)^{\gamma-\eta}$ by $P_{i, t}$ we get: $\left(\frac{P_{i, t}}{P_{H, t}} \frac{\mathcal{E}_{i, t} P_{F, t}^{i}}{P_{i, t}}\right)^{\gamma-\eta}$. The two terms that we get are basically the effective terms of trade for country (i) and the bilateral terms of trade between the domestic economy and country (i), and equation (40) simplifies to:

$$
Y_{t}=\left(\frac{P_{H, t}}{P_{t}^{i}}\right)^{-\eta}\left((1-\alpha) C_{t}+\alpha \int_{0}^{1}\left(S_{t}^{i} S i, t\right)^{\gamma-\eta} Q_{i, t}^{\eta} C_{t}^{i} d i\right)
$$


Taking the first order log-linearisation of the above equation around a symmetric steady state yields:

$$
y_{t}=(1-\alpha) c_{t}+\alpha c_{t}^{*}+\alpha[\gamma+\eta(1-\alpha)] s_{t}
$$

Adding the log-linearised form of the international risk sharing condition to the above equation yields:

$$
y_{t}=y_{t}^{*}+\frac{(1-\alpha)\left(\sigma-\sigma_{\delta}\right)}{\sigma_{\delta}}\left(g_{t}^{*}-g_{t}\right)+\frac{\omega_{\alpha}}{\sigma_{\delta}} s_{t}
$$

where $\omega=\sigma_{\delta} \gamma+(1-\alpha)\left(\eta \sigma_{\delta}-1\right)$ and $\omega_{\alpha}=(1-\alpha)+\alpha \omega$. The above equation links the actual rate of output to foreign and domestic government consumption, the rest of the world economy's output, and the terms of trade.

\subsubsection{The Supply Side of the Economy}

The log-linearised version of the real marginal cost equation could be written in the following format:

$$
m c_{t}=\nu w_{t}+(1-\nu) p_{o, t}-\nu a_{t}-p_{H, t}
$$

Adding and subtracting $(1-\nu) p_{t}$ yields:

$$
m c_{t}=\nu\left(w_{t}-p_{t}\right)+(1-\nu) \tilde{p}_{o, t}+\alpha s_{t}-\nu a_{t}
$$

Where $\tilde{p}_{o, t}$ is the real price of commodities and it is equal to: $p_{o, t}-p_{t}$. Using the log-linearised form of the labour supply equation, the international risk sharing condition, and replacing the domestic real commodity prices with international real commodity prices $\left(\tilde{p}_{o, t}=\tilde{p}_{o, t}^{*}+(1-\alpha) s_{t}\right)$, the above equation transforms to:

$$
m c_{t}=\frac{\nu \sigma_{\delta}}{1+\varphi(1-\nu)} y_{t}^{*}+\frac{\nu \varphi}{1+\varphi(1-\nu)} y_{t}+s_{t}-\frac{\nu(1+\varphi)}{1+\varphi(1-\nu)} a_{t}+\frac{(1-\nu)(1+\varphi)}{1+\varphi(1-\nu)} \tilde{p}_{o, t}^{*}+\frac{\left(\nu\left(\sigma-\sigma_{\delta}\right)\right.}{1+\varphi(1-\nu)} g_{t}^{*}
$$

Plugging in the value of the terms of trade from the international market clearing condition yields:

$$
\begin{aligned}
m c_{t} & =\frac{\nu \sigma_{\delta} \omega_{\alpha}-\sigma_{\delta}-\sigma_{\delta} \varphi(1-\nu)}{\omega_{\alpha}(1+\varphi(1-\nu))} y_{t}^{*}+\frac{\nu \varphi \omega_{\alpha}+\sigma_{\delta}+\sigma_{\delta} \varphi(1-\nu)}{\omega_{\alpha}(1+\varphi(1-\nu))} y_{t}-\frac{\nu(1+\varphi)}{1+\varphi(1-\nu)} a_{t} \\
& +\frac{(1-\nu)(1+\varphi)}{1+\varphi(1-\nu)} \tilde{p}_{o, t}^{*}+\frac{\left(\sigma-\sigma_{\delta}\right)\left(\nu \omega_{\alpha}-(1-\alpha)-(1-\alpha) \varphi(1-\nu)\right)}{\omega_{\alpha}(1+\varphi(1-\nu))} g_{t}^{*}+\frac{(1-\alpha)\left(\sigma-\sigma_{\delta}\right)}{\omega_{\alpha}} g_{t}
\end{aligned}
$$


Setting $m c=-\mu$ and solving the above equation for output yields the equation of the natural rate of output:

$$
\begin{aligned}
\bar{y}_{t} & =-\frac{\nu \sigma_{\delta} \omega_{\alpha}-\sigma_{\delta}-\sigma_{\delta} \varphi(1-\nu)}{\nu \varphi \omega_{\alpha}+\sigma_{\delta}+\sigma_{\delta} \varphi(1-\nu)} y_{t}^{*}-\frac{\left(\left(\sigma-\sigma_{\delta}\right)\left(\nu \omega_{\alpha}-(1-\alpha)-(1-\alpha) \varphi(1-\nu)\right)\right.}{\nu \varphi \omega_{\alpha}+\sigma_{\delta}+\sigma_{\delta} \varphi(1-\nu)} g_{t}^{*} \\
& -\frac{(1-\alpha)\left(\sigma-\sigma_{\delta}\right)(1+\varphi(1-\nu))}{\nu \varphi \omega_{\alpha}+\sigma_{\delta}+\sigma_{\delta} \varphi(1-\nu)} g_{t}+\frac{\nu(1+\varphi) \omega_{\alpha}}{\nu \varphi \omega_{\alpha}+\sigma_{\delta}+\sigma_{\delta} \varphi(1-\nu)} a_{t}-\frac{(1-\nu)(1+\varphi) \omega_{\alpha}}{\nu \varphi \omega_{\alpha}+\sigma_{\delta}+\sigma_{\delta} \varphi(1-\nu)} \tilde{p}_{o, t}^{*}
\end{aligned}
$$

Subtracting the above two equations from each other yields the marginal cost variable as a function of the output gap:

$$
\hat{m} c_{t}=\frac{\nu \varphi \omega_{\alpha}+\sigma_{\delta}+\sigma_{\delta} \varphi(1-\nu)}{\omega_{\alpha}(1+\varphi(1-\nu))} x_{t}
$$

Adding the above equation to the derived Phillips curve in Appendix C.2 enables us to write domestic inflation as a function of the output gap:

$$
\pi_{H, t}=\beta E_{t}\left\{\pi_{H, t+1}\right\}+\kappa \frac{\nu \varphi \omega_{\alpha}+\sigma_{\delta}+\sigma_{\delta} \varphi(1-\nu)}{\omega_{\alpha}(1+\varphi(1-\nu))} x_{t}
$$

\subsubsection{The Demand Side of the Economy}

We start this section by adding the domestic economy's market clearing condition (eq. 42) to the log form of the Euler equation (eq. 11) to get:

$$
\begin{aligned}
y_{t}= & E_{t}\left\{y_{t+1}\right\}-\frac{(1-\alpha)}{\sigma_{\delta}}\left(r_{t}-E_{t}\left\{\pi_{t+1}\right\}\right)-\alpha[\gamma+\eta(1-\alpha)] \Delta E_{t}\left\{s_{t+1}\right\}-\alpha \Delta E_{t}\left\{y_{t+1}^{*}\right\} \\
& +\frac{(1-\alpha)\left(\sigma-\sigma_{\delta}\right)}{\sigma_{\delta}} \Delta E_{t}\left\{g_{t+1}\right\} \\
& =E_{t}\left\{y_{t+1}\right\}-\frac{(1-\alpha)}{\sigma_{\delta}}\left(r_{t}-E_{t}\left\{\pi_{H, t+1}\right\}\right)-\frac{\alpha \omega}{\sigma_{\delta}} \Delta E_{t}\left\{s_{t+1}\right\}-\alpha \Delta E_{t}\left\{y_{t+1}^{*}\right\} \\
& +\frac{(1-\alpha)\left(\sigma-\sigma_{\delta}\right)}{\sigma_{\delta}} \Delta E_{t}\left\{g_{t+1}\right\} \\
& =E_{t}\left\{y_{t+1}\right\}-\frac{\omega_{\alpha}}{\sigma_{\delta}}\left(r_{t}-E_{t}\left\{\pi_{H, t+1}\right\}\right)-\alpha(\omega-1) \Delta E_{t}\left\{y_{t+1}^{*}\right\}+\frac{(1-\alpha)\left(\sigma-\sigma_{\delta}\right)}{\sigma_{\delta}} \Delta E_{t}\left\{g_{t+1}\right\} \\
& +\frac{\alpha\left(\sigma-\sigma_{\delta}\right)}{\sigma_{\delta}} \Delta E_{t}\left\{g_{t+1}^{*}\right\}
\end{aligned}
$$

In the above system of equations, we made use of the CPI index equation in the domestic economy (eq. 26) and replaced the value of the terms of trade in equation (43). It is shown above that the effects of the domestic variables (government expenditure and real interest rates) on output are parametrised by the 
home-bias parameter $(1-\alpha)$, while the effects of the external variables are parametrised by the degree of openness in the economy $\alpha$. This is inherited from the market clearing condition of the domestic economy. Solving the above IS curve for the output gap yields:

$$
x_{t}=E_{t}\left\{x_{t+1}\right\}-\frac{\omega_{\alpha}}{\sigma_{\delta}}\left(r_{t}-E_{t}\left\{\pi_{t+1}\right\}-\overline{r r}_{t}\right)
$$

Where:

$$
\begin{aligned}
\bar{r} r_{t} & =\frac{\sigma_{\delta}}{\omega_{\alpha}} \Delta E_{t}\left\{\bar{y}_{t+1}\right\}-\frac{\sigma_{\delta} \alpha(\omega-1)}{\omega_{\alpha}} \Delta E_{t}\left\{y_{t+1}^{*}\right\}+\frac{(1-\alpha)\left(\sigma-\sigma_{\delta}\right)}{\omega_{\alpha}} \Delta E_{t}\left\{g_{t+1}\right\}+\frac{\alpha\left(\sigma-\sigma_{\delta}\right)}{\omega_{\alpha}} \Delta E_{t}\left\{g_{t+1}^{*}\right\} \\
& =-\frac{\left.\nu(1+\varphi) \sigma_{\delta}\left(1-\rho_{a}\right)\right)}{\nu \varphi \omega_{\alpha}+\sigma_{\delta}+\sigma_{\delta} \varphi(1-\nu)} a_{t}+\frac{(1-\nu)(1+\varphi) \sigma_{\delta}}{\nu \varphi \omega_{\alpha}+\sigma_{\delta}+\sigma_{\delta} \varphi(1-\nu)} \Delta E_{t}\left\{\tilde{p}_{o, t+1}^{*}\right\} \\
& +\frac{\nu \varphi(1-\alpha)\left(\sigma-\sigma_{\delta}\right)}{\nu \varphi \omega_{\alpha}+\sigma_{\delta}+\sigma_{\delta} \varphi(1-\nu)} \Delta E_{t}\left\{g_{t+1}\right\}+\frac{\left(\sigma-\sigma_{\delta}\right)\left(\nu \omega_{\alpha}\left(\alpha \varphi-\sigma_{\alpha}\right)+\sigma_{\delta}(1+\varphi-\varphi \nu)\right)}{\omega_{\alpha}\left(\nu \varphi \omega_{\alpha}+\sigma_{\delta}+\sigma_{\delta} \varphi(1-\nu)\right)} \Delta E_{t}\left\{g_{t+1}^{*}\right\} \\
& +\frac{\sigma_{\delta}\left((1+\alpha) \sigma_{\delta}(1+\varphi(1-\nu))-\alpha \nu \varphi \omega_{\alpha}(\omega-1)-\alpha \omega \sigma_{\delta}(1+\varphi(1-\nu))-\nu \omega_{\alpha} \sigma_{\delta}\right)}{\omega_{\alpha}\left(\nu \varphi \omega_{\alpha}+\sigma_{\delta}+\sigma_{\delta} \varphi(1-\nu)\right)} \Delta E_{t}\left\{y_{t+1}^{*}\right\}
\end{aligned}
$$

One of the contributions that this paper makes is adding real commodity prices to the reaction of the natural rate of interest function. The weight of commodities in the production function $(\nu)$ also affects the reaction of the natural rate of interest to all the possible shocks.

Lastly, to calculate domestic demand for commodities, we replace employment in the cost minimisation equation to get:

$$
o_{t}^{d}=\frac{1+\varphi}{1+\varphi(1-\nu)} y_{t}+\frac{\nu \sigma_{\delta}}{1+\varphi(1-\nu)} y_{t}^{*}-\frac{\nu(1+\varphi)}{1+\varphi(1-\nu)} a_{t}+\frac{\nu\left(\sigma-\sigma_{\delta}\right)}{1+\varphi(1-\nu)} g_{t}^{*}-\frac{\nu}{1+\varphi(1-\nu)} \tilde{p}_{o, t}^{*}
$$

The equation shows that increases in domestic output and world output have a positive effect on domestic demand for commodities. The effect of world government consumption, however, depends on whether world government consumption is a complement or a substitute to world private consumption, as the former's effect on the domestic economy varies under the two assumptions ${ }^{16}$. As for domestic technology, given that it is also a factor of production, it has a negative effect on domestic demand for commodities. Lastly, real international commodity prices have a negative effect on the demand of commodities in the domestic economy.

\footnotetext{
${ }^{16}$ see Troug 2019 for more details.
} 


\subsection{Rest of the World economy}

\subsubsection{Households}

The representative household of the foreign economy seeks to maximise a similar utility function to the one shown above for the domestic economy:

$$
E_{0} \sum_{t=0}^{\infty} \beta^{t} U\left(\bar{C}_{t}^{*}, N_{t}^{*}\right)
$$

The utility function is assumed to be continuous and twice differentiable. $N_{t}^{*}$ is the amount of hours worked; $\bar{C}_{t}^{*}$ is the aggregate consumption bundle, and it is a constant elasticity of substitution aggregate consisting of private consumption $C_{t}^{*}$ and government consumption $G_{t}^{*}$ :

$$
\bar{C}_{t}^{*}=\left[\delta^{*} \chi^{*} C_{t}^{* 1-\chi^{*}}+\left(1-\delta^{*}\right)^{\chi} G_{t}^{* 1-\chi^{*}}\right]^{\frac{1}{1-\chi^{*}}}
$$

Similar to the domestic economy, $\delta^{*}$ is the weight of private consumption $C_{t}^{*}$ in the aggregate consumption bundle. $C_{t}^{*}$ is our basic private consumption bundle, and it is a CES composite of core consumption and consumption of commodities, defined as follows:

$$
C_{t}^{*}=\left[(1-\varpi)^{\frac{1}{\mu}} C_{Z, t}^{* \frac{\mu-1}{\mu}}+\varpi^{\frac{1}{\mu}} C_{O, t}^{* \frac{\mu-1}{\mu}}\right]^{\frac{\mu}{\mu-1}}
$$

Where $C_{O, t}^{*}$ is consumption of commodities by the foreign economy's households, and $\varpi^{*}$ is the share of oil consumption in the household's consumption bundle. $C_{Z, t}^{*}$ is the non-commodity consumption bundle (core consumption), and it has a size of $\left(1-\varpi^{*}\right)$ in the household's consumption bundle.

Using the world aggregate demand equation and plugging the foreign economy's consumption bundles, we get the aggregate CPI index for the foreign economy:

$$
P_{t}^{*}=\left[\left(1-\varpi^{*}\right) P_{Z, t}^{* 1-\mu}+\varpi^{*} P_{O, t}^{* 1-\mu}\right]^{\frac{1}{1-\mu}}
$$

Analogues to the domestic economy, the labour supply and the consumption intertemporal Euler equations take the following forms:

$$
\frac{W_{t}^{*}}{P_{t}^{*}}=N_{t}^{* \varphi} \bar{C}_{t}^{* \sigma}\left(\frac{C_{t}^{*}}{\bar{C}_{t}^{*}}\right)^{\chi} \delta^{-\chi}
$$


The intertemporal optimality condition is:

$$
\beta\left(\frac{\bar{C}_{t+1}^{*}}{\bar{C}_{t}}\right)^{\chi-\sigma}\left(\frac{P_{t}^{*}}{P_{t+1}^{*}}\right)\left(\frac{C_{t}^{*}}{C_{t+1}^{*}}\right)^{\chi}=Q_{t, t+1}
$$

\subsubsection{Firms}

\subsubsection{Production}

The representative firm in the foreign economy uses commodities and labour as inputs of production in the following form:

$$
Y_{t}^{*}(i)=\left[A_{t} N_{t}^{*}(i)\right]^{\nu} O_{t}^{* d}(i)^{1-\nu}
$$

In the above equation, $N_{t}^{*}$ is labour input, and $O_{t}^{*}$ is commodities input. $\nu$ is the share of non-commodity factors in the production function. Cost minimising with respect to the production function yields the optimal resource allocation:

$$
(1-\nu)(1-\tau) W_{t}^{*} N_{t}^{*}(i)=\nu P_{O, t}^{*} O_{t}^{* d}(i)
$$

The optimal behaviour of firms requires the technical rate of substitution to equate the relative prices of the input factors. $\tau$ is an employment subsidy which the government in the foreign economy pays to firms to offset their monopolistic power distortion. The nominal marginal cost equation is defined as:

$$
M C_{t}^{*}=\frac{(1-\tau)^{\nu} W_{t}^{* \nu} P_{O, t}^{* 1-\nu}}{\nu^{\nu}(1-\nu)^{(1-\nu)} A_{t}^{* \nu}}
$$

\subsubsection{Price Setting}

As for the price setting behaviour of the firms, we assume that the foreign economy firms also set their prices according to Calvo 1983 contracts. Thus, the resulting log-linearised New Keynesian Phillips Curve for the foreign economy is:

$$
\hat{\pi}_{t}^{*}=\beta E_{t}\left[\hat{\pi}_{t+1}^{*}\right]+\frac{(1-\theta)(1-\theta \beta)}{\theta} \hat{m} c_{t}^{*}
$$

\subsubsection{Fiscal Policy}

The government in the foreign economy also levies a lump sum tax on the agents of the economy. It also pays a subsidy to firms in order to eliminate its monopolistic power and it has access to the financial markets. Therefore, the government budget constraint is given by:

$$
G_{t}^{*}+\left(1+R_{t-1}^{*}\right) B_{t-1}^{*}+\tau^{*}=B_{t}^{*}+T_{t}^{*}
$$


Where $B_{t}^{*}$ is the quantity of a riskless one-period bond maturing in the current period, and it pays one unit. $R_{t}^{*}$ denotes the gross nominal return on bonds purchased in period t. The government levies a non-distortionary lump-sum tax $T_{t}^{*}$ to finance its consumption and pays a subsidy $\tau^{*}$ to firms. Given the above, $G_{t}^{*}$ is government consumption and takes the following form:

$$
\frac{G_{t}^{*}}{G^{*}}=\left\{\frac{G_{t-1}^{*}}{G^{*}}\right\}^{\rho_{g^{*}}} \exp \left(\zeta_{G^{*}, t}\right)
$$

Where $0<\rho_{g}^{*}<1$ is the autocorrelation of government consumption, and it captures the persistence of foreign government consumption. $\zeta_{G^{*}, t}$ represents an i.i.d. government consumption shock with constant variance $\sigma_{g^{*}}^{2}$.

\subsubsection{Monetary Policy}

The monetary authority in the foreign economy also uses a short-term interest rate as its policy tool:

$$
\frac{R_{t}^{*}}{R^{*}}=\left\{\frac{\Pi_{t}^{*}}{\Pi^{*}}\right\}^{\phi_{\pi}}\left\{\frac{Y_{t}^{*}}{Y^{*}}\right\}^{\phi_{x}} \exp \left(\zeta_{R^{*}, t}\right)
$$

Monetary policy in the foreign economy reacts to deviations of inflation from its natural level and deviations of output from its natural level. $\zeta_{R^{*}, t}$ represents an i.i.d. monetary policy shock with constant variance $\sigma_{r *}^{2}$

\subsubsection{The Supply Side of The World Economy}

We start this section by writing the log-linearised version of the real marginal cost equation in the foreign economy as follows:

$$
m c_{t}^{*}=\nu w_{t}^{*}+(1-\nu) p_{o, t}^{*}-\nu a_{t}^{*}-p_{t}^{*}
$$

Adding and subtracting $\nu p_{t}^{*}$ yields:

$$
m c_{t}^{*}=\nu\left(w_{t}^{*}-p_{t}^{*}\right)+(1-\nu)\left(\tilde{p}_{o, t}^{*}-p_{t}^{*}\right)-\nu a_{t}^{*}
$$

Using the Euler equation yields:

$$
m c_{t}^{*}=\nu\left(\sigma c_{t}^{*}+\varphi n_{t}^{*}+\left(\sigma-\sigma_{\delta}\right) g_{t}^{*}\right)+(1-\nu) \tilde{p}_{o, t}^{*}-\nu a_{t}^{*}
$$


Using the production function, and the cost minimising equation yields:

$$
m c_{t}^{*}=\frac{\nu \sigma+\nu \varphi}{1+(1-\nu) \varphi} y_{t}^{*}-\frac{\nu(1+\varphi)}{1+(1-\nu) \varphi} a_{t}^{*}+\frac{(1-\nu)(1+\varphi)}{1+(1-\nu) \varphi} \tilde{o}, t^{*}+\frac{\nu\left(\sigma-\sigma_{\delta}\right)}{1+(1-\nu) \varphi} g_{t}^{*}
$$

Equating $m c_{t}^{*}$ to the steady-state markup $\left(-\mu^{*}\right)$ and solving for output, yields the natural rate of output equation in the foreign economy:

$$
\bar{y}_{t}^{*}=-\frac{1+(1-\nu) \varphi}{\nu \sigma+\nu \varphi} \mu^{*}+\frac{\nu(1+\varphi)}{\nu \sigma+\nu \varphi} a_{t}^{*}-\frac{(1-\nu)(1+\varphi)}{\nu \sigma+\nu \varphi} \tilde{p}_{o, t}^{*}-\frac{\nu\left(\sigma-\sigma_{\delta}\right)}{\nu \sigma+\nu \varphi} g_{t}^{*}
$$

Subtracting the above two equations from each other yields the deviation of the marginal cost as a function of the output gap:

$$
\hat{m} c_{t}^{*}=\frac{\nu \sigma+\nu \varphi}{1+(1-\nu) \varphi} x_{t}^{*}
$$

Adding this to the NKPC equation gives us inflation as a function of the output gap:

$$
\hat{\pi}_{t}^{*}=\beta E_{t}\left[\hat{\pi}_{t+1}^{*}\right]+\lambda \frac{\nu \sigma+\nu \varphi}{1+(1-\nu) \varphi} x_{t}^{*}
$$

\subsubsection{The Demand Side of The World Economy}

Moving to the demand side of the foreign economy, we add the log-form of the Euler equation to the market clearing equation $\left(c_{t}^{*}=y_{t}^{*}\right)$ to get:

$$
y_{t}^{*}=E_{t}\left\{y_{t+1}^{*}\right\}-\frac{1}{\sigma_{\delta}}\left[r_{t}^{*}-E_{t}\left\{\pi_{t+1}^{*}\right\}\right]+\frac{\sigma-\sigma_{\delta}}{\sigma_{\delta}} \Delta E_{t}\left\{g_{t+1}^{*}\right\}
$$

Solving the above IS curve for the output gap yields:

$$
x_{t}^{*}=E_{t}\left\{x_{t+1}^{*}\right\}-\frac{1}{\sigma_{\delta}}\left[r_{t}^{*}-E_{t}\left\{\pi_{t+1}^{*}\right\}-\overline{r r}_{t}^{*}\right]
$$

Where:

$$
\begin{aligned}
\overline{r r}_{t}^{*} & =\sigma_{\delta} \Delta \bar{y}_{t+1}^{*}+\left(\sigma-\sigma_{\delta}\right) \Delta g_{t+1}^{*} \\
& =-\frac{\sigma_{\delta}\left(1-\rho_{a}\right)(1+\varphi) \nu}{\nu(\varphi+\sigma)} a_{t}^{*}+\frac{\nu\left(\sigma-\sigma_{\delta}\right)\left(\sigma+\varphi-\sigma_{\delta}\right)}{\nu(\varphi+\sigma)} \Delta g_{t+1}^{*}-\frac{\sigma_{\delta}(1-\nu)(1+\varphi)}{\nu(\varphi+\sigma)} \Delta \tilde{p}_{o, t+1}^{*}
\end{aligned}
$$

In the above equation, similar to the natural rate of interest in the domestic economy, the natural rate of interest in the foreign economy also reacts to expected changes in the price of commodities. 


\subsubsection{Commodities Market Equilibrium}

The supply of commodities is assumed to follow an $\mathrm{AR}(1)$ process:

$$
\frac{O_{t}^{* s}}{O^{* s}}=\left\{\frac{O_{t-1}^{* s}}{O^{* s}}\right\}^{\rho_{o}^{*}} \exp \left(\zeta_{o^{*}, t}\right)
$$

Where $0<\rho_{o}^{*}<1$ is the autocorrelation parameter of the supply of commodities, and it captures the persistence of commodity supply. $\zeta_{o^{*}, t}$ represents an i.i.d. commodity supply shock with constant variance $\sigma_{O^{*}}^{2}$.

We solve for the demand of commodities from the cost minimisation equation and by plugging the value of the equilibrium level of employment to derive the demand of commodities in the world economy as a function of the world output, world technology, world government consumption, and real commodity prices:

$$
o_{t}^{* d}=\frac{\nu \sigma+\varphi+1}{1+\varphi(1-\nu)} y_{t}^{*}-\frac{\nu(1+\varphi)}{1+\varphi(1-\nu)} a_{t}^{*}+\frac{\nu\left(\sigma-\sigma_{\delta}\right)}{1+\varphi(1-\nu)} g_{t}^{*}-\frac{\nu}{1+\varphi(1-\nu)} \tilde{p}_{o, t}^{*}
$$

Using the commodities market equilibrium condition $\left(o_{t}^{* s}=o_{t}^{* d}\right)$, the above equation can be solved for the equilibrium real commodity price:

$$
\tilde{p}_{o, t}^{*}=\frac{\nu \sigma+\varphi+1}{\nu} y_{t}^{*}-(1+\varphi) a_{t}^{*}+\left(\sigma-\sigma_{\delta}\right) g_{t}^{*}-\frac{1+\varphi(1-\nu)}{\nu} o_{t}^{* s}
$$

The above equation illustrates how the real prices of commodities are driven by demand and supply factors in the world economy. Government consumption and world output are demand factors that have a positive effect on real commodity prices. Conversely, the supply of commodities and the world technology are supply factors that negatively affect the real prices of commodities.

\subsection{Calibrated Parameters and Moments of the Model}

\subsubsection{Baseline Calibration}

In this section, we illustrate the baseline calibration of the above model (table shown in Appendix 4). The parameters set is divided into two sections. The first section illustrates the parameters that this model adopts from the standard literature ${ }^{17}$, and the second section highlights the parameters that are specific to this model.

In the first section of the parameters set, we set $\theta$ equal to 0.75 , implying that firms only change their

\footnotetext{
${ }^{17}$ See Taylor 1993, Galí and Monacelli 2005, Smets and Wouters 2007 and Shousha 2016
} 
prices once a year. The discount factor $\beta$ is equal to 0.99 . This implies that, given that $\beta=1 / r$ at the steady state, annual return is approximately equal to 4 percent. We set $\varphi$ equal to 3 , under the assumption that the labour supply elasticity is $\frac{1}{3}$. We set $\phi_{\pi} \& \phi_{x}$ equal to 1.5 and 0.5 following Taylor 1993 . The size of household's private consumption in the aggregate consumption bundle $\delta$ equal to 0.95 . The share of non-commodity inputs in the production functions are set to 0.95 . The inverse elasticity of intertemporal substitution of consumption $\sigma$ is set equal to 1 , which implies log utility in consumption. The elasticity of substitution between domestic and foreign produced goods $\eta$ is set to 1 . This elasticity describes the change in consumption of imported goods in response to changes in the prices of foreign goods relative to domestic prices. The value of the parameter implies that demand of imported goods increases by exactly $1 \%$ when the relative price of foreign goods declines by $1 \%$. The elasticity of substitution between the domestically produced goods $\epsilon$ equals 6 which corresponds to a steady state markup of 1.2 . As for the standard deviations and persistence of the interest rates and productivity shock processes, we use the ones used by Smets and Wouters 2007 and Galí and Monacelli 2005, respectively.

As for the second section, the shares of foreign goods in the private consumption baskets of the domestic economies $\alpha$ are set equivalent to the average share of import to GDP over the sample period (1980-2015). The standard deviation and the persistence of the commodity supply variable are calculated by fitting an AR (1) model for the supply of energy which was extracted from the International Energy Agency's database. As for the rest of the standard deviations and persistence of the other shock processes, they were calculated in Table (3). The responses of government consumption to changes in commodity prices $\phi_{g}$ are adopted from the estimates shown in Table (4). This implies that a few of the results, which are based on the baseline calibration, will be inconsistent with the results obtained in the structural VAR estimations. Nevertheless, the Bayesian estimations will be decisive in this matter.

The inverse elasticities of substitution between government consumption and private consumption for each of the five economies were all calibrated to values that generate responses of private consumption to changes in government consumption that are equivalent to the ones estimated in Table (2). As for the share of commodities consumption in the private consumption bundle, we use the share of energy consumption in the CPI basket from the OECD.stat database. In this regard, this share was not available for Saudi Arabia. Therefore, we use the lowest share of commodities in the KSA CPI given the generous subsidies scheme that was implemented in the country during our sample period, as highlighted by Abusaaq 2015. 


\subsubsection{Moments of the Model}

Figure 4: Response to a Commodity Shock
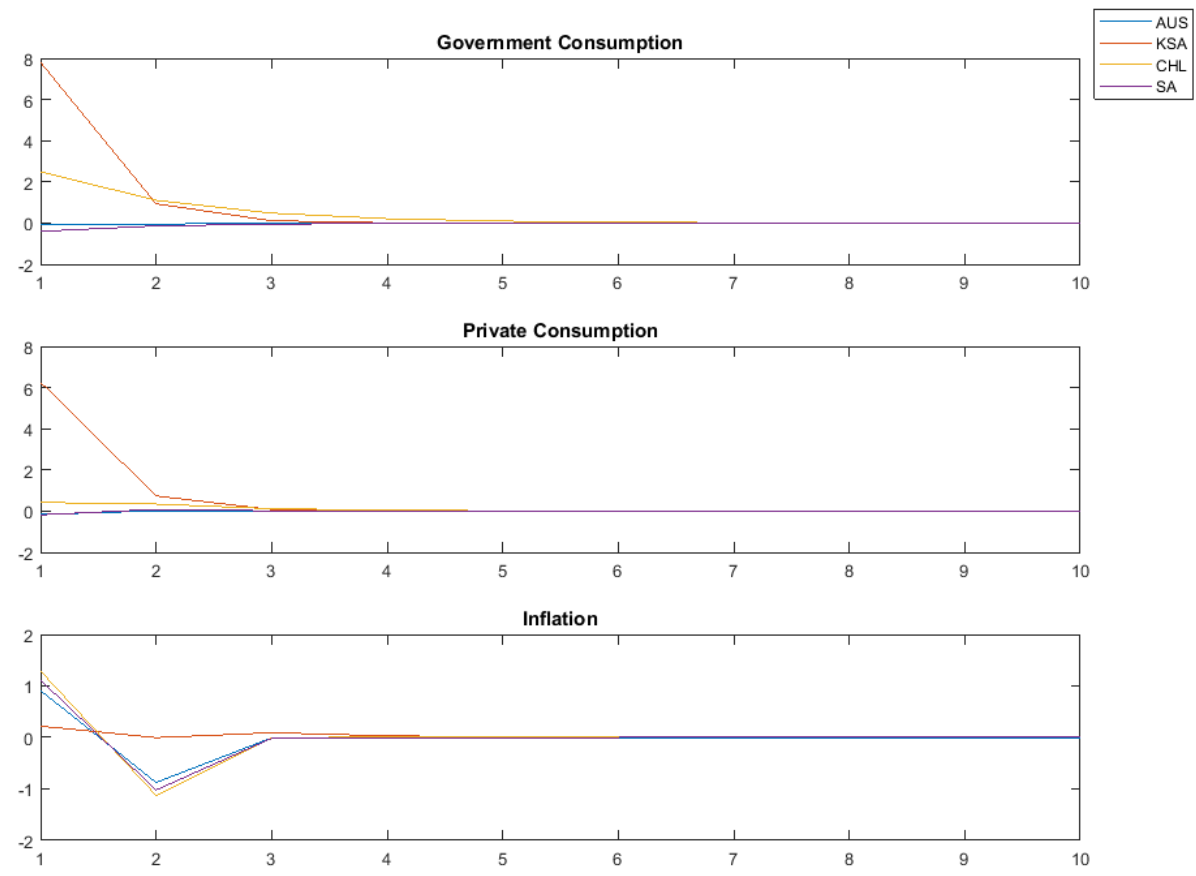

In the above graph, we show how the domestic economies react to a commodity shock under the model structure. In this regard, we add a commodity i.i.d shock to our framework specifically for this part of the analysis $^{18}$. The graph illustrates how the four economies react in a different manner to a commodity shock, similar to all of the results above. It also shows how government consumption in Saudi Arabia, an oil-rich economy, reacts to the shock more than its counterparts and how inflation in Saudi Arabia moderately reacts to the commodity shocks given the low share of commodities in the Saudi private consumption basket $^{19}$.

Nevertheless, the model seems to overstate the reaction of the Chilean government consumption to the commodity shock. In addition, government consumption in South Africa behaves countercyclically which also contradicts with the Structural VAR estimations. These differences reflect the difference between the previous estimations, as noted above. However, we will re-estimate each of the behaviour parameters below

\footnotetext{
${ }^{18}$ The shock process for the average commodity index was constructed by fitting the series to an AR(1) model to capture the persistence of the index (0.9).

${ }^{19}$ We show the theoretical effect of all the seven shock of the model on our variables of interest for all of the four economies in Appendix 4.
} 
using Bayesian estimation techniques. In addition, the below table shows that the theoretical moments, under the seven imposed shocks of the model, qualitatively resemble the moments found in the data.

Table 5: Theoretical Moments of the Model

\begin{tabular}{lccc}
\hline KSA & Gov. Consumption & Private Consumption & Inflation \\
\hline Std. Deviation & 1.01 & 1.27 & 0.77 \\
Persistence & 0.12 & 0.34 & 0.26 \\
& & & \\
Correlation with Gov. Consumption & 1.00 & 0.64 & 0.01 \\
Correlation with Private consumption & 0.64 & 1.00 & 0.08 \\
Correlation with inflation & 0.01 & 0.08 & 1.00 \\
\hline CHL & Gov. Consumption & Private Consumption & Inflation \\
\hline Std. Deviation & 1.11 & 0.75 & 0.41 \\
Persistence & 0.44 & 0.16 & -0.18 \\
& & & \\
Correlation with Gov. Consumption & 1.00 & 0.32 & 0.01 \\
Correlation with Private consumption & 0.32 & 1.00 & -0.04 \\
Correlation with inflation & 0.01 & -0.04 & 1.00 \\
\hline SA & Gov. Consumption & Private Consumption & Inflation \\
\hline Std. Deviation & 1.08 & 0.78 & 0.46 \\
Persistence & 0.36 & 0.61 & -0.09 \\
& & & \\
Correlation with Gov. Consumption & 1.00 & 0.19 & -0.00 \\
Correlation with Private consumption & 0.19 & 1.00 & 0.00 \\
Correlation with inflation & 0.00 & 0.00 & 1.00 \\
\hline AUS & Gov. Consumption & Private Consumption & Inflation \\
\hline Std. Deviation & 1.11 & 1.10 & 0.51 \\
Persistence & 0.44 & 0.46 & 0.23 \\
Correlation with Gov. Consumption & 1.00 & & \\
Correlation with Private consumption & 0.71 & 0.71 & 0.10 \\
Correlation with inflation & 0.10 & 0.02 & 0.02 \\
\hline \hline & & & 1.00 \\
\hline
\end{tabular}

\section{Estimation}

The Bayesian estimations in this section are conducted using three observable variables for each of our domestic economies in addition to the commodities index. All observables are directly mapped to variables in the structural model using the following equations:

$$
\begin{gathered}
\Delta \ln G_{t}^{o b s}=\ln G_{t}-\ln G_{t-1}+\text { Trend }_{g} \\
\Delta \ln C_{t}^{o b s}=\ln C_{t}-\ln C_{t-1}+\text { Trend }_{c} \\
\pi_{t}^{o b s}=\pi_{t}+\text { Trend } \\
p_{o, t}^{o b s}=p_{o, t}
\end{gathered}
$$

The Bayesian estimations are conducted on our selected parameters using an MCMC algorithm to obtain draws from the marginal posterior distribution of the parameters ${ }^{20}$. We estimate the stochastic

${ }^{20}$ We take 1,000,000 draws with an acceptance rate of 32.4 for Chile, 34.2 for Saudi Arabia, 34.5 for Australia, and 33.3 for South Africa. We also discard 25 percent of the draws and keep the remaining ones for inference. 
processes of each of the exogenous disturbances of the model, along with the parameter that governs the response of government consumption to changes in the commodity prices $\phi_{g}$ and the parameter that shows the effect of government consumption on private consumption $\chi$, as shown in the below table. The estimation of these two parameters, using the data, allows us to capture the size of these two parameters within the framework of our model.

In this regard, we use the calibrated values for $\chi$ and $\phi_{g}$ as the prior values for those two parameters while obtaining the values of the standard deviation from the regression results of this paper for $\phi_{g}$. As for $\chi$, we used standard deviations that are equivalent to the standard deviations of the regression results in percentage terms. Moreover, we impose a non-negativity assumption on $\chi$ by assuming an inverse gamma prior distribution. As for $\phi_{g}$, we assume a prior normal distribution in order to give the parameter the freedom to move between negative and positive values. In addition, the prior values and the standard deviations for the stochastic processes of all the shocks were taken from Smets and Wouters 2007. Also, we impose the same prior values and standard deviations for all the shocks to have the same relative importance for all the shocks at the starting point.

Table 6: Estimated Parameters

\begin{tabular}{|c|c|c|c|}
\hline Parameter & Prior & Mean & std. dev. \\
\hline \multicolumn{4}{|l|}{ AUS } \\
\hline$\chi$ & Inverse-Gamma & 67.6 & 12.82 \\
\hline$\hat{\phi}_{g}$ & Normal & -0.01 & 0.017 \\
\hline \multicolumn{4}{|l|}{ CHL } \\
\hline$\chi$ & Inverse-Gamma & 8.19 & 4.84 \\
\hline$\phi_{g}$ & Normal & 0.25 & 0.048 \\
\hline \multicolumn{4}{|l|}{$\mathrm{SA}$} \\
\hline$\chi$ & Inverse-Gamma & 5.3 & 2.266 \\
\hline$\phi_{g}$ & Normal & -0.04 & \\
\hline \multicolumn{4}{|l|}{$\overline{\mathrm{KSA}}$} \\
\hline$\chi$ & Inverse-Gamma & 102.4 & 19.42 \\
\hline$\phi_{g}$ & Normal & 0.78 & 0.14 \\
\hline$\rho_{i}$ & Beta & 0.5 & 0.2 \\
\hline \multirow[t]{2}{*}{$\sigma_{i}$} & Inverse-Gamma & 0.05 & 2 \\
\hline & $i=a, a^{*}, g^{*}, o, g, r, r$ & & \\
\hline
\end{tabular}


Table 7: Historical Decomposition

\begin{tabular}{|c|c|c|c|c|c|c|c|}
\hline KSA & & & & & & & \\
\hline Observed Variable & $\epsilon_{a}$ & $\epsilon_{a^{*}}$ & $\epsilon_{O^{*}}$ & $\epsilon_{g}$ & $\epsilon_{g^{*}}$ & $\epsilon_{r}$ & $\epsilon_{r^{*}}$ \\
\hline$\Delta \ln G_{t}^{o b s}$ & $0.00 \%$ & $18.86 \%$ & $0.00 \%$ & $67.32 \%$ & $5.92 \%$ & $0.00 \%$ & $7.89 \%$ \\
\hline$\Delta \ln C_{t}^{\text {obs }}$ & $0.00 \%$ & $28.70 \%$ & $0.00 \%$ & $35.67 \%$ & $12.61 \%$ & $0.00 \%$ & $23.03 \%$ \\
\hline$\pi_{t}^{o b s}$ & $0.00 \%$ & $44.97 \%$ & $0.00 \%$ & $3.10 \%$ & $44.71 \%$ & $0.00 \%$ & $7.22 \%$ \\
\hline \multicolumn{8}{|l|}{$\overline{\mathrm{CHL}}$} \\
\hline Observed Variable & $\epsilon_{a}$ & $\epsilon_{a^{*}}$ & $\epsilon_{o^{*}}$ & $\epsilon_{g}$ & $\epsilon_{g^{*}}$ & $\epsilon_{r}$ & $\epsilon_{r^{*}}$ \\
\hline$\Delta \ln G_{t}^{o b s}$ & $15.48 \%$ & $0.85 \%$ & $0.00 \%$ & $57.37 \%$ & $0.00 \%$ & $5.68 \%$ & $20.63 \%$ \\
\hline$\Delta \ln C_{t}^{o b s}$ & $55.95 \%$ & $0.23 \%$ & $0.00 \%$ & $0.21 \%$ & $0.00 \%$ & $40.54 \%$ & $3.08 \%$ \\
\hline$\pi_{t}^{o b s}$ & $13.35 \%$ & $0.21 \%$ & $0.00 \%$ & $0.00 \%$ & $0.00 \%$ & $85.85 \%$ & $0.59 \%$ \\
\hline \multicolumn{8}{|l|}{ AUS } \\
\hline Observed Variable & $\epsilon_{a}$ & $\epsilon_{a^{*}}$ & $\epsilon_{o^{*}}$ & $\epsilon_{g}$ & $\epsilon_{g^{*}}$ & $\epsilon_{r}$ & $\epsilon_{r^{*}}$ \\
\hline$\Delta \ln G_{t}^{o b s}$ & $0.00 \%$ & $3.35 \%$ & $0.00 \%$ & $94.67 \%$ & $0.00 \%$ & $0.04 \%$ & $1.94 \%$ \\
\hline$\Delta \ln C_{t}^{o b s}$ & $0.00 \%$ & $22.70 \%$ & $0.00 \%$ & $5.89 \%$ & $0.01 \%$ & $1.96 \%$ & $69.44 \%$ \\
\hline$\pi_{t}^{o b s}$ & $0.00 \%$ & $26.93 \%$ & $0.00 \%$ & $0.27 \%$ & $0.01 \%$ & $53.66 \%$ & $19.12 \%$ \\
\hline \multicolumn{8}{|l|}{$\overline{\mathrm{SA}}$} \\
\hline Observed Variable & 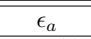 & 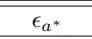 & 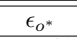 & $\epsilon_{g}$ & 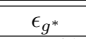 & 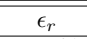 & 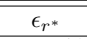 \\
\hline$\Delta \ln G_{t}^{o b s}$ & $2.25 \%$ & $0.00 \%$ & $0.00 \%$ & $84.15 \%$ & $0.00 \%$ & $0.27 \%$ & $13.33 \%$ \\
\hline$\Delta \ln C_{t}^{o b s}$ & $74.20 \%$ & $0.00 \%$ & $0.00 \%$ & $0.20 \%$ & $0.00 \%$ & $17.74 \%$ & $7.86 \%$ \\
\hline$\pi_{t}^{o b s}$ & $20.40 \%$ & $0.00 \%$ & $0.00 \%$ & $0.01 \%$ & $0.00 \%$ & $76.50 \%$ & $3.09 \%$ \\
\hline
\end{tabular}

The estimation results (shown in Appendix C.5) indicate no significant change in the elasticity of substitution between government consumption and private consumption $\chi$ for each of the four economies from the baseline calibrated values. These results support the literature that shows the crowding in effect of government consumption on private consumption in our selected economies. As for the response of government consumption to changes in the commodity index $\phi_{g}$, the response of the Australian government consumption is in line with the baseline calibrations, indicating a countercyclical fiscal stance. As for the Chilean government consumption, the results show a significant drop in $\phi_{g}$, contradicting the results shown in Table (4) but supporting the SVAR impulse responses and are backed by the adopted fiscal rule by the Chilean government. The results for $\phi_{g}$ of the South African economy indicate a change in the response from a negative value of -0.04 to a positive response of 0.032 , which is also in line with the SVAR impulse responses, and indicating a procyclical fiscal stance by the South African government. Lastly, the response of $\phi_{g}$ in the Saudi economy is reduced to 0.13 , but it is not robust for changes in the standard deviation, and it is biased towards increasing whenever the standard deviation is increased. Overall, the posterior densities are considerably different from the loose priors that we choose, implying that the data is informative regarding this estimated parameter. As a robustness check, we re-estimate the model while increasing the standard deviations of the structural parameters by $50 \%$. The robustness checks show that the values of the structural parameters for all four economies are not sensitive to these changes in the standard deviations. The only exception to this, as noted above, is the response of the Saudi government consumption to changes in the commodity price index. The response increased from 0.13 to 0.22 , which is still the highest among the government response of all selected economies. 
The above results, which are based on an infinite horizon forecast-error variance decomposition, show some results which are worth highlighting. First, the results show no role for shocks in the supply of commodities on any of the domestic variables across all four economies. This is also shown in the posterior estimation of the standard deviations of the supply of commodities across all economies (see Appendix C.5). Second, domestic interest rates explain the behaviour of all the domestic variables except in the Saudi economy. This is apparently a result of the policy crowding-out effect of fiscal policy on monetary policy and explains the adoption of an exchange rate peg regime by the monetary authorities in Saudi Arabia. In the other three economies, interest rates explain a significant percentage of domestic CPI inflation, showing an indication of an active monetary policy stance in these economies. Third, foreign government consumption has no effect on all economies except for the Saudi economy in this case as well, where foreign government consumption has a significant effect on all of the domestic variables of the Saudi economy. Lastly, the behaviour of private consumption and CPI inflation in Saudi Arabia are mostly explained by external shocks, unlike the two variables in Chile and South Africa which are mainly explained by domestic factors. The behaviour of those two variables in Australia, on the other hand, shows dominance in the effect of external shocks. Nevertheless, the Australian economy, unlike its counterparts, has a well-developed financial market which makes it more linked to the rest of the world economy.

\section{Conclusion}

The previous literature on commodity-rich economies has always assumed that this group of countries was homogeneous and that the only source of heterogeneity among those countries comes from the difference in the volatility of the prices of commodities. This paper sought to investigate the heterogeneity among commodity-rich countries beyond the prices of commodities. We achieved this by imposing the same commodity-price index on four economies which are rich with different types of commodities. We build a model that nests different sources of shocks that were proposed in the previous literature and add a central role for commodities in the model. Our model allows for a quadruple role for commodities. First, the domestic government collects the windfalls of selling commodities to the rest of the world. Second, commodities are consumed by households both in the domestic economy and the foreign economy. Third, firms both in the domestic economy and the foreign economy use commodities as an input in their production. Lastly, the domestic economy is affected by the second-round effect of an increase in the commodity prices in the form of high foreign inflation and low world demand. Government consumption is included in the utility function as a complement to private consumption in a non-separable form. This results 
in comovement between government consumption and private consumption and it generates volatility in private consumption which is qualitatively similar to the one shown in the data.

We focus on two key behavioural parameters in the model: the elasticity of substitution between government consumption and private consumption and the response of government consumption to changes in the prices of commodities. Our results show that government consumption in all four economies has a crowding in effect on private consumption with differing degrees of complementarity. These results support the findings of Bouakez and Rebei 2007 and Gali et al. 2007 who show similar results to ours. In addition, the crowding in effect of government consumption on private consumption affects the transmission mechanism of monetary policy and leads to a policy crowding out effect of fiscal policy towards monetary policy, as in the case of Saudi Arabia, which might be an explanation to the adoption of an exchange rate peg regime in Saudi Arabia and the majority of oil-rich countries. The response of government consumption to changes in commodity prices, on the other hand, was an indication of two essential factors. The first one is the fiscal stance of government consumption (Institutional factors), while the second one is the size of natural resources rents in the domestic economy. The latter shows discrepancy across commodity-rich countries. The data (shown in Appendix C.3) and our estimations show that, given the significantly larger share of oil rents relative to other commodities, oil-rich countries are more vulnerable to external shocks.

The model is estimated using Australian, Chilean, Saudi and South African data from 1980 to 2015. Doing so allows us to evaluate the contribution of different sources of shock in the behaviour of the model's three domestic variables over a time horizon. The results show that our key variables in Saudi Arabia, an oil-rich country, were more vulnerable to developments in the foreign economy than its developing counterparts, namely Chile and South Africa, which, as highlighted above, explains the adoption of an exchange rate peg regime in most oil-rich countries. The macro variables in Australia also appeared to be affected by developments in the foreign economy, but this is mainly attributed to its developed financial sector which is highly linked to the rest of the world economy. Nevertheless, Australia, despite being a developed country, showed higher fluctuations in private consumption relative to output, a characteristic which is normally assigned to developing and emerging economies.

The results of the paper clearly illustrate that the proposed solutions for commodity-rich economies by various papers in the literature, which are based on a "quintessential" single economy, should be read with caution. 


\section{References}

Abusaaq, Hussain (2015). Inflation forecasting models for Saudi Arabia. SAMA working paper WP/15/7. Saudi Arabian Monetary Agency.

Acemoglu, Daron, Simon Johnson, James Robinson, and Yunyong Thaicharoen (2003). "Institutional causes, macroeconomic symptoms: volatility, crises and growth". In: Journal of Monetary Economics 50.1, pp. 49-123.

Agénor, Pierre-Richard (2014). Optimal Fiscal Management of Commodity Price Shocks. Centre for Growth and Business Cycle Research Discussion Paper Series. Economics, The Univeristy of Manchester.

Aghion, Philippe, Philippe Bacchetta, Romain Ranciere, and Kenneth Rogoff (2009). "Exchange rate volatility and productivity growth: The role of financial development". In: Journal of Monetary Economics 56.4, pp. 494-513.

Aguiar, Mark and Gita Gopinath (2007). "Emerging Market Business Cycles: The Cycle Is the Trend". In: Journal of Political Economy 115.1, pp. 69-102.

Ahmed, Shaghil (1986). "Temporary and permanent government spending in an open economy: Some evidence for the United Kingdom". In: Journal of Monetary Economics 17.2, pp. 197-224.

Akinci, Ozge (2014). Financial Frictions and Macroeconomic Fluctuations in Emerging Economies. International Finance Discussion Papers 1120. Board of Governors of the Federal Reserve System (U.S.)

Alexeev, Michael and Robert Conrad (2009). "The Elusive Curse of Oil". In: The Review of Economics and Statistics 91.3 , pp. 586-598.

Arezki, Rabah and Kareem Ismail (2013). "Boom?bust cycle, asymmetrical fiscal response and the Dutch disease". In: Journal of Development Economics 101.C, pp. 256-267.

Aschauer, David (1985). "Fiscal Policy and Aggregate Demand". In: American Economic Review 75.1, pp. 117-27.

Bastourre, Diego, Jorge Carrera, Javier Ibarlucia, and Mariano Sardi (2012). Common Drivers in Emerging Market Spreads and Commodity Prices. BCRA Working Paper Series 201257. Central Bank of Argentina, Economic Research Department. 
Berg, Andrew, Rafael Portillo, Shu-Chun Yang, and Luis-Felipe Zanna (2013). "Public Investment in Resource-Abundant Developing Countries". In: IMF Economic Review 61.1, pp. 92-129.

Bouakez, Hafedh and Nooman Rebei (2007). "Why Does Private Consumption Rise after a Government Spending Shock? (Pourquoi est-ce que la consommation privée augmente après un choc de dépenses gouvernementales?)" In: The Canadian Journal of Economics / Revue canadienne d'Economique 40.3, pp. 954-979.

Broda, Christian (2004). "Terms of trade and exchange rate regimes in developing countries". In: Journal of International Economics 63.1, pp. 31-58. URL: https://EconPapers.repec.org/ RePEc:eee:inecon:v:63:y:2004:i:1:p:31-58.

Bullard, James and Kaushik Mitra (2002). "Learning about monetary policy rules". In: Journal of Monetary Economics 49.6, pp. 1105-1129.

Calvo, Guillermo A. (1983). "Staggered prices in a utility-maximizing framework". In: Journal of Monetary Economics 12.3, pp. 383-398.

Cespedes, Luis and Andrés Velasco (2014). "Was this time different?: Fiscal policy in commodity republics". In: Journal of Development Economics 106.C, pp. 92-106.

Coenen, Günter, Roland Straub, and Mathias Trabandt (2013). "Gauging the effects of fiscal stimulus packages in the euro area". In: Journal of Economic Dynamics and Control 37.2. Fiscal Policy in the Aftermath of the Financial Crisis, pp. 367-386.

Cotet, Anca and Kevin Tsui (2010). Resource Curse or Malthusian Trap? Evidence from Oil Discoveries and Extractions. Working Papers 201001. Ball State University, Department of Economics.

Dauvin, Magali and David Guerreiro (2017). "The Paradox of Plenty: A Meta-Analysis". In: World Development 94.C, pp. 212-231.

Dixit, Avinash and Joseph Stiglitz (1977). "Monopolistic Competition and Optimum Product Diversity". In: American Economic Review 67.3, pp. 297-308.

Drechsel, Thomas and Silvana Tenreyro (2017). Commodity Booms and Busts in Emerging Economies. Discussion Papers 1723. Centre for Macroeconomics (CFM).

Englebert, Pierre (2000). "Pre-Colonial Institutions, Post-Colonial States, and Economic Development in Tropical Africa". In: Political Research Quarterly 53.1, pp. 7-36.

Fatas, Antonio and Ilian Mihov (2001). The Effects of Fiscal Policy on Consumption and Employment: Theory and Evidence. CEPR Discussion Papers 2760. C.E.P.R. Discussion Papers. 
Fernández Martin, Andrés, Stephanie Schmitt-Grohé, and Martin Uribe (2017). World Shocks, World Prices, and Business Cycles: An Empirical Investigation. IDB Publications (Working Papers) 8315. Inter-American Development Bank.

Fernández, Andrés, Andrés González, and Diego Rodríguez (2018). "Sharing a ride on the commodities roller coaster: Common factors in business cycles of emerging economies". In: Journal of International Economics 111.C, pp. 99-121.

Fiorito, Riccardo and Tryphon Kollintzas (2004). "Public goods, merit goods, and the relation between private and government consumption". In: European Economic Review 48.6, pp. 13671398.

Frankel, Jeffrey (2011). How Can Commodity Exporters Make Fiscal and Monetary Policy Less Procyclical? Scholarly Articles. Harvard Kennedy School of Government.

Gali, Jordi (2008). "Introduction to Monetary Policy, Inflation, and the Business Cycle: An Introduction to the New Keynesian Framework". In: Monetary Policy, Inflation, and the Business Cycle: An Introduction to the New Keynesian Framework. Princeton University Press.

Gali, Jordi, David Lopez-Salido, and Javier Vallés (2007). "Understanding the Effects of Government Spending on Consumption". In: Journal of the European Economic Association 5.1, pp. $227-270$.

Galí, Jordi and Tommaso Monacelli (2005). "Monetary Policy and Exchange Rate Volatility in a Small Open Economy". In: Review of Economic Studies 72.3, pp. 707-734.

Garcia-Cicco, Javier, Roberto Pancrazi, and Martin Uribe (2010). "Real Business Cycles in Emerging Countries?" In: American Economic Review 100.5, pp. 2510-2531.

Havranek, Tomas, Roman Horvath, and Ayaz Zeynalov (2016). "Natural Resources and Economic Growth: A Meta-Analysis". In: World Development 88.C, pp. 134-151.

Iimi, Atsushi (2006). Did Botswana Escape from the Resource Curse? IMF Working Papers 06/138. International Monetary Fund.

Isham, Jonathan, Michael Woolcock, Lant Pritchett, and Gwen Busby (2005). "The Varieties of Resource Experience: Natural Resource Export Structures and the Political Economy of Economic Growth". In: World Bank Economic Review 19.2, pp. 141-174. 
Kaminsky, Graciela, Carmen Reinhart, and Carlos Vegh (2005). "When It Rains, It Pours: Procyclical Capital Flows and Macroeconomic Policies". In: NBER Macroeconomics Annual 2004, Volume 19. National Bureau of Economic Research, Inc, pp. 11-82.

Larsen, Erling Røed (2006). "Norway, the Resource Curse, and the Dutch Disease". In: American Journal of Economics and Sociology 65.3, pp. 605-640.

Mehlum, Halvor, Karl Ove Moene, and Ragnar Torvik (2006). "Cursed by Resources or Institutions?" In: The World Economy 29.8, pp. 1117-1131.

Neumeyer, Pablo A. and Fabrizio Perri (2005). "Business cycles in emerging economies: the role of interest rates". In: Journal of Monetary Economics 52.2, pp. 345-380.

Pieschacon, Anamaria (2012). "The value of fiscal discipline for oil-exporting countries". In: Journal of Monetary Economics 59.3, pp. 250-268.

Ploeg, Frederick van der (2011). "Natural Resources: Curse or Blessing?" In: Journal of Economic Literature 49.2, pp. 366-420.

Ploeg, Frederick van der and Steven Poelhekke (2009). "Volatility and the natural resource curse". In: Oxford Economic Papers 61.4, pp. 727-760.

Rodrik, Dani (1999). "Where Did All the Growth Go? External Shocks, Social Conflict, and Growth Collapses". In: Journal of Economic Growth 4.4, pp. 385-412.

Rotemberg, Julio (1982). "Sticky Prices in the United States". In: Journal of Political Economy 90.6, pp. $1187-1211$.

Sachs, Jeffrey D. and Andrew Warner (1995). Natural Resource Abundance and Economic Growth. NBER Working Papers 5398. National Bureau of Economic Research, Inc.

Sarraf, Maria and Moortaza Jiwanji (2001). "Beating the resource curse : the case of Botswana". In: Environment Department working paper 83.

Schmitt-Grohe, Stephanie and Martin Uribe (2017). How Important Are Terms of Trade Shocks. Tech. rep. 1, pp. 85-111.

Shousha, Samer (2016). Macroeconomic Effects of Commodity Booms and Busts: The Role of Financial Frictions.

Smets, Frank and Raf Wouters (2007). "Shocks and Frictions in US Business Cycles: A Bayesian DSGE Approach". In: American Economic Review 97.3, pp. 586-606. 
Taylor, John B. (1993). "Discretion versus policy rules in practice". In: Carnegie-Rochester Conference Series on Public Policy 39, pp. 195-214.

Troug, Haytem (2019). Monetary Policy in a Small Open Economy with Non-Separable Government Spending. MPRA Paper. University Library of Munich, Germany.

Wills, Samuel (2014). Optimal Monetary Responses to Oil Discoveries. Discussion Papers 1408. Centre for Macroeconomics (CFM). 


\section{Appendices}

\section{Appendix C.1}

\section{- Domestic economy}

- Optimal consumption bundles:

$$
\begin{gathered}
c_{Z, t}=c_{t}-m u * p_{Z, t} \\
c_{O, t}=c_{t}-m u * p_{O, t} \\
c_{H, t}=c_{Z, t}-m u *\left(p_{H, t}-p_{Z, t}\right) \\
c_{F, t}=c_{t}-m u *\left(p_{F, t}-p_{Z, t}\right)
\end{gathered}
$$

- Relative prices and inflation rates:

$$
\begin{gathered}
0=(1-\varpi) * p_{Z, t}+\varpi * p_{O, t} \\
p_{Z, t}=(1-\alpha) * p_{H, t}+\alpha * p_{F, t} \\
\pi_{Z, t}=p_{Z, t}-p_{Z, t-1}+\pi_{t} \\
\pi_{H, t}=p_{H, t}-p_{H, t-1}+\pi_{t} \\
\pi_{F, t}=p_{F, t}-p_{F, t-1}+\pi_{t}
\end{gathered}
$$

- Labour supply:

$$
\text { Real wages }=\sigma * c_{t}+\varphi * n_{t}+\left(\sigma-\sigma_{\delta}\right) * g_{t}
$$

- IS curve:

$$
x_{t}=E_{t}\left\{x_{t+1}\right\}-\frac{\omega_{\alpha}}{\sigma_{\delta}}\left(r_{t}-E_{t}\left\{\pi_{t+1}\right\}-\overline{r r}_{t}\right)
$$

- Phillips curve

$$
\pi_{H, t}=\beta E_{t}\left\{\pi_{H, t+1}\right\}+\kappa \frac{\nu \varphi \omega_{\alpha}+\sigma_{\delta}+\sigma_{\delta} \varphi(1-\nu)}{\omega_{\alpha}(1+\varphi(1-\nu))} x_{t}
$$


- Natural rate of interest:

$$
\begin{aligned}
\overline{r r}_{t}= & -\frac{\left.\nu(1+\varphi) \sigma_{\delta}\left(1-\rho_{a}\right)\right)}{\nu \varphi \omega_{\alpha}+\sigma_{\delta}+\sigma_{\delta} \varphi(1-\nu)} a_{t}+\frac{(1-\nu)(1+\varphi) \sigma_{\delta}}{\nu \varphi \omega_{\alpha}+\sigma_{\delta}+\sigma_{\delta} \varphi(1-\nu)} \Delta E_{t}\left\{\tilde{p}_{o, t+1}^{*}\right\} \\
& +\frac{\nu \varphi(1-\alpha)\left(\sigma-\sigma_{\delta}\right)}{\nu \varphi \omega_{\alpha}+\sigma_{\delta}+\sigma_{\delta} \varphi(1-\nu)} \Delta E_{t}\left\{g_{t+1}\right\}+\frac{\left(\sigma-\sigma_{\delta}\right)\left(\nu \omega_{\alpha}\left(\alpha \varphi-\sigma_{\alpha}\right)+\sigma_{\delta}(1+\varphi-\varphi \nu)\right)}{\omega_{\alpha}\left(\nu \varphi \omega_{\alpha}+\sigma_{\delta}+\sigma_{\delta} \varphi(1-\nu)\right)} \Delta E_{t}\left\{g_{t+1}^{*}\right\} \\
& +\frac{\sigma_{\delta}\left((1+\alpha) \sigma_{\delta}(1+\varphi(1-\nu))-\alpha \nu \varphi \omega_{\alpha}(\omega-1)-\alpha \omega \sigma_{\delta}(1+\varphi(1-\nu))-\nu \omega_{\alpha} \sigma_{\delta}\right)}{\omega_{\alpha}\left(\nu \varphi \omega_{\alpha}+\sigma_{\delta}+\sigma_{\delta} \varphi(1-\nu)\right)} \Delta E_{t}\left\{y_{t+1}^{*}\right\}
\end{aligned}
$$

- Flexible-price output:

$$
\begin{aligned}
\bar{y}_{t} & =-\frac{\nu \sigma_{\delta} \omega_{\alpha}-\sigma_{\delta}-\sigma_{\delta} \varphi(1-\nu)}{\nu \varphi \omega_{\alpha}+\sigma_{\delta}+\sigma_{\delta} \varphi(1-\nu)} y_{t}^{*}-\frac{\left(\left(\sigma-\sigma_{\delta}\right)\left(\nu \omega_{\alpha}-(1-\alpha)-(1-\alpha) \varphi(1-\nu)\right)\right.}{\nu \varphi \omega_{\alpha}+\sigma_{\delta}+\sigma_{\delta} \varphi(1-\nu)} g_{t}^{*} \\
& -\frac{(1-\alpha)\left(\sigma-\sigma_{\delta}\right)(1+\varphi(1-\nu))}{\nu \varphi \omega_{\alpha}+\sigma_{\delta}+\sigma_{\delta} \varphi(1-\nu)} g_{t}+\frac{\nu(1+\varphi) \omega_{\alpha}}{\nu \varphi \omega_{\alpha}+\sigma_{\delta}+\sigma_{\delta} \varphi(1-\nu)} a_{t}-\frac{(1-\nu)(1+\varphi) \omega_{\alpha}}{\nu \varphi \omega_{\alpha}+\sigma_{\delta}+\sigma_{\delta} \varphi(1-\nu)} \tilde{p}_{o, t}^{*}
\end{aligned}
$$

- Output gap:

$$
x_{t}=y_{t}-\bar{y}_{t} .
$$

- Production function:

$$
y_{t}=\nu a_{t}+\nu n_{t}+(1-\nu) o_{d}
$$

- Domestic commodity demand:

$$
o_{t}^{d}=\frac{1+\varphi}{1+\varphi(1-\nu)} y_{t}+\frac{\nu \sigma_{\delta}}{1+\varphi(1-\nu)} y_{t}^{*}-\frac{\nu(1+\varphi)}{1+\varphi(1-\nu)} a_{t}+\frac{\nu\left(\sigma-\sigma_{\delta}\right)}{1+\varphi(1-\nu)} g_{t}^{*}-\frac{\nu}{1+\varphi(1-\nu)} \tilde{p}_{o, t}^{*}
$$

- Monetary policy:

$$
r_{t}=\rho_{r} r_{t-1}+\phi_{\pi} \pi_{Z, t}+\phi_{y} x_{t}+\epsilon_{t}
$$

- Fiscal policy

$$
g_{t}=\rho_{g} g_{t-1}+\phi_{g} *\left(p_{O}\right)+\epsilon_{g}
$$

\section{- Rest of the world}

- Optimal consumption bundles:

$$
c_{Z, t}^{*}=c_{t}^{*}-m u^{*} * p_{Z, t}^{*}
$$




$$
c_{O, t}^{*}=c_{t}^{*}-m u^{*} * p_{O, t}^{*}
$$

- Relative prices and inflation rates:

$$
\begin{gathered}
0=\left(1-\varpi^{*}\right) * p_{Z, t}^{*}+\varpi^{*} * p_{O, t}^{*} \\
\pi_{Z, t}^{*}=p_{Z, t}^{*}-p_{Z, t-1}^{*}+\pi_{t}^{*}
\end{gathered}
$$

- Labour supply:

$$
\text { Real wages }=\sigma * c_{t}^{*}+\varphi * n_{t}^{*}+\left(\sigma-\sigma_{\delta}\right) * g_{t}^{*}
$$

- IS curve:

$$
x_{t}^{*}=E_{t}\left\{x_{t+1}^{*}\right\}-\frac{1}{\sigma_{\delta}}\left[r_{t}^{*}-E_{t}\left\{\pi_{t+1}^{*}\right\}-\overline{r r}_{t}^{*}\right]
$$

- Natural rate of interest:

$$
\overline{r r}_{t}^{*}=-\frac{\sigma_{\delta}\left(1-\rho_{a}\right)(1+\varphi) \nu}{\nu(\varphi+\sigma)} a_{t}^{*}+\frac{\nu\left(\sigma-\sigma_{\delta}\right)\left(\sigma+\varphi-\sigma_{\delta}\right)}{\nu(\varphi+\sigma)} \Delta g_{t+1}^{*}-\frac{\sigma_{\delta}(1-\nu)(1+\varphi)}{\nu(\varphi+\sigma)} \Delta \tilde{p}_{o, t+1}^{*}
$$

- Phillips curve

$$
\hat{\pi}_{t}^{*}=\beta E_{t}\left[\hat{\pi}_{t+1}^{*}\right]+\lambda \frac{\nu \sigma+\nu \varphi}{1+(1-\nu) \varphi} x_{t}^{*}
$$

- Flexible-price output:

$$
{\overline{y_{t}}}^{*}=-\frac{1+(1-\nu) \varphi}{\nu \sigma+\nu \varphi} \mu^{*}+\frac{\nu(1+\varphi)}{\nu \sigma+\nu \varphi} a_{t}^{*}-\frac{(1-\nu)(1+\varphi)}{\nu \sigma+\nu \varphi} \tilde{p}_{o, t}^{*}-\frac{\nu\left(\sigma-\sigma_{\delta}\right)}{\nu \sigma+\nu \varphi} g_{t}^{*}
$$

- Output gap:

$$
x_{t}^{*}=y_{t}^{*}-\bar{y}^{*}
$$

- Production function:

$$
y_{t}^{*}=\nu a_{t}^{*}+\nu n_{t}^{*}+(1-\nu) o_{d}^{*}
$$

- Market clearing condition

$$
y_{t}^{*}=c_{Z, t}^{*}
$$

- World commodity demand:

$$
o_{t}^{* d}=\frac{\nu \sigma+\varphi+1}{1+\varphi(1-\nu)} y_{t}^{*}-\frac{\nu(1+\varphi)}{1+\varphi(1-\nu)} a_{t}^{*}+\frac{\nu\left(\sigma-\sigma_{\delta}\right)}{1+\varphi(1-\nu)} g_{t}^{*}-\frac{\nu}{1+\varphi(1-\nu)} \tilde{p}_{o, t}^{*}
$$


- Real commodity prices:

$$
\tilde{p}_{o, t}^{*}=\frac{\nu \sigma+\varphi+1}{\nu} y_{t}^{*}-(1+\varphi) a_{t}^{*}+\left(\sigma-\sigma_{\delta}\right) g_{t}^{*}-\frac{1+\varphi(1-\nu)}{\nu} o_{t}^{* s}
$$

- Monetary policy:

$$
r_{t}^{*}=\rho_{r} r_{t-1}^{*}+\phi_{\pi} \pi_{t}^{*}+\phi_{y} x_{t}^{*}+\epsilon_{r^{*}, t}
$$

\section{- International linkages}

- Goods market clearing:

$$
y_{t}=(1-\alpha) c_{t}+\alpha c_{t}^{*}+\alpha[\gamma+\eta(1-\alpha)] s_{t}
$$

- Domestic output as a function of world output and the terms of trade

$$
y_{t}=y_{t}^{*}+\frac{(1-\alpha)\left(\sigma-\sigma_{\delta}\right)}{\sigma_{\delta}}\left(g_{t}^{*}-g_{t}\right)+\frac{\omega_{\alpha}}{\sigma_{\delta}} s_{t}
$$

- Real exchange rate:

$$
q_{t}=(1-\alpha) s_{t}
$$

\section{- Exogenous processes:}

$$
\begin{aligned}
& a_{t}=\rho_{a} a_{t-1}+\epsilon_{a, t} \\
& a_{t}^{*}=\rho_{a} a_{t-1}^{*}+\epsilon_{a^{*}, t} \\
& o_{t}^{*}=\rho_{o} o_{t-1}^{*}+\epsilon_{o^{*}, t} \\
& g_{t}^{*}=\rho_{g^{*}} g_{t-1}^{*}+\epsilon_{g^{*}, t}
\end{aligned}
$$

- Measurement equations:

$$
\begin{gathered}
d g_{t}^{o b s}=g_{t}-g_{t-1}+\text { Trend }_{g} \\
d c_{t}^{o b s}=c_{t}-c_{t-1}+\text { Trend }_{c} \\
\pi_{t}^{o b s}=\pi_{t}+\text { Trend } \\
p_{o, t}^{o b s}=p_{o, t}
\end{gathered}
$$




\section{Appendix C.2}

To understand the inflation dynamics in the model, we start by analysing the price-setting behaviour of firms. We follow the steps of Galí and Monacelli 2005, and the 3rd chapter of Gali 2008 to derive the price-setting behaviour of firms in the model under a sticky prices framework. The aggregate domestic price index in the model is a weighted average of prices that have been adjusted at period $t$ and prices that have not been adjusted:

$$
P_{H, t}=\left[\theta\left(P_{H, t-1}\right)^{1-\epsilon}+(1-\theta)\left(\bar{P}_{H, t}\right)^{1-\epsilon}\right]^{\frac{1}{1-\epsilon}}
$$

$\bar{P}_{H, t}$ is the re-optimised price that a fraction of the firms $(1-\theta)$ choose at period $t$, and this is normally higher than the prevailing price during the last period before. $P_{t-1}$ is the price imposed by the other fraction of firms who have not been able to adjust their prices, and this is why we keep last period's prices as the prevailing prices for those firms. We divide the above equation by $P_{H, t-1}$ to get:

$$
\Pi_{H, t}^{1-\epsilon}=\theta+(1-\theta)\left(\frac{\bar{P}_{H, t}}{P_{H, t-1}}\right)^{1-\epsilon}
$$

Log-linearising the above equation around a steady state with zero inflation yields ${ }^{21}$

$$
\pi_{H, t}=(1-\theta)\left(\bar{p}_{H, t}-p_{H, t-1}\right)
$$

In the above equation, inflation at the current period is affected by the price adjustment that a fraction of the firms in the economy make to their prices. Therefore, as mentioned above, we start deriving the price-setting behaviour of firms to capture the dynamics of prices in the economy. When firms set their prices according to Calvo 1983 contract scheme, they aim to maximise the expected discounted value of their profits under the assumption that the newly set price will still be effective:

$$
\max _{\bar{P}_{H, t}} \sum_{k=0}^{\infty} \theta^{k} E_{t}\left\{Q_{t, t+k}\left[c_{j t+k \mid t}\left(\bar{P}_{H, t}-\Psi_{t+k}\right)\right]\right\}
$$

$\Psi$ is the cost function, $\theta^{k}$ is the probability that the re-optimised price at period $\mathrm{t}$ will remain effective at period $\mathrm{t}+\mathrm{k}$, and $Q_{t, t+k}$ is a the discount factor of nominal pay off and it is defined in equation (9). $c_{j t+k \mid t}$ is the Expected demand/production for period $t+k$ at period $t$. The equation is subject to the following demand constraint: $c_{j t+k}=\left(\frac{\bar{P}_{t}}{P_{t+k}}\right)^{-\epsilon} C_{t}$. Plugging in the demand function into the firm's maximisation

\footnotetext{
${ }^{21} \mathrm{Log}$-linearising around a steady state of zero inflation allows us to get rid of the price dispersion created by the nominal friction in the model.
} 
problem yields:

$$
\max _{\bar{P}_{H, t}} \sum_{k=0}^{\infty} \theta^{k} E_{t}\left\{Q_{t, t+k}\left[\left(\frac{\bar{P}_{H, t}}{P_{t+k}}\right)^{-\epsilon} C_{t+k}\left(\bar{P}_{t}-\Psi_{t+k}\right)\right]\right\}
$$

Taking the first order condition of the above equation yields:

$$
\sum_{k=0}^{\infty} \theta^{k} E_{t}\left\{Q_{t, t+k} C_{t+k}\left[\bar{P}_{H, t}-\mathcal{M} \psi_{t+k \mid t}\right]\right\}=0
$$

$\psi$ is the nominal marginal cost, and $\mathcal{M}$ is the gross mark-up and its equal to $\frac{\epsilon}{\epsilon-1}$. Now, we divide the above equation by $P_{H, t-1}$ and divide and multiply the second term by $P_{H, t+k}$ :

$$
\sum_{k=0}^{\infty} \theta^{k} E_{t}\left\{Q_{t, t+k} C_{t+k}\left[\frac{\bar{P}_{H, t}}{P_{H, t-1}}-\mathcal{M} M C_{t+k \mid t} \Pi_{t-1, t+k}^{H}\right]\right\}=0
$$

Where $\Pi_{t-1, t+k}^{H}=\frac{P_{H, t+k}}{P_{H, t-1}}$, and $M C_{t+k \mid t}=\frac{\psi_{t+k \mid t}}{P_{H, t+k}}$. We log-linearise the above equation around a zeroinflation steady state. Noting that $Q_{t, t+k}$ in the steady state will equal $\beta^{k}$ :

$$
\bar{p}_{H, t}-p_{H, t-1}=(1-\beta \theta) \sum_{k=0}^{\infty}(\beta \theta)^{k} E_{t}\left\{m c_{t+k \mid t}+\mu+\left(p_{H, t+k}-p_{H, t-1}\right)\right\}
$$

We notice from the above equation that the firms discount the expected stream of their future profits using the household's discount factor. This is simply attributed to the fact that the households are the share holders of those firms. Rearranging the above equation gives:

$$
\bar{p}_{H, t}=\mu+(1-\beta \theta) \sum_{k=0}^{\infty}(\beta \theta)^{k} E_{t}\left\{m c_{t+k \mid t}+p_{H, t+k}\right\}
$$

The above equation is describing how firm set their prices with a certain mark-up and the discounted present value of the stream of marginal costs. In the case when $\theta=0$ all firms will be able to adjust their prices in each period (flexible prices scheme), and the above equation will simplify to:

$$
\bar{p}_{H, t}=\mu+m c_{t}
$$

The price the firms set in this case is equal to their markup over the nominal marginal cost. Of course, this shows that the price set by the firms is above their marginal cost since the markup is greater than 1. As a result, output will be lower than its level under perfect competition. It will be shown how the government can offset this distortion by giving the firms a certain employment subsidy. Now going back 
to equation (137), if we rewrite down the equation in a compact form we get:

$$
\bar{p}_{H, t}-p_{H, t-1}=\beta \theta E_{t}\left\{p_{H, t+1}-p_{H, t}\right\}+\pi_{t}+(1-\beta \theta) \hat{m} c_{t}
$$

Where $\hat{m} c_{t}=m c_{t}-p_{H, t}+\mu$. Adding the above equation to the price setting equation gives us:

$$
\pi_{H, t}=\beta E_{t}\left\{\pi_{H, t+1}\right\}+\kappa \hat{m} c_{t}
$$

Where $\kappa=\frac{(1-\theta)(1-\beta \theta)}{\theta}$. The above equation is the core New Keynesian Phillips Curve. We develop it in the text to link inflation to the output gap through the relationship between the $\hat{m} c$ and the output gap $x_{t}$. $\kappa$ in the Phillips curve equation is strictly decreasing in the stickiness parameter $\theta$. From the above equation, we see that inflation in this type of models is a result of aggregate price-setting of the firms who adjust their prices based on current and future stream of their marginal costs. 


\section{Appendix C.3}

Table 8: Averages of Natural Resources Rents During 1980-2015

\begin{tabular}{|c|c|c|c|c|c|}
\hline Country & Dominant Resource & Natural Resources Rents (\% of GDP) & Country & Dominant Resource & Natural Resources Rents (\% of GDP) \\
\hline Albania & Oil & 4.44 & Madagascar & Forests & 6.15 \\
\hline Algeria & Oil & 14.9 & Malawi & Forests & 8.27 \\
\hline Angola & Oil & 38.64 & Malaysia & Forests and Oil & 15.4 \\
\hline Australia & Minerals & 4.49 & Mali & Forests & 6.78 \\
\hline Bahrain & Forests & 6.53 & Mauritania & Minerals & 19.43 \\
\hline Benin & Forests & 6.53 & Mongolia & Coal and Minerals & 14.93 \\
\hline Botswana & Minerals & 3.09 & Mozambique & Forests & 10.41 \\
\hline Brunei Darussalam & Oil & 23.47 & Myanmar & Forests & 8.07 \\
\hline Burkina Faso & Forests and Minerals & 10.06 & Namibia & Minerals & 4.3 \\
\hline Burundi & Forests & 18.45 & Niger & Forests & 8.61 \\
\hline Cambodia & Forests & 3.76 & Nigeria & Oil & 28.58 \\
\hline Cameroon & Forests and Oil & 9.36 & Norway & Oil & 7.16 \\
\hline Canada & Oil & 3.52 & Oman & Oil & 34.7 \\
\hline Central Africa & Forests & 9.69 & Papa New Guinea & Minerals & 29.21 \\
\hline Chad & Forests and Oil & 16.16 & Qatar & Natural Gas and Oil & 27.5 \\
\hline Chile & Minerals & 10.86 & Republic of Congo & Oil & 41.37 \\
\hline China & Coal and Oil & 5.93 & Russia & Natural Gas and Oil & 13.3 \\
\hline Comoros & Forests & 2.18 & Rwanda & Forests & 7.34 \\
\hline Dem. Congo & Forests and Minerals & 24.19 & Senegal & Forests & 3.43 \\
\hline Egypt & Oil & 11.2 & Sierra Leone & Forests & 14.29 \\
\hline Equatorial Guinea & Oil & 11.2 & Solomon Islands & Forests and Minerals & 11.26 \\
\hline Eritrea & Forests & 5.59 & South Africa & Coal and Minerals & 6.25 \\
\hline Ethiopia & Forests & 17.94 & South Sudan & Oil & 32.77 \\
\hline Gabon & Oil & 31.34 & Sudan & Oil & 5.51 \\
\hline Gambia & Forests & 3.83 & Suriname & Minerals & 14.56 \\
\hline Ghana & Forests and Oil & 10.19 & Swaziland & Forests & 5.32 \\
\hline Guinea & Forests and Minerals & 20.01 & Syria & Oil & 16.7 \\
\hline Guinea-Bissau & Forests & 18.55 & Tanzania & Forests & 8.05 \\
\hline Guyana & Forests and Minerals & 20.5 & Togo & Forests and Minerals & 11.58 \\
\hline India & Coal and Oil & 3.16 & Trinidad and Tobago & Oil & 13.02 \\
\hline Indonesia & Oil & 8.62 & Tunisia & Oil & 5.38 \\
\hline Iran & Oil & 19.44 & Turkmenistan & Natural Gas & 41.1 \\
\hline Iraq & Oil & 32.3 & UAE & Oil & 19.7 \\
\hline Ivory Coast & Forests & 5.02 & Uganda & Forests & 16.6 \\
\hline Jamaica & Minerals & 4.12 & Ukraine & Minerals & 4.39 \\
\hline Kazakhstan & Oil & 15.98 & Uzbekistan & Natural Gas & 14.66 \\
\hline Kenya & Forests & 4.21 & Venezuela & Oil & 15.67 \\
\hline Kuwait & Oil & 38.8 & Vietnam & Forests and Oil & 7.04 \\
\hline Kyrgyzstan & Minerals & 3.98 & Yemen & Oil & 25.2 \\
\hline Lao & Forests and Minerals & 9.03 & Zambia & Minerals & 12.83 \\
\hline Lesotho & Forests & 4.98 & Zimbabwe & Coal and Minerals & 7.45 \\
\hline Liberia & Forests and Minerals & 40.98 & KSA & Oil & 34.8 \\
\hline Libya & Oil & 39.08 & & & \\
\hline Macedonia & Minerals & 2.19 & & & \\
\hline
\end{tabular}




\section{Appendix 4}

Table 9: Baseline Calibration

\begin{tabular}{|c|c|c|}
\hline Fixed & & Value \\
\hline$\beta$ & Discount factor & 0.99 \\
\hline$\delta$ & share of private consumption in the aggregate consumption bundle & 0.95 \\
\hline$\epsilon$ & Elasticity of substitution & 6 \\
\hline$\eta$ & elasticity of substitution between domestic and foreign goods & 1 \\
\hline$\gamma$ & Elasticity of substitution between goods in the world economy & 1 \\
\hline$\nu$ & Share of non-commodity factors in the production function & 0.95 \\
\hline$\sigma$ & Inverse elasticity of intertemporal substitution & 1 \\
\hline$\varphi \& \varphi^{*}$ & Inverse Frisch labour supply elasticity & 3 \\
\hline$\mu$ & Elasticity of substitution between commodity and core consumption & 0.3 \\
\hline$\theta$ & Calvo probability & 0.75 \\
\hline$\phi_{\pi}$ & Inflation elasticity of the nominal interest rate & 1.5 \\
\hline$\phi_{x}$ & Output gap elasticity of the nominal interest rate & 0.5 \\
\hline$\rho_{a, a^{*}}$ & $\operatorname{AR}(1)$ coefficient of domestic and foreign productivity & 0.66 \\
\hline$\rho_{r, r^{*}}$ & $\mathrm{AR}(1)$ coefficient of domestic and foreign interest rates & 0.12 \\
\hline$\sigma_{a, a^{*}}$ & standard deviation of a domestic and foreign productivity shocks & 0.0071 \\
\hline$\sigma_{r, r^{*}}$ & standard deviation of a domestic and foreign interest rates shocks & 0.24 \\
\hline \multicolumn{3}{|c|}{ Calibrated } \\
\hline \multirow[t]{5}{*}{$\alpha$} & Degree of openness in the domestic economy & \\
\hline & CHL & 28.6 \\
\hline & AUS & 19.2 \\
\hline & $\mathrm{SA}$ & 25.0 \\
\hline & KSA & 31.7 \\
\hline \multirow[t]{5}{*}{$\varpi$} & share of consumption of commodities in the consumption basket of the domestic economy & \\
\hline & CHL & 8.7 \\
\hline & AUS & 7.2 \\
\hline & SA & 7.9 \\
\hline & KSA & 2.2 \\
\hline$\varpi^{*}$ & share of consumption of commodities in the consumption basket of the foreign economy & 8.8 \\
\hline \multirow{5}{*}{$\chi$} & inverse elasticity of substitution between $C \& G$ in the domestic economy & \\
\hline & CHL & 8.19 \\
\hline & AUS & 67.6 \\
\hline & SA & 5.3 \\
\hline & KSA & 102.4 \\
\hline \multirow{6}{*}{$\begin{array}{l}\chi^{*} \\
\phi_{g}\end{array}$} & inverse elasticity of substitution between $C \& G$ in the foreign economy & 7.25 \\
\hline & response of domestic government consumption to changes in commodity prices & \\
\hline & CHL & 0.25 \\
\hline & AUS & -0.01 \\
\hline & SA & -0.04 \\
\hline & KSA & 0.78 \\
\hline$\rho_{o}$ & $\mathrm{AR}(1)$ coefficient of aggregate commodity supply & 0.376 \\
\hline \multirow[t]{5}{*}{$\rho_{g}$} & $\mathrm{AR}(1)$ coefficient of domestic government consumption & \\
\hline & $\mathrm{CHL}$ & 0.44 \\
\hline & AUS & 0.58 \\
\hline & SA & 0.35 \\
\hline & KSA & 0.12 \\
\hline \multirow{7}{*}{$\begin{array}{c}\rho_{g^{*}} \\
\sigma_{o} \\
\sigma_{g}\end{array}$} & $\mathrm{AR}(1)$ coefficient of foreign government consumption & 0.59 \\
\hline & standard deviation of an aggregate commodity supply shock & 0.0166 \\
\hline & standard deviation of domestic government consumption & \\
\hline & CHL & 0.0286 \\
\hline & AUS & 0.0122 \\
\hline & SA & 0.0256 \\
\hline & KSA & 0.1002 \\
\hline$\sigma_{g^{*}}$ & standard deviation of foreign government consumption & 0.0168 \\
\hline
\end{tabular}


Figure 5: Impulse Response Functions in the Australian
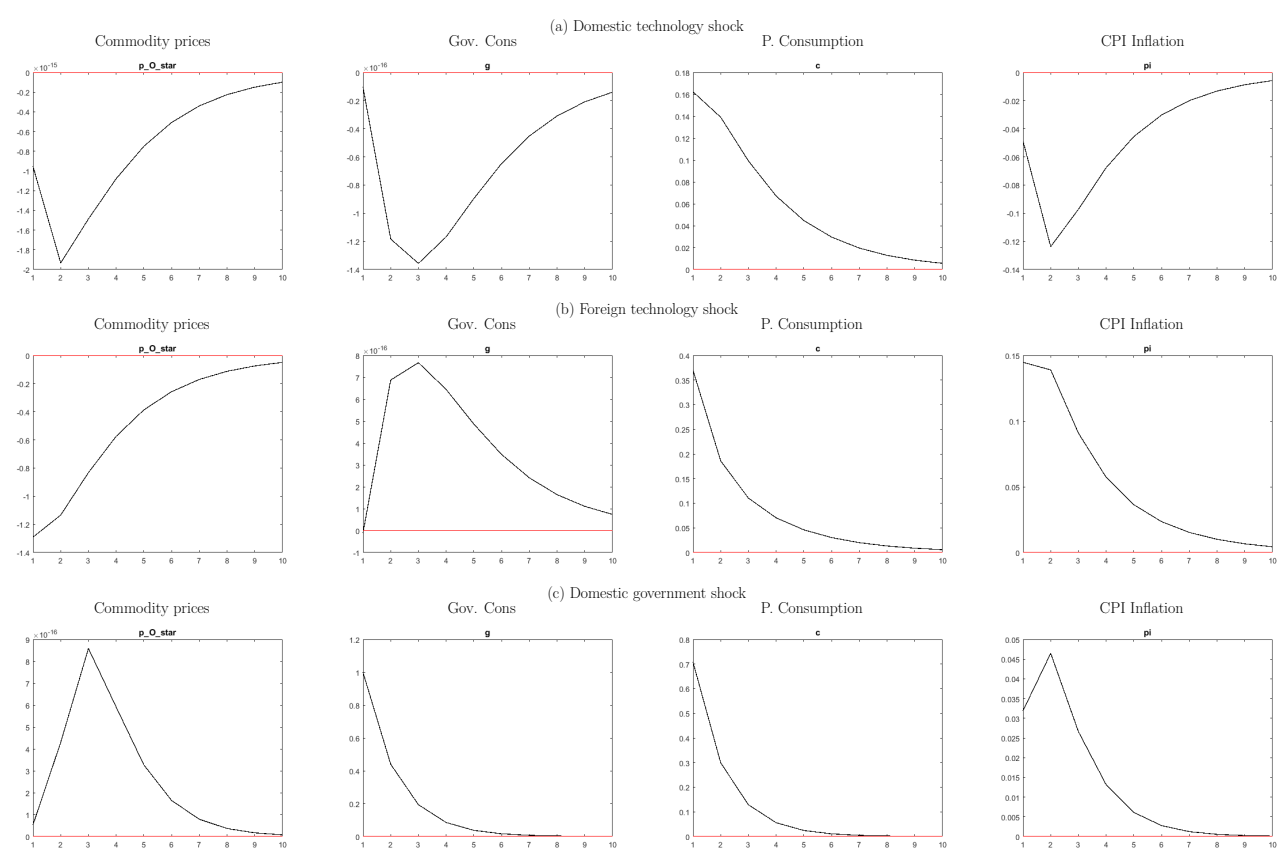

Gov. Cons (c) Domestic government shock P. Consumption
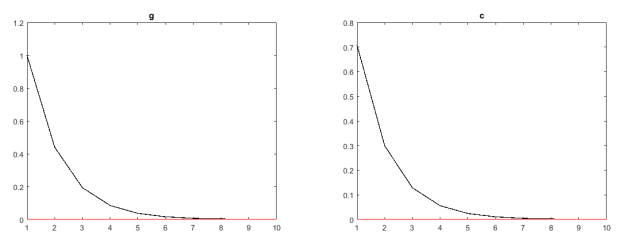

CPI Inflation
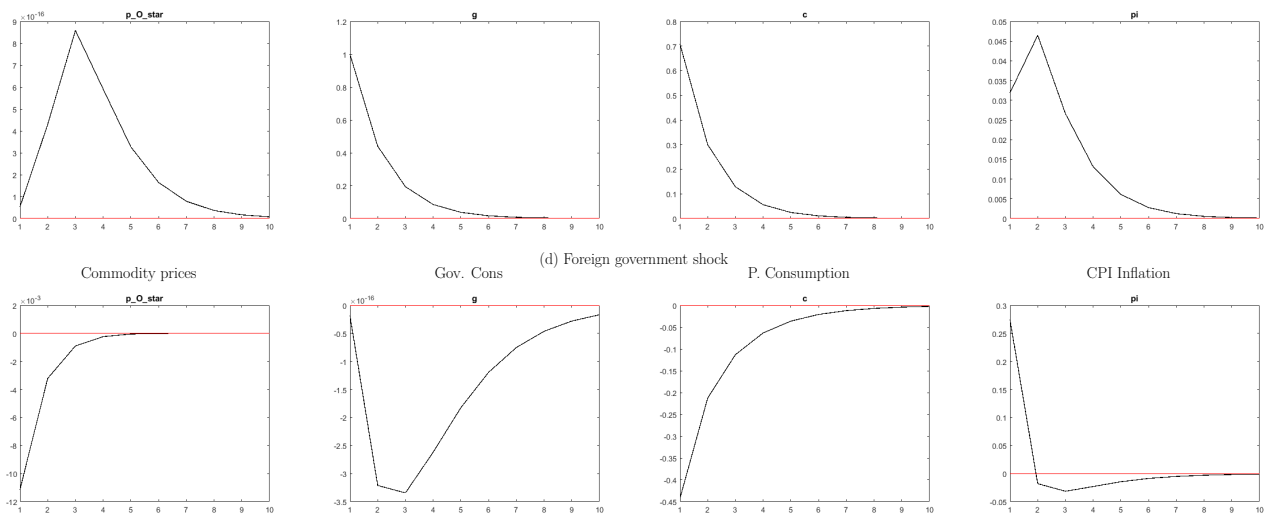

Gov. Cons (d) Foreign government shock
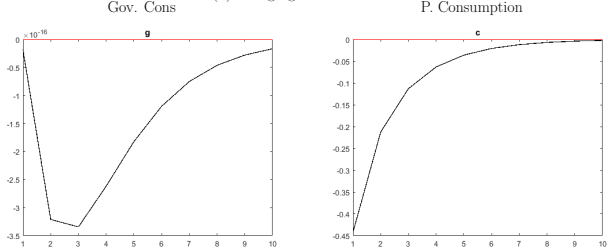

CPI Inflation

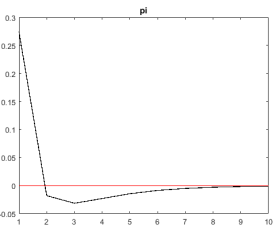

Commodity prices

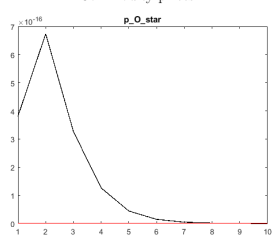

Gov. Cons (e) Domestic interest rates shock P. Consumption
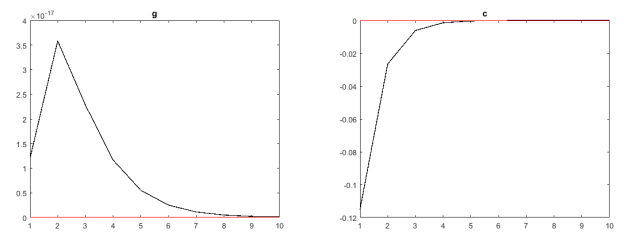

CPI Inflation
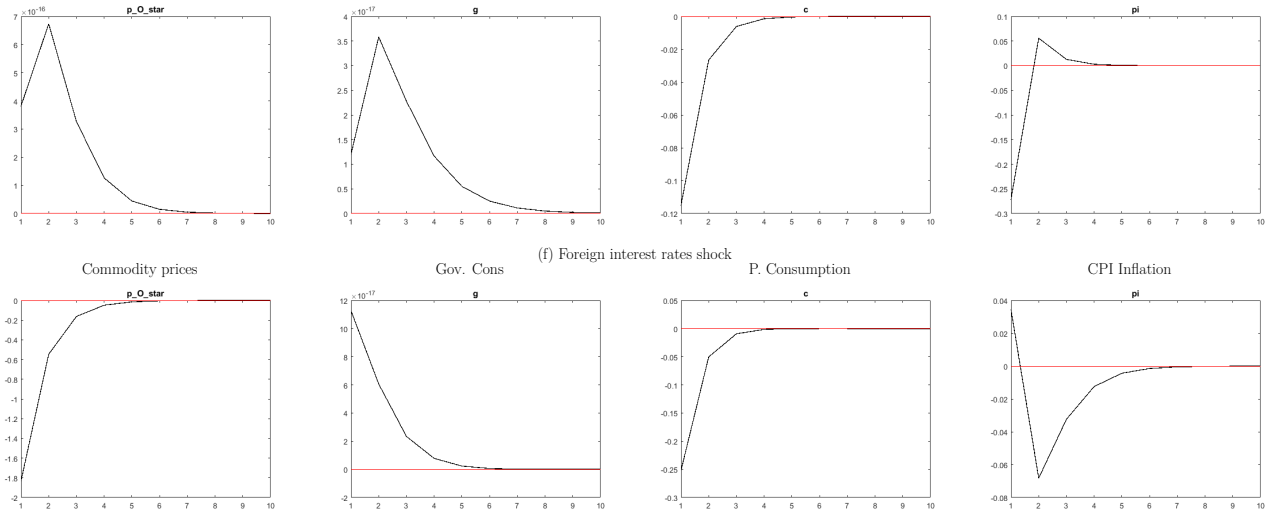

Gov. Cons

f) Foreign interest rates shock


Gov. Cons (g) World commodity supply shock ${ }_{\text {P. Consumption }}$


CPI Inflation

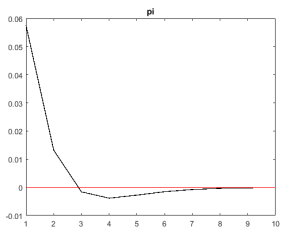

Note: all seven shocks are normalised to 1. 
Figure 6: Impulse Response Functions in the Chilean Economy
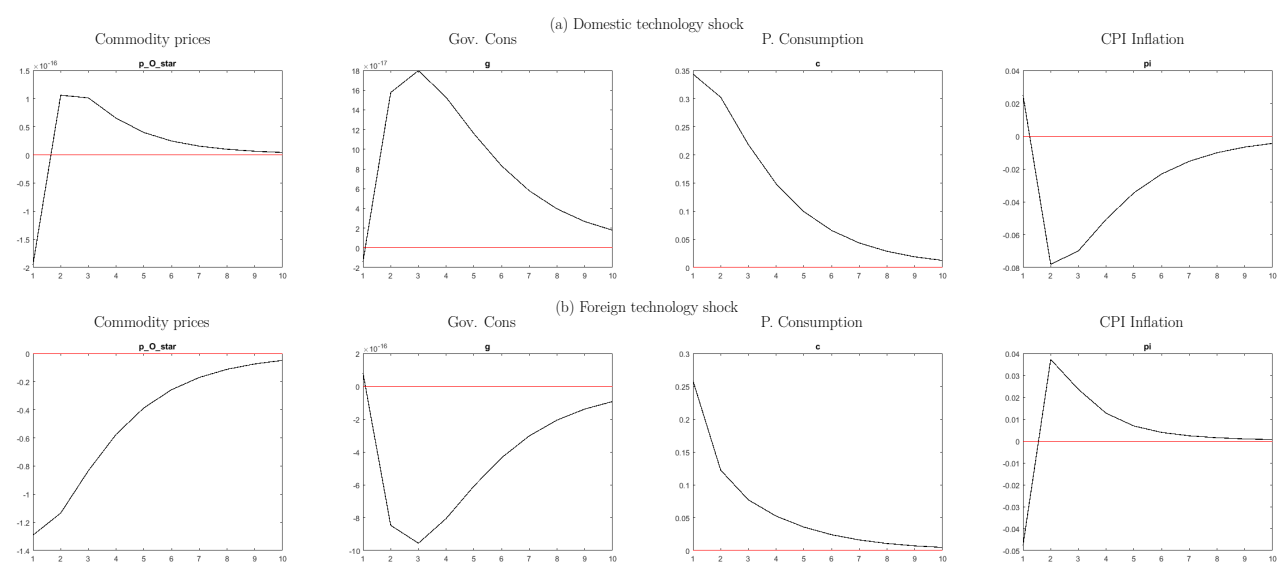

Gov. Cons $\quad$ (b) Foreign technology shock $\quad$ P. Consumption
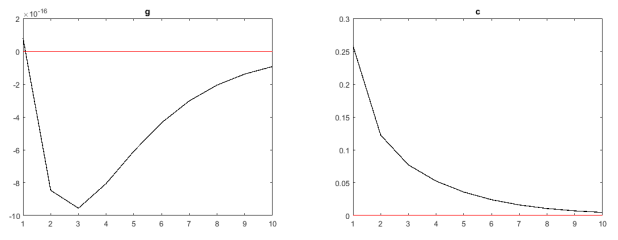

CPI Inflation

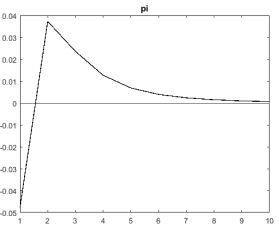

Gov. Cons (c) Domestic government shock P. Consumption
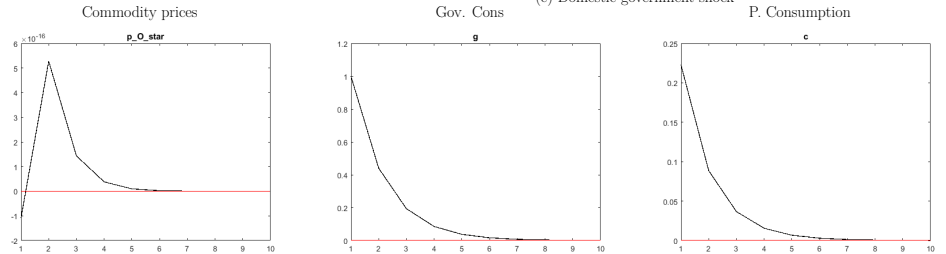

CPI Inflation

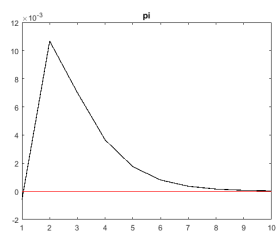

Gov Cons (d) Foreign government shock
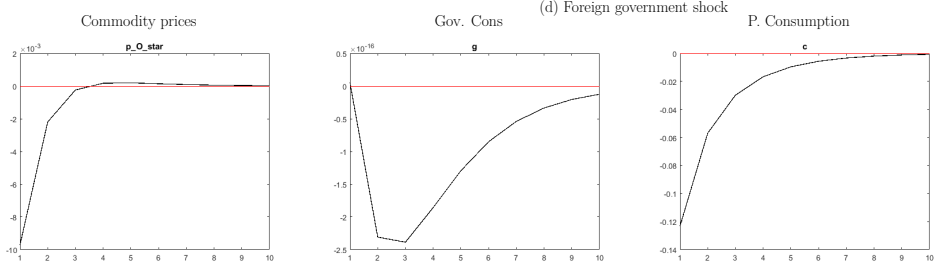

CPI Inflation

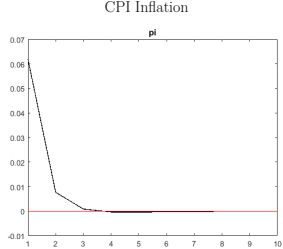

Commodity prices

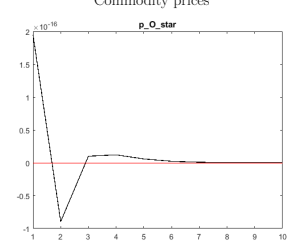

Gov. Cons (e) Domestic interest rates shock P. Consumption
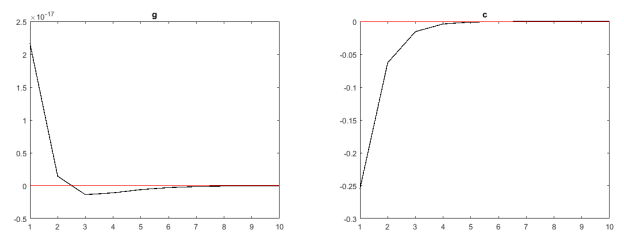

CPI Inflation

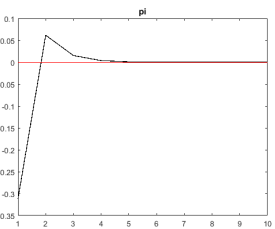

Commodity prices

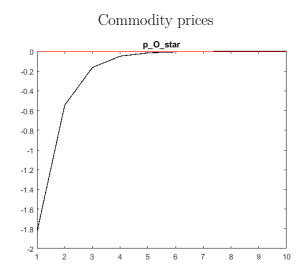

Gov. Cons (f) Foreign interest rates shock P. Consumption
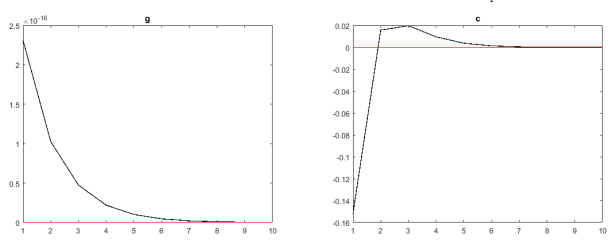

Gov. Cons (g) World commodity supply shock ${ }_{\text {P. Consumption }}$
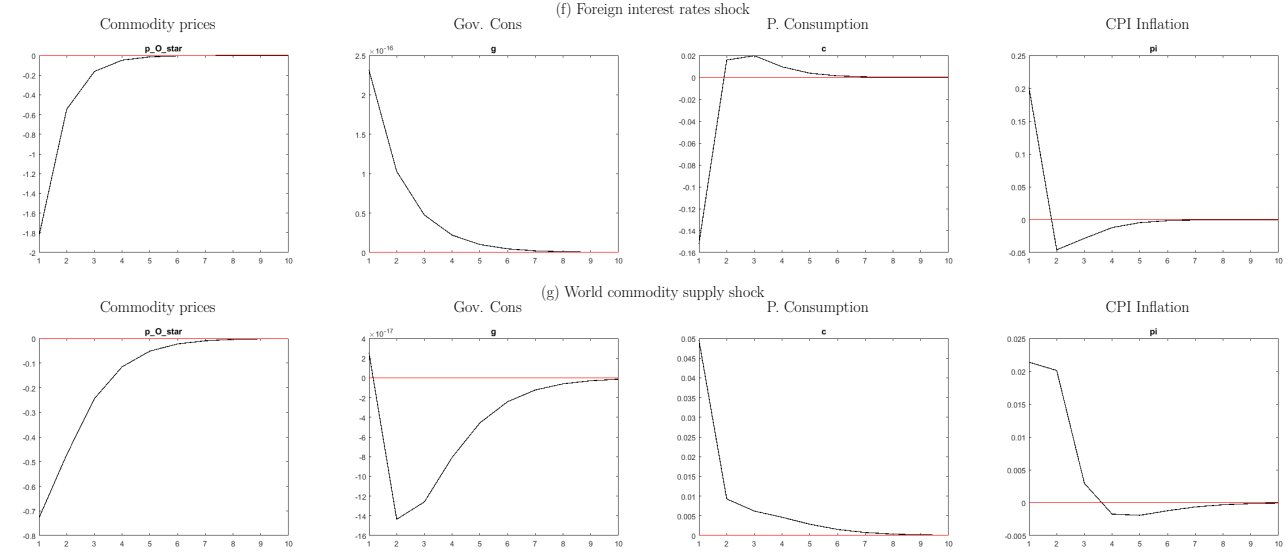

CPI Inflation

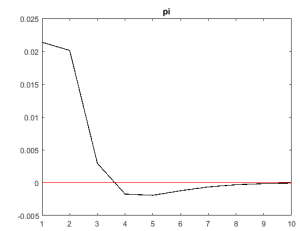

Note: all seven shocks are normalised to 1. 
Figure 7: Impulse Response Functions in the Saudi Economy
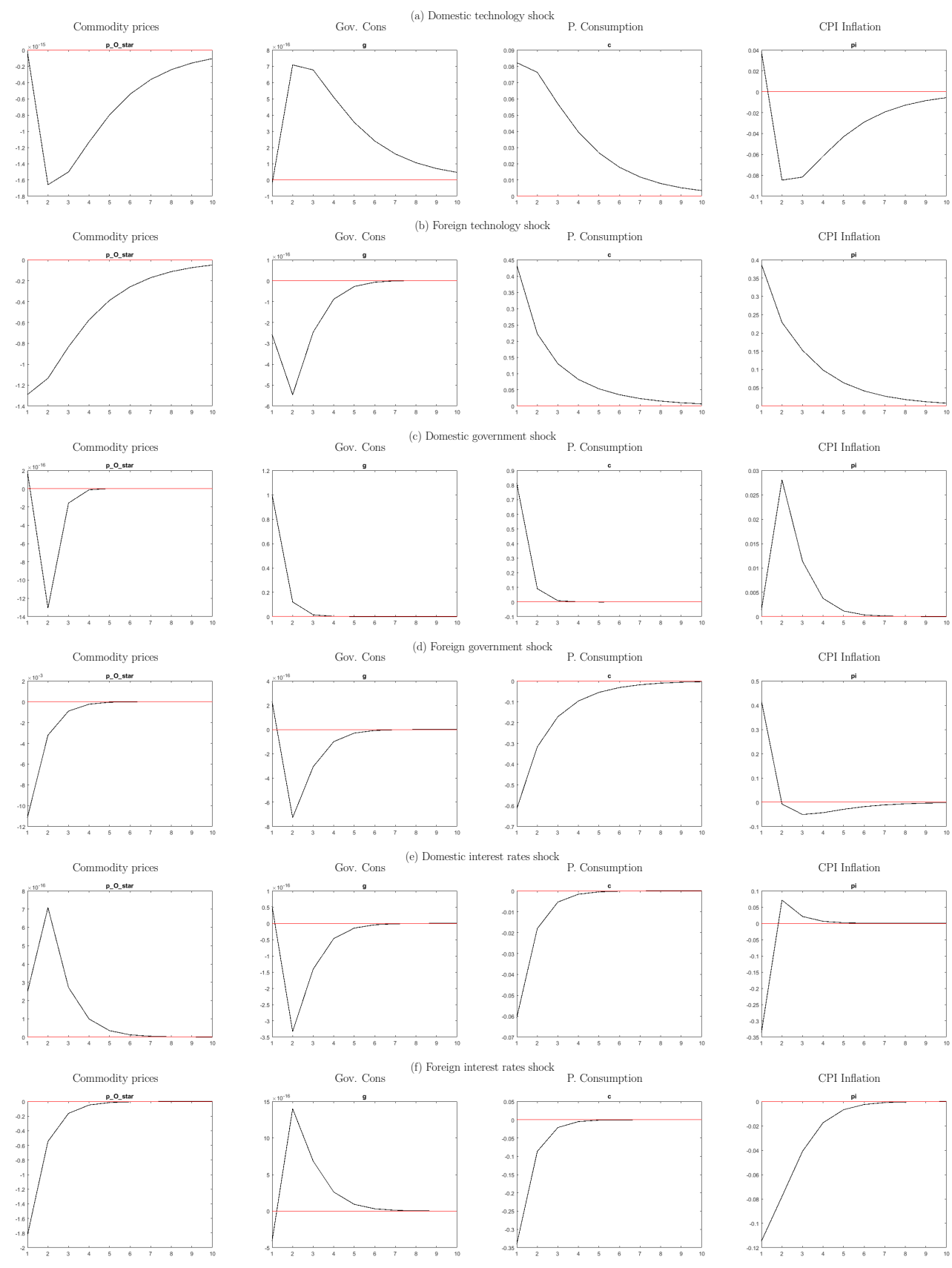

Gov. Cons (g) World commodity supply shock ${ }_{\text {P. Consumption }}$
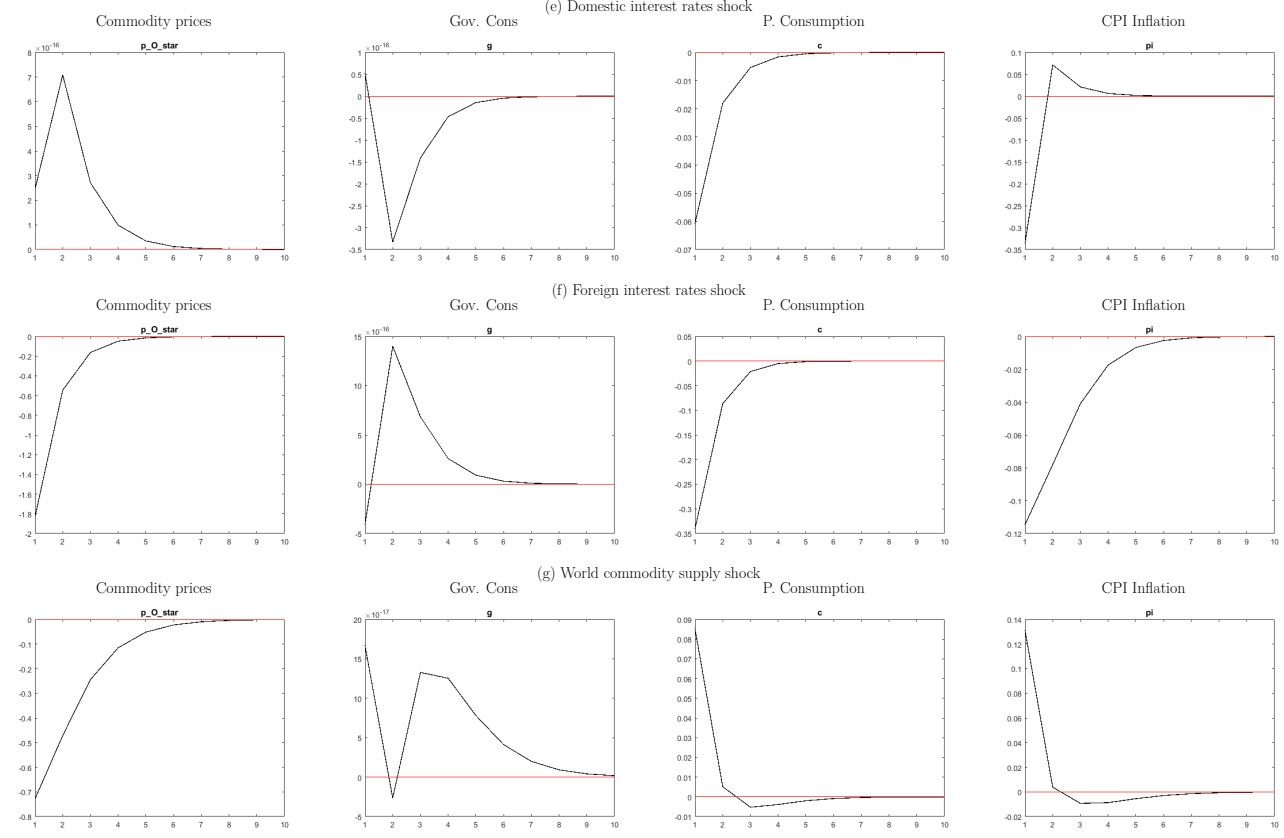

CPI Inflation



Note: all seven shocks are normalised to 1. 
Figure 8: Impulse Response Functions in the South African Economy
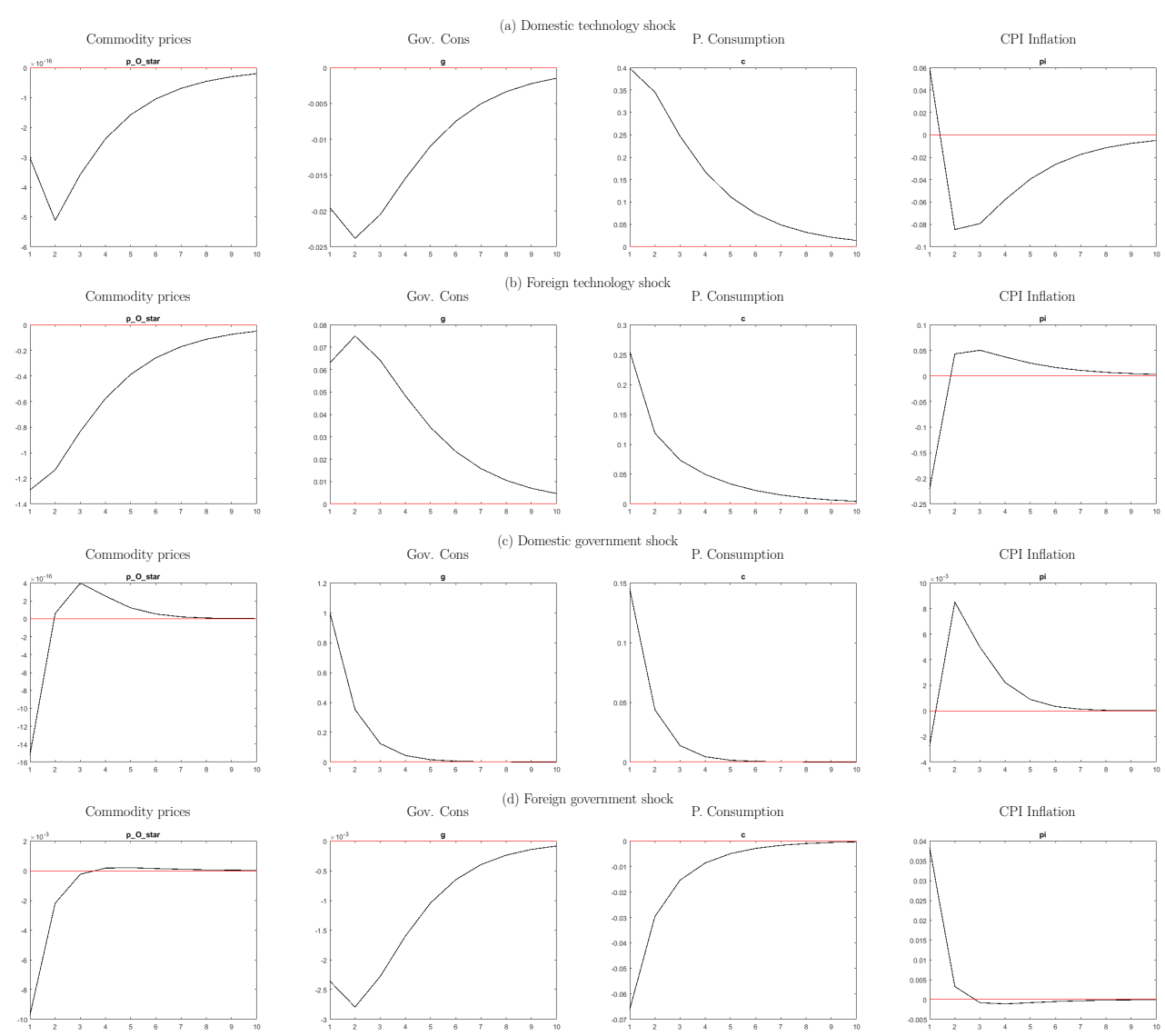

Gov. Cons

(d) Foreign government shock


CPI Inflation

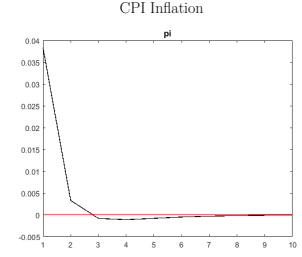

Commodity prices

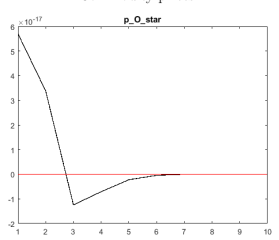

Gov. Cons (e) Domestic interest rates shock P. Consumption
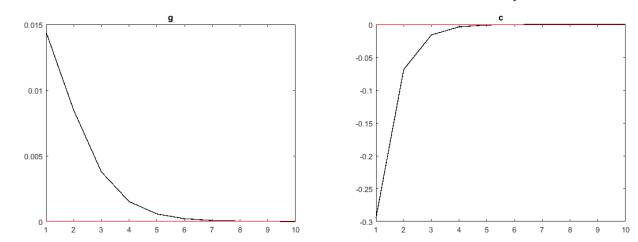

CPI Inflation
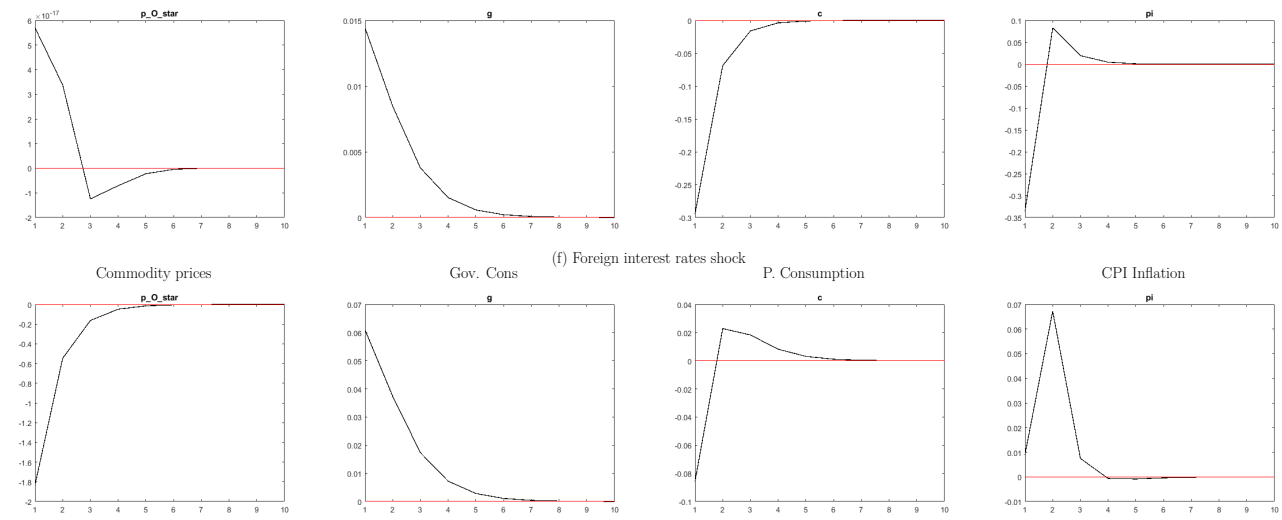

Gov. Cons

(f) Foreign interest rates shock
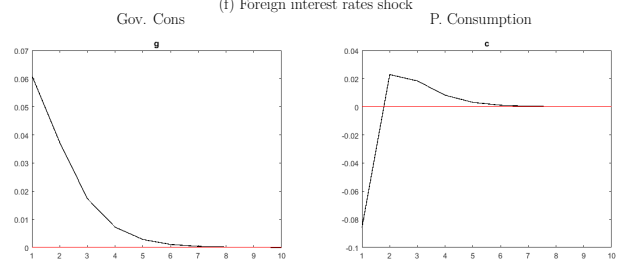

Gov. Cons (g) World commodity supply shock ${ }_{\text {P. Consumption }}$
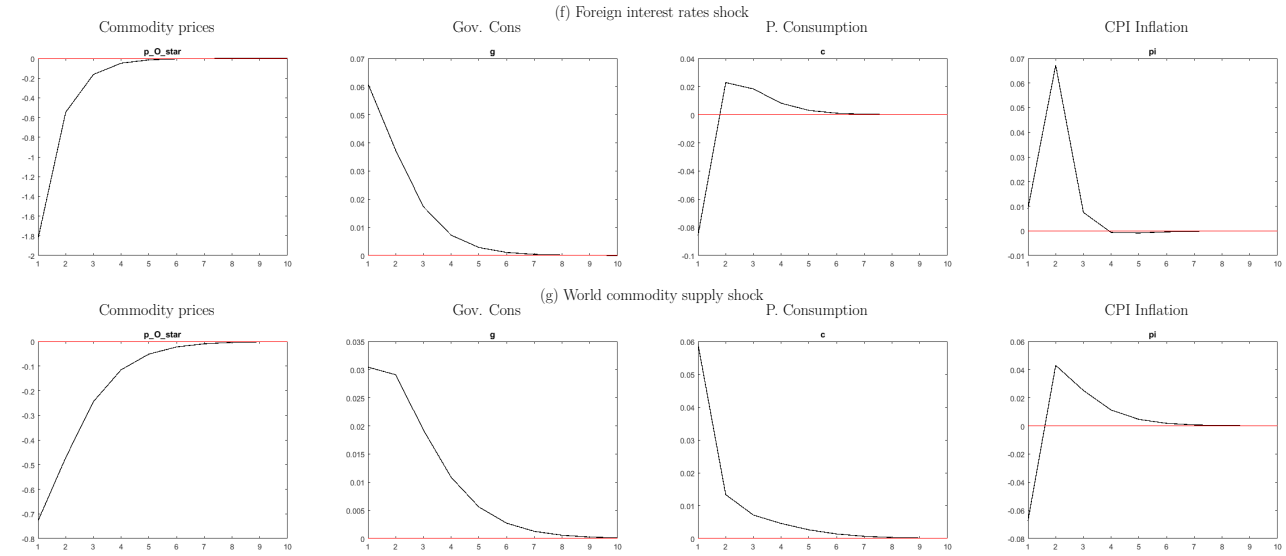

CPI Inflation



Note: all seven shocks are normalised to 1. 


\section{Appendix C.5}

\section{- Saudi Arabia}

Table 10: KSA Estimation Output

\begin{tabular}{|c|c|c|c|c|c|c|}
\hline & $\begin{array}{l}\text { Prior Mean } \\
\end{array}$ & Posterior Mean & Posterior Mode & 90\% HPD Interval & Prior & Prior. Stdev \\
\hline \multicolumn{7}{|c|}{ Parameter } \\
\hline$\rho_{a}$ & 0.5 & 0.4957 & 0.5 & $0.1680-0.8196$ & Beta & 0.2 \\
\hline$\rho_{a^{*}}$ & 0.5 & 0.6123 & 0.6213 & $0.5439-0.6809$ & Beta & 0.2 \\
\hline$\rho_{r}$ & 0.5 & 0.977 & 0.9851 & $0.9590-0.9969$ & Beta & 0.2 \\
\hline$\rho_{r^{*}}$ & 0.5 & 0.6478 & 0.7121 & $0.4002-0.9132$ & Beta & 0.2 \\
\hline$\rho_{g}$ & 0.5 & 0.8666 & 0.8841 & $0.7762-0.9596$ & Beta & 0.2 \\
\hline$\rho_{g^{*}}$ & 0.5 & 0.9345 & 0.9570 & $0.8792-0.9921$ & Beta & 0.2 \\
\hline$\rho_{o^{*}}$ & 0.5 & 0.5086 & 0.5 & $0.1835-0.8377$ & Beta & 0.2 \\
\hline$\chi$ & 102.4 & 102.6194 & 94.6648 & 72.4744-134.1410 & inv-Gamma & 19.42 \\
\hline$\phi_{g}$ & 0.78 & 0.1994 & 0.1826 & 0.1128-0.2866 & Normal & 0.14 \\
\hline \multicolumn{7}{|c|}{ Standard deviations } \\
\hline$\epsilon_{a}$ & 0.05 & 0.0474 & 0.0230 & $0.0115-0.0879$ & inv-Gamma & 2.0 \\
\hline$\epsilon_{a^{*}}$ & 0.05 & 14.8362 & 14.1357 & $11.7893-17.8101$ & inv-Gamma & 2.0 \\
\hline$\epsilon_{r}$ & 0.05 & 0.0476 & 0.0230 & $0.0114-0.0864$ & inv-Gamma & 2.0 \\
\hline$\epsilon_{r^{*}}$ & 0.05 & 9.8784 & 9.2001 & $7.7125-12.0271$ & inv-Gamma & 2.0 \\
\hline$\epsilon_{g}$ & 0.05 & 9.9372 & 9.1847 & 7.6239-12.1326 & inv-Gamma & 2.0 \\
\hline$\epsilon_{q^{*}}$ & 0.05 & 8.2126 & 7.9655 & $6.5845-9.7930$ & inv-Gamma & 2.0 \\
\hline$\epsilon_{O^{*}}$ & 0.05 & 0.0449 & 0.0230 & $0.0118-0.0826$ & inv-Gamma & 2.0 \\
\hline
\end{tabular}

Figure 9: Historical Decomposition of government consumption in KSA 1981-2015

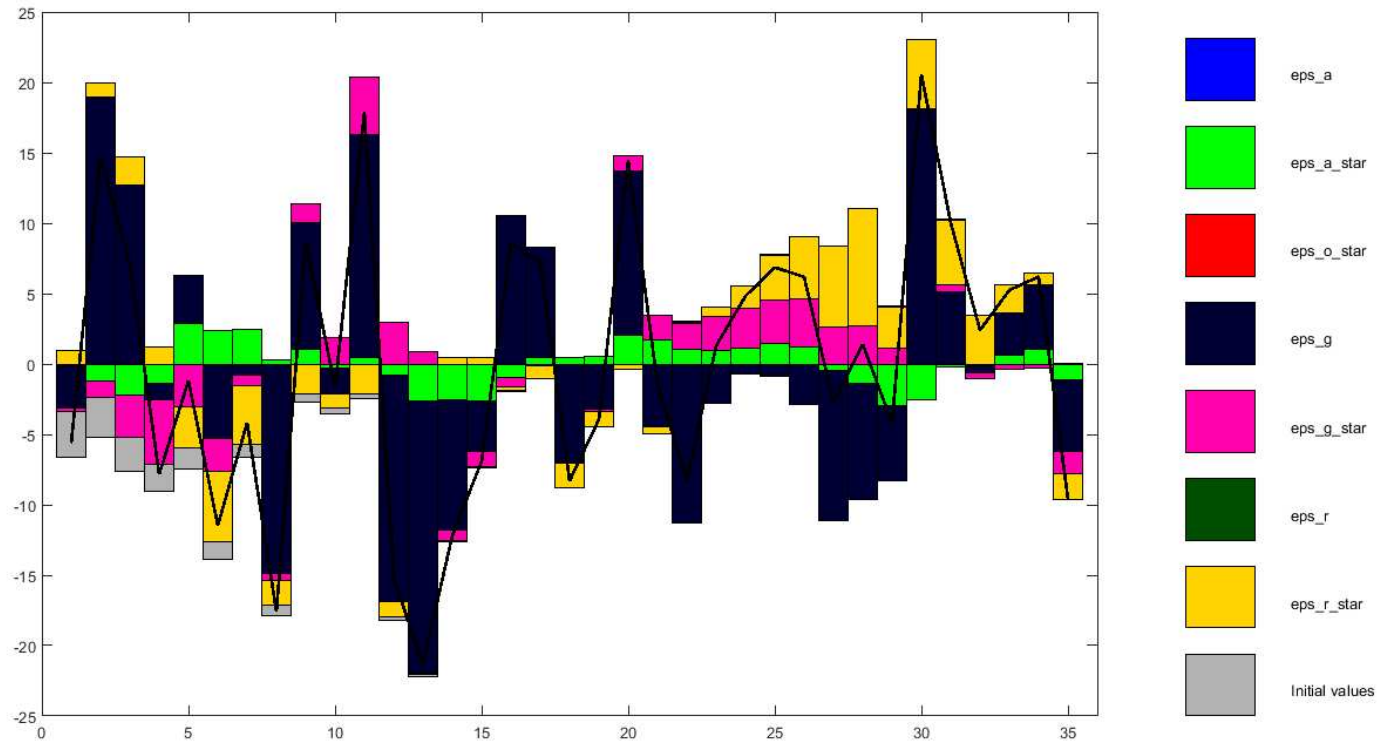


Figure 10: Historical Decomposition of private consumption in KSA 1981-2015

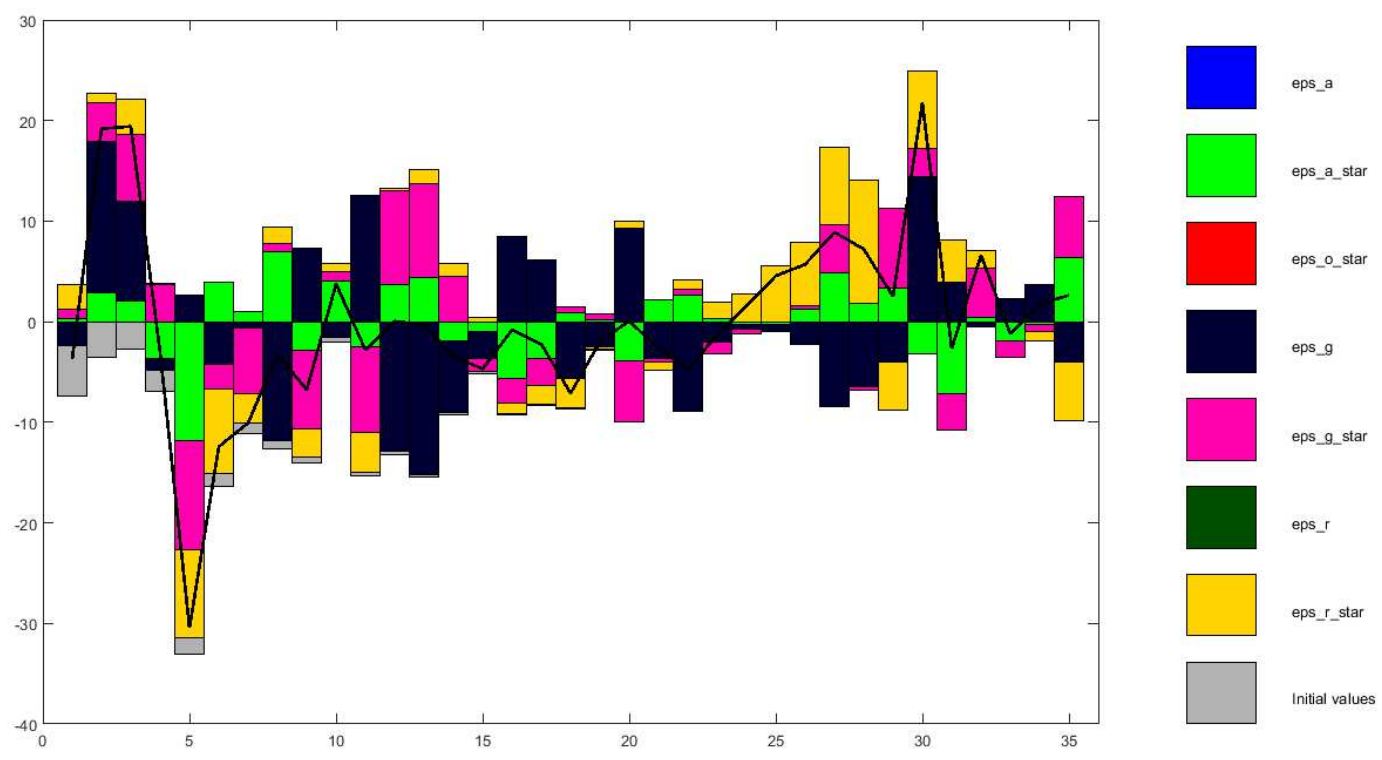

Figure 11: Historical Decomposition of inflation in KSA 1981-2015

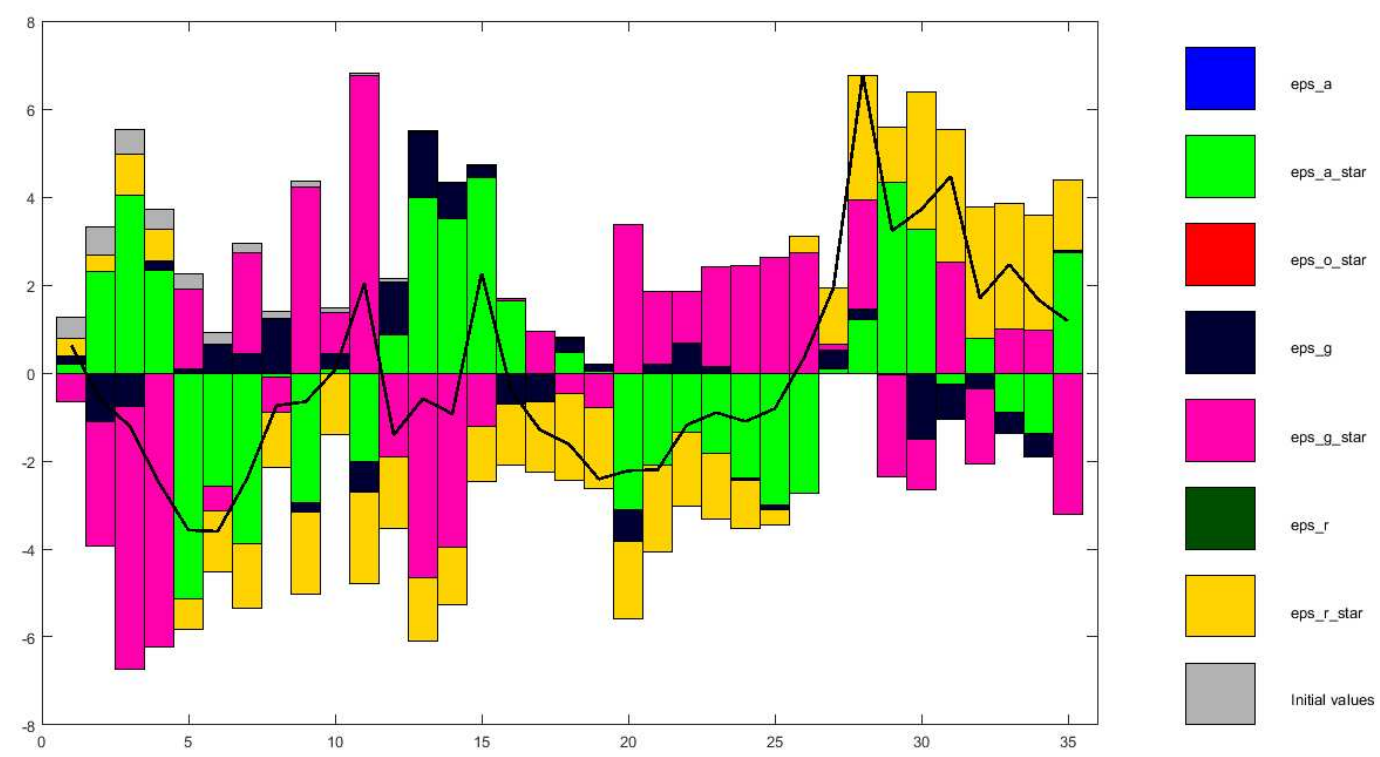




\section{Australia}

Table 11: AUS Estimation Output

\begin{tabular}{|c|c|c|c|c|c|c|}
\hline & Prior Mean & Posterior Mean & Posterior Mode & 90\% HPD Interval & Prior & Prior. Stdev \\
\hline \multicolumn{7}{|c|}{ Parameter } \\
\hline$\rho_{a}$ & 0.5 & 0.4930 & 0.5000 & $0.1703-0.8199$ & Beta & 0.2 \\
\hline$\rho_{a^{*}}$ & 0.5 & 0.8371 & 0.8371 & $0.7444-0.9237$ & Beta & 0.2 \\
\hline$\rho_{r}$ & 0.5 & 0.8765 & 0.9049 & $0.7822-0.9762$ & Beta & 0.2 \\
\hline$\rho_{r^{*}}$ & 0.5 & 0.6877 & 0.7603 & 0.4524-0.9400 & Beta & 0.2 \\
\hline$\rho_{g}$ & 0.5 & 0.9035 & 0.9136 & $0.8402-0.9724$ & Beta & 0.2 \\
\hline$\rho_{g^{*}}$ & 0.5 & 0.4949 & 0.5001 & $0.1701-0.8245$ & Beta & 0.2 \\
\hline$\rho_{O^{*}}$ & 0.5 & 0.5007 & 0.5000 & $0.1768-0.8298$ & Beta & 0.2 \\
\hline$\chi$ & 67.6 & 67.8278 & 62.4937 & $47.6358-87.3705$ & inv-Gamma & 12.82 \\
\hline$\phi_{g}$ & -0.01 & -0.0122 & -0.0124 & $-0.0206--0.0040$ & Normal & 0.017 \\
\hline \multicolumn{7}{|c|}{ Standard deviations } \\
\hline$\epsilon_{a}$ & 0.05 & 0.0581 & 0.0230 & $0.0113-0.0973$ & inv-Gamma & 2.0 \\
\hline$\epsilon_{a^{*}}$ & 0.05 & 4.4787 & 4.3014 & $3.5909-5.3540$ & inv-Gamma & 2.0 \\
\hline$\epsilon_{r}$ & 0.05 & 3.0546 & 2.8909 & $2.4017-3.6755$ & inv-Gamma & 2.0 \\
\hline$\epsilon_{r^{*}}$ & 0.05 & 8.7136 & 8.2294 & $6.9810-10.4489$ & inv-Gamma & 2.0 \\
\hline$\epsilon_{g}$ & 0.05 & 1.1069 & 1.0447 & $0.8834-1.3229$ & inv-Gamma & 2.0 \\
\hline$\epsilon_{g^{*}}$ & 0.05 & 0.0589 & 0.0230 & $0.0111-0.0907$ & inv-Gamma & 2.0 \\
\hline$\epsilon_{o^{*}}$ & 0.05 & 0.0509 & 0.0230 & 0.0110-0.0899 & inv-Gamma & 2.0 \\
\hline
\end{tabular}

Figure 12: Historical Decomposition of government consumption in Australia 1981-2015

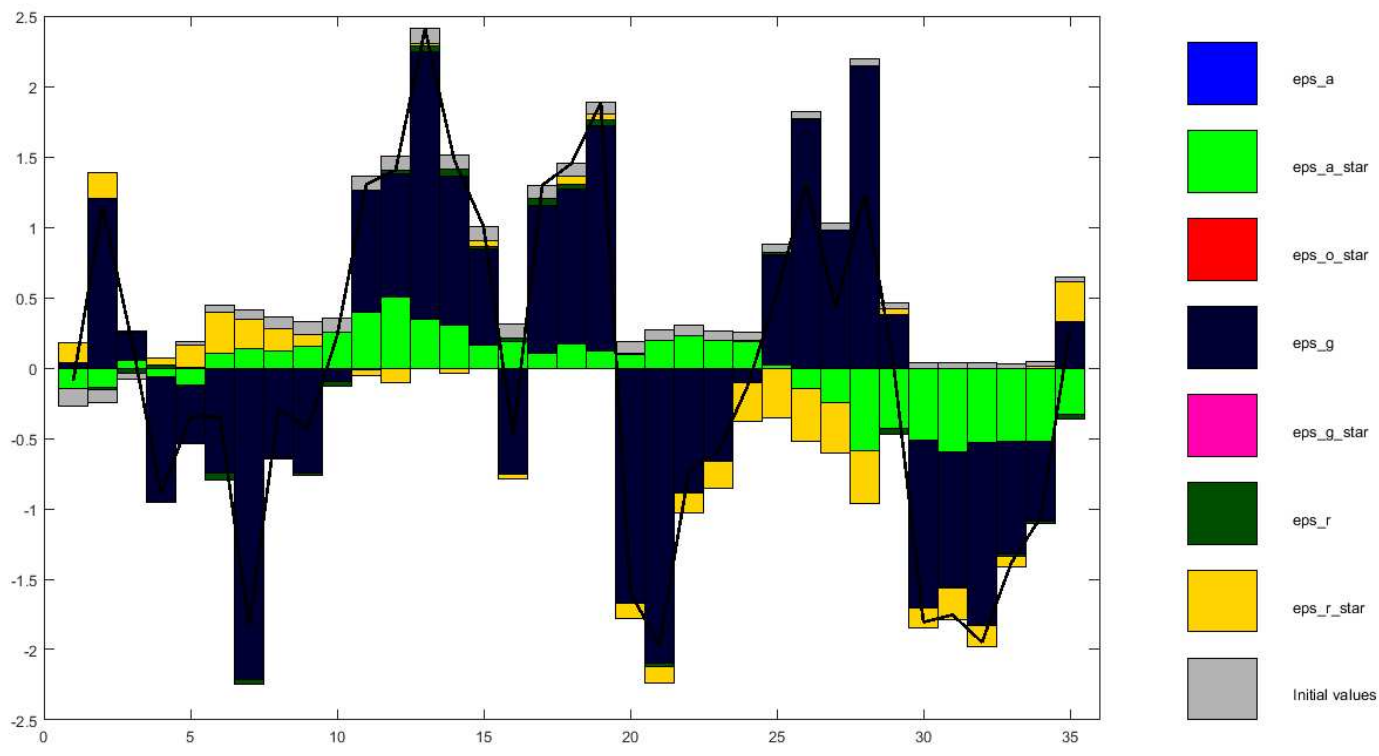


Figure 13: Historical Decomposition of private consumption in Australia 1981-2015

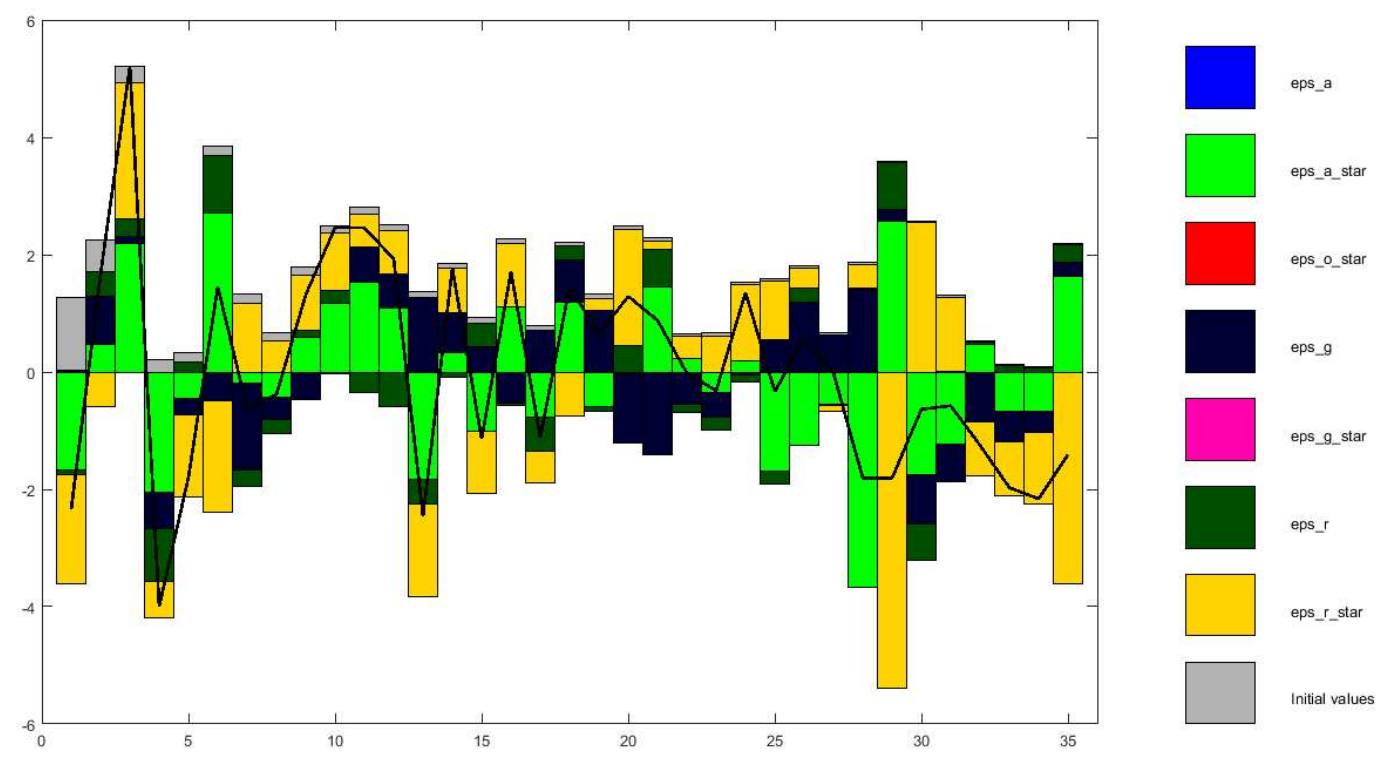

Figure 14: Historical Decomposition of inflation in Australia 1981-2015

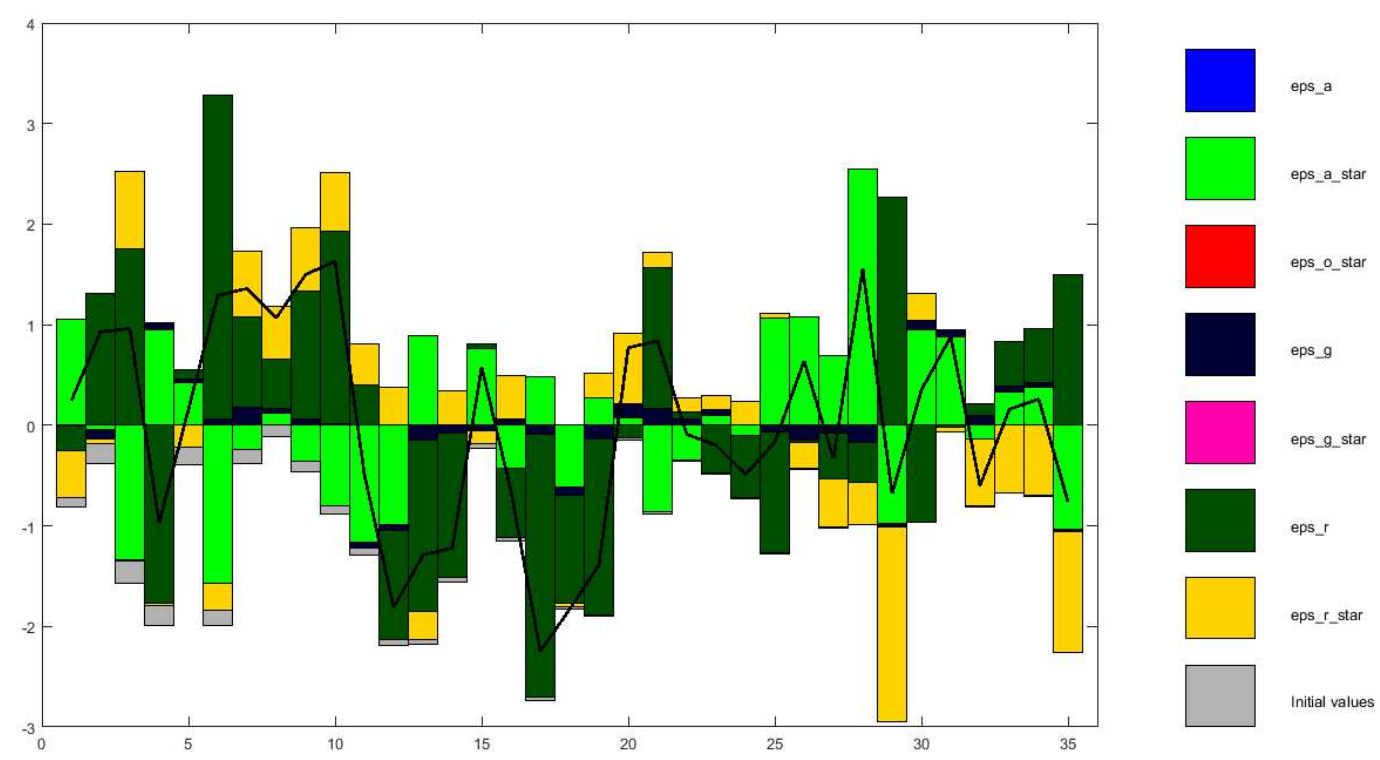


Chile

Table 12: CHL Estimation Output

\begin{tabular}{|c|c|c|c|c|c|c|}
\hline & $\begin{array}{l}\text { Prior Mean } \\
\end{array}$ & $\begin{array}{l}\text { Posterior Mean } \\
\end{array}$ & Posterior Mode & $90 \%$ HPD Interval & Prior & Prior. Stdev \\
\hline \multicolumn{7}{|c|}{ Parameter } \\
\hline$\rho_{a}$ & 0.5 & 0.6155 & 0.6466 & $0.4147-0.7960$ & Beta & 0.2 \\
\hline$\rho_{a^{*}}$ & 0.5 & 0.6640 & 0.9309 & $0.3015-0.9794$ & Beta & 0.2 \\
\hline$\rho_{r}$ & 0.5 & 0.2166 & 0.0860 & $0.0078-0.4871$ & Beta & 0.2 \\
\hline$\rho_{r^{*}}$ & 0.5 & 0.6416 & 0.5141 & $0.3480-0.9520$ & Beta & 0.2 \\
\hline$\rho_{g}$ & 0.5 & 0.7512 & 0.7493 & $0.6465-0.8582$ & Beta & 0.2 \\
\hline$\rho_{g^{*}}$ & 0.5 & 0.5157 & 0.5 & $0.1865-0.8364$ & Beta & 0.2 \\
\hline$\rho_{o^{*}}$ & 0.5 & 0.5062 & 0.5 & $0.1731-0.8238$ & Beta & 0.2 \\
\hline$\chi$ & 8.19 & 7.6746 & 5.5958 & $3.3082-12.1583$ & inv-Gamma & 4.84 \\
\hline$\phi_{g}$ & 0.25 & 0.0921 & 0.0750 & $0.0565-0.1261$ & Normal & 0.048 \\
\hline \multicolumn{7}{|c|}{ Standard deviations } \\
\hline$\epsilon_{a}$ & 0.05 & 25.7249 & 22.4146 & 18.3701-33.3067 & inv-Gamma & 2.0 \\
\hline$\epsilon_{a^{*}}$ & 0.05 & 1.8607 & 4.1777 & $0.0089-5.7465$ & inv-Gamma & 2.0 \\
\hline$\epsilon_{r}$ & 0.05 & 24.4385 & 24.5309 & $19.2848-29.5408$ & inv-Gamma & 2.0 \\
\hline$\epsilon_{r^{*}}$ & 0.05 & 9.9686 & 5.5864 & $4.1676-15.2937$ & inv-Gamma & 2.0 \\
\hline$\epsilon_{g}$ & 0.05 & 2.4501 & 2.2099 & $1.9075-2.9527$ & inv-Gamma & 2.0 \\
\hline$\epsilon_{q^{*}}$ & 0.05 & 0.0472 & 0.0230 & $0.0111-0.0923$ & inv-Gamma & 2.0 \\
\hline$\epsilon_{O^{*}}$ & 0.05 & 0.0466 & 0.0230 & $0.0118-0.0837$ & inv-Gamma & 2.0 \\
\hline
\end{tabular}

Figure 15: Historical Decomposition of government consumption in Chile 1981-2015




Figure 16: Historical Decomposition of private consumption in Chile 1981-2015



Figure 17: Historical Decomposition of inflation in Chile 1981-2015

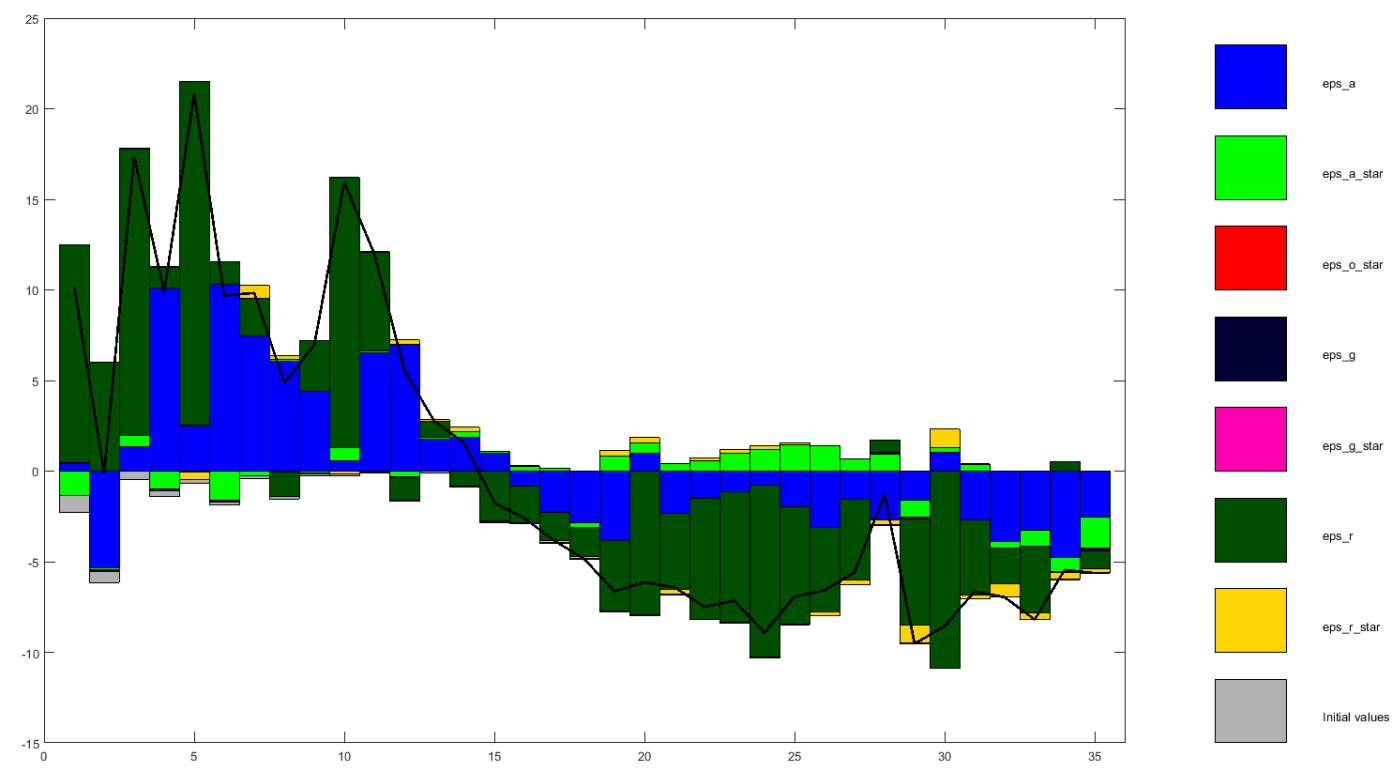




\section{South Africa}

Table 13: SA Estimation Output

\begin{tabular}{|c|c|c|c|c|c|c|}
\hline & $\begin{array}{l}\text { Prior Mean } \\
\end{array}$ & Posterior Mean & Posterior Mode & $90 \%$ HPD Interval & Prior & Prior. Stdev \\
\hline \multicolumn{7}{|c|}{ Parameter } \\
\hline$\rho_{a}$ & 0.5 & 0.5689 & 0.5825 & $0.3897-0.7525$ & Beta & 0.2 \\
\hline$\rho_{a^{*}}$ & 0.5 & 0.4915 & 0.5 & $0.1543-0.8121$ & Beta & 0.2 \\
\hline$\rho_{r}$ & 0.5 & 0.7647 & 0.7955 & $0.6015-0.9364$ & Beta & 0.2 \\
\hline$\rho_{r^{*}}$ & 0.5 & 0.7129 & 0.7835 & $0.4902-0.9498$ & Beta & 0.2 \\
\hline$\rho_{g}$ & 0.5 & 0.8729 & 0.8773 & $0.8075-0.9433$ & Beta & 0.2 \\
\hline$\rho_{g^{*}}$ & 0.5 & 0.4987 & 0.5 & $0.1724-0.8253$ & Beta & 0.2 \\
\hline$\rho_{o^{*}}$ & 0.5 & 0.4967 & 0.5 & $0.1675-0.8263$ & Beta & 0.2 \\
\hline$\chi$ & 5.3 & 5.2948 & 4.0505 & 2.5256-8.1299 & inv-Gamma & 2.266 \\
\hline$\phi_{g}$ & -0.04 & 0.0419 & 0.0415 & 0.0244-0.0597 & Normal & 0.08 \\
\hline \multicolumn{7}{|c|}{ Standard deviations } \\
\hline$\epsilon_{a}$ & 0.05 & 13.8192 & 13.2063 & $10.6822-16.8417$ & inv-Gamma & 2.0 \\
\hline$\epsilon_{a^{*}}$ & 0.05 & 0.0487 & 0.0230 & $0.0113-0.0881$ & inv-Gamma & 2.0 \\
\hline$\epsilon_{r}$ & 0.05 & 7.3169 & 6.9333 & $5.7996-8.7983$ & inv-Gamma & 2.0 \\
\hline$\epsilon_{r^{*}}$ & 0.05 & 12.2104 & 11.5483 & $9.7760-14.5750$ & inv-Gamma & 2.0 \\
\hline$\epsilon_{g}$ & 0.05 & 2.1457 & 2.0189 & $1.7181-2.5694$ & inv-Gamma & 2.0 \\
\hline$\epsilon_{q^{*}}$ & 0.05 & 0.0470 & 0.0230 & $0.0116-0.0870$ & inv-Gamma & 2.0 \\
\hline$\epsilon_{O^{*}}$ & 0.05 & 0.0455 & 0.0230 & $0.0113-0.0837$ & inv-Gamma & 2.0 \\
\hline
\end{tabular}

Figure 18: Historical Decomposition of government consumption in South Africa 1981-2015

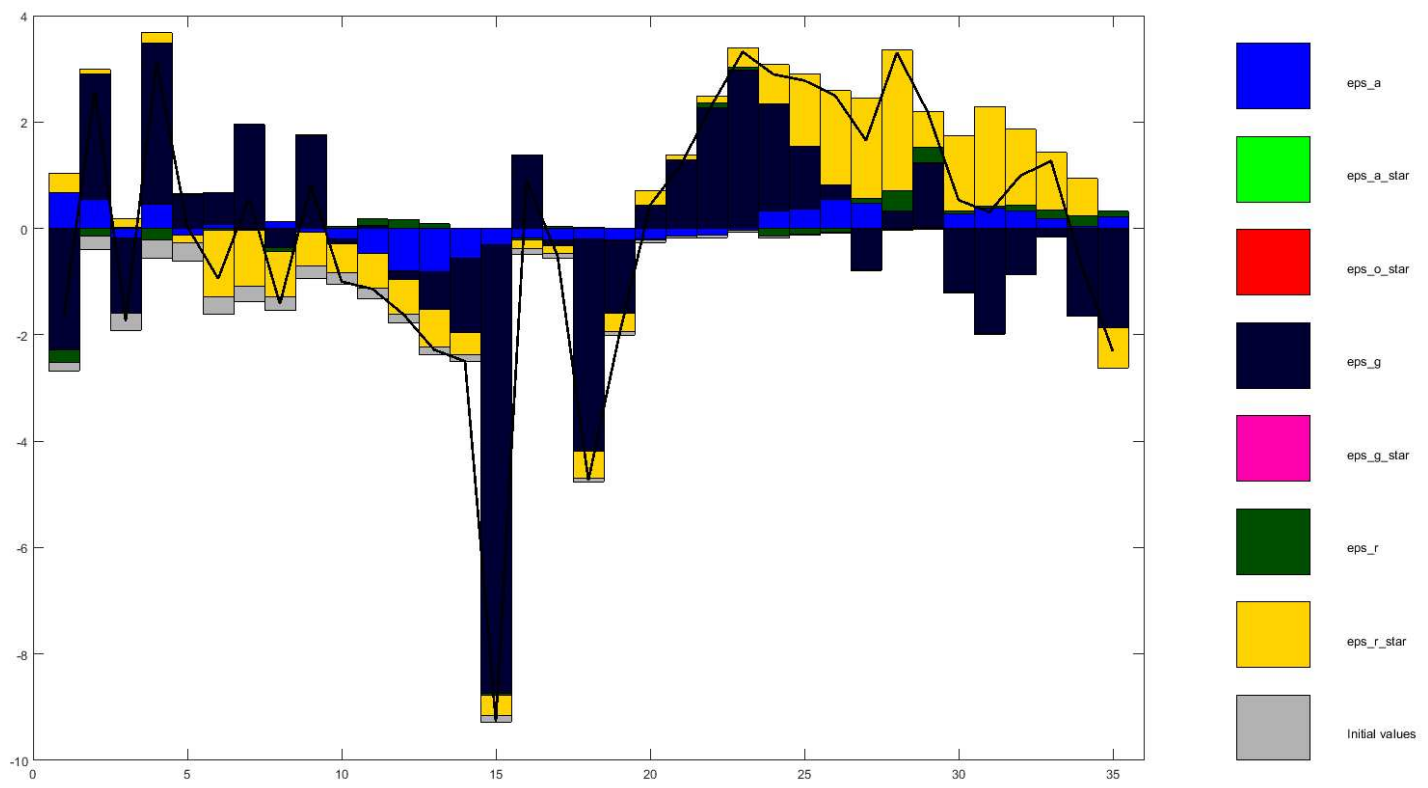


Figure 19: Historical Decomposition of private consumption in South Africa 1981-2015

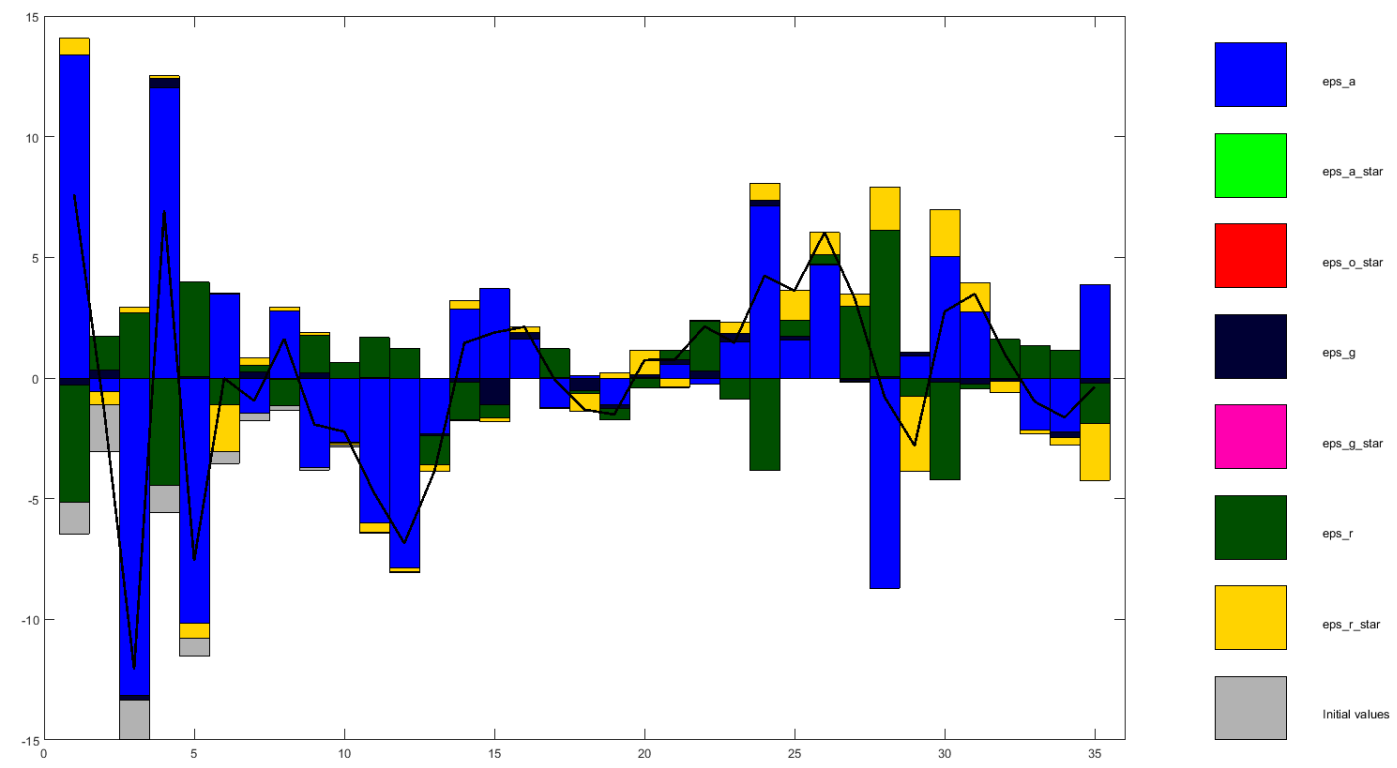

Figure 20: Historical Decomposition of inflation in South Africa 1981-2015

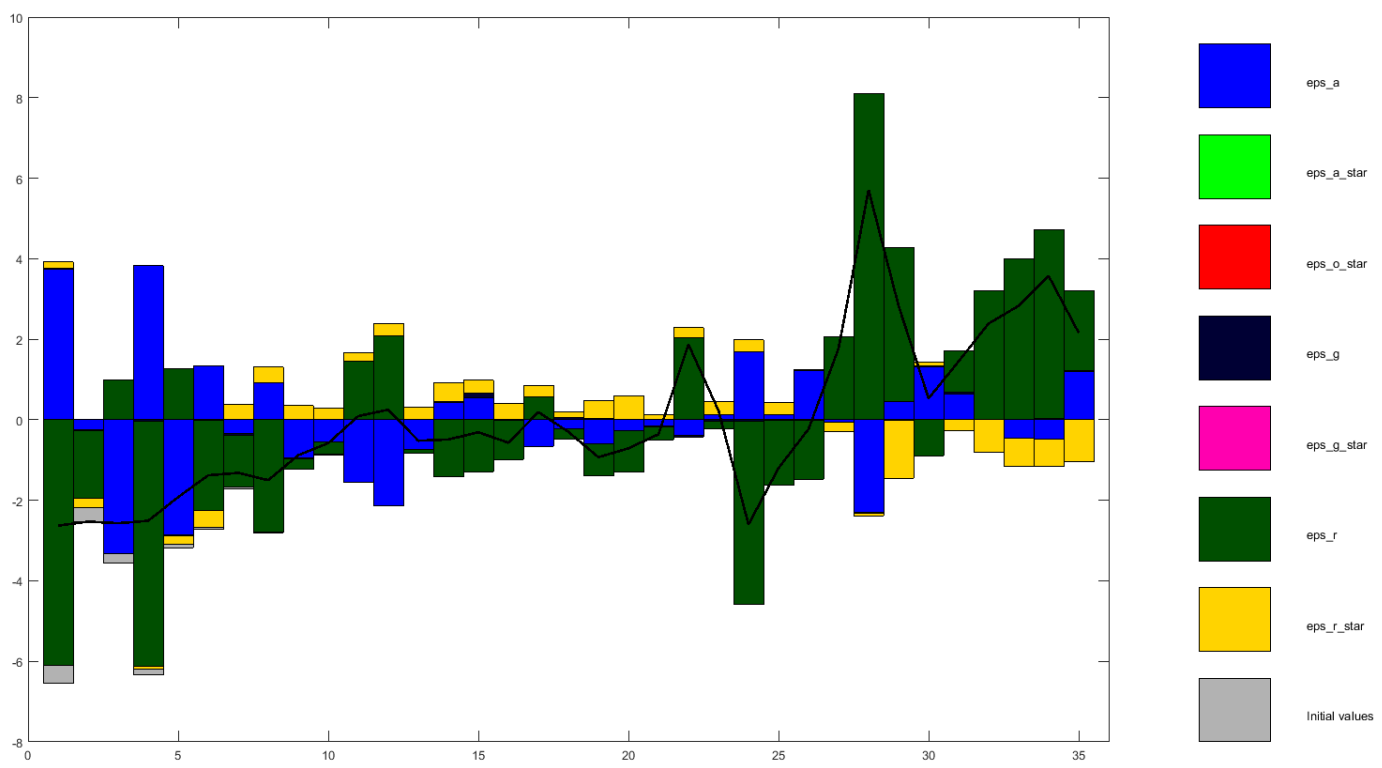

